\title{
PAPEL DA OUABAÍNA ENDÓGENA SOBRE O SISTEMA CARDIOVASCULAR DO MODELO DE HIPERTENSÃO ARTERIAL DOCA-SAL
}

Tese apresentada ao Programa de PósGraduação em Fisiologia Humana do Instituto de Ciências Biomédicas da Universidade de São Paulo, para obtenção do Título de Doutor em Ciências.

SÃO PAULO

2012 


\title{
PAPEL DA OUABAÍNA ENDÓGENA SOBRE O SISTEMA CARDIOVASCULAR DO MODELO DE HIPERTENSÃO ARTERIAL DOCA-SAL
}

\author{
Tese apresentada ao Programa de Pós- \\ Graduação em Fisiologia Humana do \\ Instituto de Ciências Biomédicas da \\ Universidade de São Paulo, para obtenção \\ do Título de Doutor em Ciências. \\ Área de concentração: Fisiologia \\ Orientador: Profa. Dra. Luciana Venturini \\ Rossoni \\ Co-orientador: Prof. Dr. Vagner Roberto \\ Antunes \\ Versão Original
}

SÃO PAULO

2012 
DADOS DE CATALOGAÇÃO NA PUBLICAÇÃO (CIP)

Serviço de Biblioteca e Informação Biomédica do

Instituto de Ciências Biomédicas da Universidade de São Paulo

reprodução não autorizada pelo autor

Wenceslau, Camilla Ferreira.

Papel da ouabaína endógena sobre o sistema cardiovascular do modelo de hipertensão arterial doca-sal / Camila Ferreira Wenceslau. - São Paulo, 2012.

Orientador: Profa. Dra. Luciana Venturini Rossoni.

Tese (Doutorado) - Universidade de São Paulo. Instituto de Ciências Biomédicas. Departamento de Fisiologia e Biofísica. Área de concentração: Fisiologia Humana. Linha de pesquisa: Fisiologia Humana - Órgãos e Sistemas

Versão do título para o inglês: Role of endogenous ouabain on the cardiovascular system of doca-salt hypertensive rats.

$\begin{array}{llll}\text { 1. Oubaína } & \text { 2. Hipertensão arterial } & 3 \text {. Artérias de resistência } 4 .\end{array}$ Disfunção vascular 5. Estresse oxidativo 6. Hiperatividade simpática I. Rossoni, Profa. Dra. Luciana Venturini II. Universidade de São Paulo. Instituto de Ciências Biomédicas. Programa de Pós-Graduação em Fisiologia Humana III. Título. 


\section{UNIVERSIDADE DE SÃO PAULO \\ INSTITUTO DE CIÊNCIAS BIOMÉDICAS}

Candidato(a): $\quad$ Camilla Ferreira Wenceslau.

Título da Tese: $\quad$ Papel da oubaína endógena sobre o sistema cardiovascular do modelo de hipertensão arterial doca-sal.

Orientador(a): $\quad$ Profa. Dra. Luciana Venturini Rossoni.

A Comissão Julgadora dos trabalhos de Defesa da Tese de Doutorado, em sessão pública realizada a considerou

\section{( ) Aprovado(a) ( ) Reprovado(a)}

Examinador(a): Assinatura:

Nome:

Instituição:

Examinador(a): Assinatura:

Nome:

Instituição:

Examinador(a): Assinatura:

Nome:

Instituição:

Examinador(a): Assinatura:

Nome:

Instituição:

Presidente: Assinatura:

Nome:

Instituição: 


\section{UNIVERSIDADE DE SÃO PAULO INSTITUTO DE CIÊNCIAS BIOMÉDICAS}

Cidade Universitária "Armando de Salles Oliveira"

Av. Prof. Lineu Prestes, 2415 - CEP. 05508-000 São Paulo, SP - Brasil

Telefone :(55) (011) 3091.7733 - telefax : (55) (011) 3091.7438

e-mail: cep@icb.usp.br

\section{Certificado}

Certificamos que o protocolo registrado sob $\mathrm{n}^{\circ} \mathbf{0 2 3}$ nas fls. 55 do livro 02 para uso de animais em experimentação, sob a responsabilidade de Luciana Venturini Rossoni, Coordenador(a) da Linha de pesquisa "Efeito do bloqueio da Ouabaina endógena sobre a atividade simpática renal e a função vascular de artérias de resistência de ratos hipertensos" do qual participou(aram) o(s) alunos Camila Ferreira Wenceslau e o pesquisador Vagner Roberto Antunes está de acordo com os Princípios Éticos de Experimentação Animal adotado pelo Colégio Brasileiro de Experimentação Animal (COBEA) e foi aprovado pela COMISSÃO DE ÉTICA EM EXPERIMENTAÇÃO ANIMAL (CEEA) em 29.04.08, com validade de 3 anos.

São Paulo, 29 de abril de 2008.

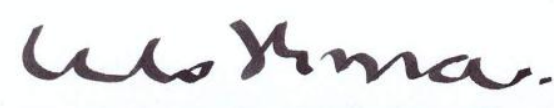

Prof. Dr. Wothan TAVARES DE Lima Coordenador CEEA - ICB/USP

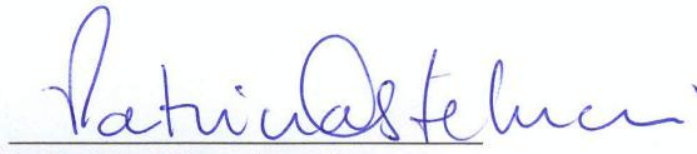

Profa. Dra. PATRÍCIA CASTELUCCI Secretária CEEA - ICB/USP 
Aa meu pai querida pela incentiva canstante e incansáuel para a minha farmaçãa.

à minha mãe querida par mastrar tadas as dias que a dar é ineuitáuel, mas que a sofrimenta é apcianal.

Cas meus irmãas e a minha Vá par me amarem independente das circunstâncias.

à Luciana par fazer de mim uma cientista e mastrar, a cada segunda, que: "Quem deseja waar deve primeira a aprender a caminhar, a carrer, a escalar $e$ a dançar. Nãa se aprende a war waanda." 


\section{AGRADECIMENTOS}

À Gisele Kruger Couto

Conheço-a pelo simples silêncio ou o sorriso.

Pouco me importa o assunto em nossas conversas.

Pouco me importa que tenham peso e profundidade,

Pois há sempre graça e razão de ser.

Frequentá-la é sempre um exercício a alma.

À Emília Cristina Peres, à Ana Paula C. Davel e à Eliana Akamine Por alegrarem-se pela minha alegria e sofrerem pelo meu sofrimento, assim tornaramse minhas amigas.

$\mathrm{Na}$ amizade a que me refiro é onde se mesclam as almas, e se confundem em tão completa união, que não mais se vê a costura que as prende.

$E$ se insistirem em me perguntar por que eu as quis, sinto que não responderia outra coisa: "Porque elas eram elas e eu era eu".

Ao prof. Vagner por ser tão próspero e capaz de fazer o amor fluir em todas as direções. Assim, me fez enxergar que nada é tão meu quanto meu sonho.

Aos companheiros da minha odisseia de 7 anos no laboratório de Fisiologia Vascular, pela delicadeza diária e por me tornarem mais forte que Ulisses de Tróia:

Kari, Angeletes, Lívóides, Helaneto, Susu, Rafael Play, Laís, Netin, Juliana Sobrancelha, Renatin Pernilongo, Luana, Jujubeleza, Rafael Cachinhos, Renê, Barbaroviskz, Fabi Bocão, Carol, Flávia Olímpica, Milene, Paulo City, Samucaca e Meleca.

Todos, sem exceção, fizeram os dias serem mais saborosos.

Aos amigos da Farmacologia e da Renal por serem tão prestativos.

Ao grande Zé Maria, as super-gatas da secretaria (Tarcisío também) do Depto da Fisiologia e à Socorro, Valéria e Eva da Biblioteca. Pela grandiosidade e excelência, sem exageros, do trabalho realizado.

Ao prof. Thiago e seus alunos, em especial Leonardo, pela resignação e astúcia nos ensinamentos.

Aos professores, técnicos e funcionários do Departamento de Fisiologia e Biofísica do ICB.

Ao Seu Pena por me tornar princesa todos os dias.

Aos companheiros: Karlota, Renato, meninos homens do Ibira e runners por simplesmente escolherem ficar ao meu lado. Não por bajulação, mas por aceitarem as coisas como são.

Ao CNPq.

A Deus. 
"Quem tem uma razãa de wiver é capaz de supartar qualquer caisa." Nietzsche 


\section{RESUMO}

Wenceslau CF. Papel da ouabaína endógena sobre o sistema cardiovascular do modelo de hipertensão arterial DOCA-Sal. [tese (Doutorado em Fisiologia Humana)] São Paulo: Instituto de Ciências Biomédicas, Universidade de São Paulo; 2012.

Há pelo menos quatro décadas, tem sido demonstrado que alguns modelos de hipertensão arterial apresentam aumento dos níveis plasmáticos de ouabaína, um fator inibidor da $\mathrm{Na}^{+} \mathrm{K}^{+}$-ATPase. Além disso, o tratamento crônico com ouabaína em ratos induz hipertensão arterial, a qual está associada à ativação de vias simpatoexcitatórias e mecanismos periféricos cardíacos, renais e vasculares. Sabe-se atualmente que a ouabaína além de inibir a $\mathrm{Na}^{+} \mathrm{K}^{+}$-ATPase interage com esta proteína levando a ativação da tirosina quinase não associada a receptor (c-SRC). Em 1998, Ferrari e colaboradores desenvolveram uma molécula denominada de rostafuroxina, a qual é capaz de antagonizar os efeitos da ouabaína. Dentro desse contexto, parece razoável sugerir que um anti-hipertensivo capaz de antagonizar os efeitos da ouabaína endógena possa representar uma nova e específica ferramenta farmacológica para o tratamento da hipertensão arterial. Assim, o presente estudo avaliou o papel da ouabaína endógena por meio do tratamento com rostafuroxina por 3 semanas em ratos DOCA-sal sobre: a pressão arterial pela técnica de pletismografia de cauda, a função vascular em artérias mesentéricas de resistência utilizando miógrafo para pequenos vasos e ensaio bioquímico, e a atividade simpática do nervo esplâncnico. Os resultados da presente tese demonstraram que os animais DOCA-sal tratados com rostafuroxina apresentaram redução significativa da pressão arterial sistólica e da hiperatividade simpática. Além disso, o tratamento com rostafuroxina melhorou a função vascular dos animais DOCA-sal via: (1) aumento do relaxamento à acetilcolina devido aumento da síntese e biodisponibilidade do óxido nítrico; (2) redução da geração de ânion superóxido via ativação da $\mathrm{NAD}(\mathrm{P}) \mathrm{H}$ oxidase e COX-2; (3) melhora na contração ao $\mathrm{KCl}$; e (4) redução do influxo de $\mathrm{Ca}^{2+}$. Conclui-se que no modelo de hipertensão arterial DOCA-sal a ouabaína endógena promove estresse oxidativo, disfunção endotelial e hipeartividade simpática. Estas alterações em conjunto contribuem para a manutenção da elevada pressão arterial. Assim, sugere-se que a ouabaína seja um possível alvo para o tratamento da hipertensão arterial dependente de volume.

Palavras-chave: Hipertensão arterial. Ouabaína endógena. Artérias de resistência. Disfunção vascular. Estresse oxidativo. Hiperatividade simpática. 


\begin{abstract}
Wenceslau CF. Role of endogenous ouabain on the cardiovascular system of DOCAsalt hypertensive rats. [thesis (Ph.D. Thesis)] Sao Paulo: Instituto de Ciências Biomédicas, Universidade de São Paulo; 2012.

It has been shown, in the last four decades, that some types of hypertension have increased plasma levels of ouabain, a factor inhibitor of $\mathrm{Na}^{+} \mathrm{K}^{+}$-ATPase. Previous studies showed that chronic treatment with ouabain induces hypertension in rats, which appears to be associated with activation of sympathetic outflow and cardiac, renal and vascular mechanisms. Besides the ouabain elicits an inhibition of the $\mathrm{Na}^{+} \mathrm{K}^{+}$-ATPase it also interacts with this protein leading to activation of a signaling cascade via c-SRC. In 1998, Ferrari et al. developed a molecule called rostafuroxin that antagonizes the effects of ouabain. In this context, it seems reasonable to suggest that an antihypertensive capable of antagonizing the effects of endogenous ouabain might be a new and specific pharmacological tool for the treatment of hypertension. In so doing, the present study aimed to evaluate the role of endogenous ouabain by treatment with rostafuroxin for 3 weeks on blood pressure using tail-cuff method, vascular function in resistance arteries by wire myograph system and splanchnic nerve sympathetic activity of DOCA-salt rats. Our data have shown that the treatment with rostafuroxin decreased the systolic blood pressure and sympathetic activity of the DOCA-salt rats. Moreover, rostafuroxin treatment in DOCA-salt rats produced several changes in the vascular function of the resistance arteries, such as: (1) improvement in the relaxation to acetylcholine due to increase in synthesis and bioavailability of nitric oxide, (2) decrease the superoxide anion generation from $\mathrm{NAD}(\mathrm{P}) \mathrm{H}$ oxidase and $\mathrm{COX}-2$, (3) improvement in the $\mathrm{KCl}$ inducedcontraction and, (4) reduction in the $\mathrm{Ca} 2+$ influx. Taken all the results together it is plausible to conclude that the endogenous ouabain in the DOCA-salt rats induces oxidative stress, vascular dysfunction and overactivity of the sympathetic outflow to maintain the elevated blood pressure in this hypertension model. Thus, it is suggested that ouabain is a putative target for the treatment of volume-dependent hypertension.
\end{abstract}

Keywords: Hypertension. Endogenous ouabain. Resistance arteries. Vascular dysfunction. Oxidative stress. Sympathetic hyperactivity. 


\section{LISTA DE ABREVIATURAS E SIGLAS}

ACTH - hormônio adrenocorticotrófico

AKT - proteína quinase $B$

ANOVA - análise de variância

ASNE - atividade simpática do nervo esplâncnico

AUC - área abaixo da curva

AV3V - anteroventral do terceiro ventrículo

BKCa - canais para potássio ativados por cálcio

$\mathrm{Ca}^{2+}$ - cálcio

$\mathrm{Ca}^{2+}$-ATPase - bomba de cálcio

CEEA - Comissão de Ética em Experimentação Animal

COBEA - Colégio Brasileiro de Experimentação Animal

COX-1 - ciclooxigenase 1

COX-2 - ciclooxigenase 2

CSRC - tirosina quinase não associada a receptor

DAF - diaminofluoresceína

dAUC - diferença da área abaixo da curva

DTT - Ditiotreitol

DHE - dihidroetidina

DOCA - desoxicorticosterona

ERGF - receptor para fator de crescimento epidermal

ERK - quinase regulada por sinal extracelular

$E T_{A}-$ receptor para endotelina

FXYD - regulador de transporte iônico contendo o domínio FXYD

$\mathrm{H}_{2} \mathrm{O}_{2}$ - peróxido de hidrogênio

JNC - Comitê de Encontro Nacional para Prevenção, Detecção, Avaliação e

Tratamento da Elevada Pressão Arterial

$\mathrm{KCl}$ - cloreto de potássio

LLC-PK1 - células epiteliais de rim de porco

L-NAME - Nw-nitro-l-arginina metil ester hidrocloreto

MAPK - proteína quinase ativada por mitógeno

MDA - malondialdeído 
$\mathrm{Na}^{+} / \mathrm{Ca}^{2+}$ - trocador de sódio e cálcio

$\mathrm{Na}^{+} \mathrm{K}^{+}$-ATPase - bomba de sódio e potássio

NADPH - nicotinamida adenina dinucleotídeo fosfato

NF кB - fator de transcrição nuclear kappa B

NO - óxido nítrico

NOX - homólogo da isoforma gp91 da NAD(P)H oxidase de fagócito

NOS - óxido nítrico sintase

NPS - nitroprussiato de sódio

NS-398 - N-[2-(ciclohexiloxi)-4-nitrofenil]-metanesulfonamida

$\mathrm{O}_{2}{ }^{-*}$ - ânion superóxido

OASIS-HT - intervenção específica para ouabaína e aducina sobre o sódio na hipertensão arterial

OCT - meio para congelamento de tecido

OUA - ouabaína

PA - pressão arterial

PAP - pressão arterial pulsátil

$\mathrm{PHOX}$ - isoforma da $\mathrm{NAD}(\mathrm{P}) \mathrm{H}$ oxidase de fagócito

PKC - proteína quinase $C$

PLC - fosfolipase C

PMSF - fluoreto de fenilmetilsulfonil

RPM - rotação por minuto

ROS - espécies reativas derivadas do oxigênio

ROSTA -rostafuroxina

SDS - dodecil sulfato de sódio

SC-560 - 5-(4-clorofenil)-1-(4-metoxifenil)-3-(trifluorometil)-1H-pirazol

SOD - superóxido dismutase

SHR - ratos espontaneamente hipertensos

SNS - sistema nervoso simpático

RAC - proteína G pequena

RIPA - tampão para análise de radioimunoensaio

TBARS - substâncias que reagem com o ácido tiobarbitúrico

TP - receptor para tromboxano $A_{2}$

$\mathrm{TxA}_{2}$ - tromboxano $\mathrm{A}_{2}$

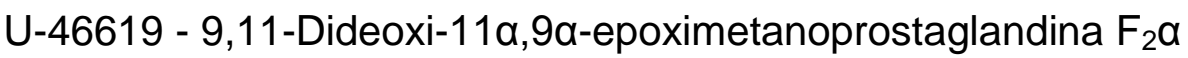


1R1C - um rim um clipe 


\section{SUMÁRIO}

1 INTRODUÇÃO 16

1.1 Ouabaína, Hipertensão arterial e sua fina relação com o sal 18

1.2 Ouabaína, hipertensão arterial e o sistema vascular 21

1.3 Ouabaína, hipertensão arterial e a $\mathrm{Na}^{+} \mathrm{K}^{+}$-ATPase 23

1.3.1 Ouabaína, $\mathrm{Na}^{+} \mathrm{K}^{+}$-ATPase e cSRC $\quad 27$

1.4 Ouabaína, hipertensão arterial e o sistema nervoso simpático (SNS) 27

1.5 Ouabaína e o modelo de hipertensão DOCA-Sal. 29

1.6 Ouabaína: Um possível alvo para o tratamento da Hipertensão arterial? 31

2 HIPÓTESE E OBJETIVO 34

3 MATERIAIS E MÉTODOS 35

3.1 Animais experimentais $\quad 35$

3.2 Obtenção dos modelos animais experimentais 35

3.2.1 Indução da hipertensão DOCA-Sal $\quad 35$

3.2.2 Tratamento terapêutico com Rostafuroxina $\quad 36$

3.3 Avaliação das variações de pressão arterial sistólica, do peso corporal e taxa de mortalidade $\quad 36$

3.4 Registro e análise da atividade do nervo simpático esplâncnico $\quad 37$

3.4.1 Análise da atividade basal do nervo simpático esplâncnico 38

3.4.2 Análise da sensibilidade barorreflexa $\quad 39$

3.5 Quantificação de malondialdeído no plasma pelo método da reação de substâncias com o ácido tiobarbitúrico (TBARS) 40

3.6 Estudo de reatividade vascular em artérias de resistência do leito vascular $\begin{array}{ll}\text { mesentérico } & 40\end{array}$

3.6.1 Normalização das artérias de resistência $\quad \mathbf{4 1}$

3.7 Protocolos experimentais $\quad 42$

3.7.1 Avaliação da resposta à agentes contráteis $\quad \mathbf{4 2}$

3.7.2 Análise do papel do cálcio intracelular e extracelular na resposta vasoconstritora à noradrenalina $\quad 42$

3.7.3 Avaliação da resposta a agentes vasodilatadores $\quad \mathbf{4 3}$

3.7.3.1 Avaliação das vias envolvidas na resposta vasodilatadora dependente do endotélio. 
3.7.3.1.1 Efeito do bloqueio da síntese de óxido nítrico e das espécies reativas derivadas do oxigênio sobre a resposta vasodilatadora à acetilcolina

3.7.3.1.2 Efeito do inibidor da NADPH oxidase e da ciclooxigenase-2 (COX-2) sobre a resposta vasodilatadora acetilcolina

3.8 Atividade funcional da $\mathrm{Na}^{+} \mathrm{K}^{+}$-ATPase sensível à ouabaína

3.9 Medida de tromboxano $B_{2}\left(T x B_{2}\right)$ do sobrenadante de artérias mesentéricas de resistência

3.10 Avaliação da expressão proteica pela técnica de Western Blot

3.11 Determinação da produção das espécies reativas derivadas do oxigênio pelo método de oxidação da dihidroetidina (DHE)

3.12 Medida da produção de NO em artérias de resistência

3.13 Apresentação dos resultados e análise estatística

3.14 Reagentes e Diluições

4 RESULTADOS

4.1 Avaliação da taxa de mortalidade, dos valores de pressão arterial de cauda e do peso corporal

4.2 Medida de Atividade Simpática e Sensibilidade barorreflexa

4.3 Quantificação de malondialdeído no plasma pela técnica TBARS

4.4 Reatividade vascular em artérias mesentéricas de resistência

4.4.1 Diâmetro luminal e tensão vascular ativa

4.4.2 Resposta vasocontritora à noradrenalina, à serotonina e ao $\mathrm{KCl}$

4.4.3 Papel do cálcio intracelular e extracelular na resposta vasoconstritora à noradrenalina

4.4.4 Avaliação da resposta aos agentes vasodilatadores

4.4.4.1 Resposta de relaxamento independente do endotélio

4.4.4.2 Resposta de relaxamento dependente do endotélio

4.4.4.3 Efeito do bloqueio da síntese de óxido nítrico e das espécies reativas derivadas do oxigênio sobre a resposta vasodilatadora à acetilcolina

4.4.4.4 Efeito do bloqueio da NADPH oxidase e da ciclooxigenase-2 (COX-2) sobre a resposta vasodilatadora à acetilcolina

4.4.5 Avaliação da atividade funcional da $\mathrm{Na}+\mathrm{K}+-\mathrm{ATPase}$ sensível à ouabaína

4.5 Medida de tromboxano $B_{2}\left(T_{x B}\right)$ do sobrenadante de artérias mesentéricas de resistência 
4.7 Produção das espécies reativas derivadas do oxigênio

4.8 Avaliação da expressão proteica

5 DISCUSSÃO

5.1 papel da ouabaína endógena sobre a mortalidade e a pressão arterial de ratos DOCA-sal

5.2 Interação ouabaína-NA ${ }^{+} \mathrm{K}^{+}$ATPase no modelo de hipertensão arterial DOCAsal

5.3 Papel da ouabaína endógena sobre a atividade simpática do nervo esplâncnico de ratos DOCA-sal

5.4 Papel da ouabaína endógena sobre a função vascular: relaxamento vascular

5.5 Papel da ouabaína endógena sobre o estresse oxidativo

5.6 Papel da ouabaína endógena sobre a função vascular: contração vascular

6 CONCLUSÃO 


\section{INTRODUÇÃO}

De acordo com o último JNC VII (The Seventh Report of the Joint National Committee on Prevention, Detection, Evaluation, and Treatment of High Blood Pressure; 2004), a hipertensão arterial acomete até 1 bilhão de indivíduos com cerca de 7,1 milhões de mortes por ano em todo mundo.

O Brasil, desde a década de 40 , vem passando por um processo de inversão das curvas de mortalidade, em que se observa um declínio na mortalidade por doenças infecciosas e um concomitante aumento na mortalidade por doenças crônicas não transmissíveis. Conforme o Banco de dados do sistema único de saúde do Brasil (2011), as doenças cardiovasculares são responsáveis por 1.150 .000 internações por ano, com um custo aproximado de 475 milhões de reais, onde a proporção de brasileiros com diagnóstico de hipertensão arterial aumentou de 21,5\% em 2006 para 24,4\% em 2009. Conforme dados do suplemento de saúde da Pesquisa Nacional de Amostras por Domićlio coletado em 2008 e divulgado em março de 2010 pelo Instituto Brasileiro de Geografia e Estatística, a hipertensão arterial foi apontada como a principal doença crônica diagnosticada na população brasileira. É digno de nota que, um número razoável dos pacientes hipertensos, aproximadamente $20-30 \%$, apresenta a chamada hipertensão refratária ou resistente, a qual é formada por um subgrupo de pacientes onde a pressão sanguínea elevada é controlada apenas com o uso de três ou mais antihipertensivos de classes diferentes (Calhoun et al., 2008).

O JNC VII (2004) classificou a hipertensão arterial em adultos, conforme a tabela 1:

Tabela 1 - Valores de pressão arterial sistólica e diastólica

\begin{tabular}{lcc}
\hline \multicolumn{1}{c}{ CATEGORIA } & $\begin{array}{c}\text { PRESSÃO SISTÓLICA } \\
(\mathrm{mmHg})\end{array}$ & $\begin{array}{c}\text { PRESSÃO DIASTÓLICA } \\
(\mathbf{m m H g})\end{array}$ \\
NORMAL & $<120$ & $<80$ \\
PRÉ-HIPERTENSÃO & $120-139$ & $80-89$ \\
HIPERTENSÃO ARTERIAL & - & - \\
ESTÁGIO 1 & $140-159$ & $90-99$ \\
ESTÁGIO 2 & $\geq 160$ & $\geq 100$ \\
\hline \multicolumn{2}{c}{ Fonte: Modificado de JNC VII (Seventh Report of the Joint National Committee on } \\
Prevention, Detection, Evaluation and Treatment of High Blood Pressure), 2004.
\end{tabular}


Desta forma, segundo o JNC VII (2004), todo indivíduo que apresentar pressão arterial sístolica $\geq 140 \mathrm{mmHg}$ e distólica $\geq 90 \mathrm{mmHg}$ é considerado hipertenso.

A hipertensão arterial é dividida etiologicamente em dois grandes grupos: (1) primária ou essencial e (2) secundária. Na hipertensão arterial primária ou essencial a causa pela qual a pressão arterial eleva-se cronicamente é desconhecida. Porém, quando a causa que acarreta hipertensão arterial é conhecida denomina-se hipertensão arterial secundária. Assim, a insuficiência renal, o hiperaldosteronismo, a hipertensão gestacional, a síndrome de Cushing, entre outras, são exemplo de hipertensão arterial secundária (Kaplan, 2006).

$\mathrm{Na}$ hipertensão arterial ocorrem inúmeras alterações em órgãos vitais, como o encéfalo, os rins, o coração e os vasos sanguíneos. Nestes últimos, as alterações associadas à hipertensão arterial têm sido amplamente investigadas e tem-se buscado cada vez mais a elucidação de mecanismos que contribuam para sua gênese e/ou manutenção.

Independente da etiologia da hipertensão arterial, seja ela primária ou secundária, no cerne desta doença há elevada resistência vascular periférica. Não há dúvida que dentre as consequências da hipertensão arterial há alterações dos vasos de condutância. Entretanto, as alterações determinantes tanto para a gênese quando para a manutenção da hipertensão arterial, residem nas artérias de resistência (Kaplan, 2006; Mulvany, 2002), as quais possuem diâmetro menor que $300 \mu \mathrm{m}$ (Mulvany, 2002). Mudanças intrínsecas da parede vascular das artérias de resistência, tanto funcionais quanto estruturais, acometem as células endoteliais, as células musculares lisas e os componentes da matriz extracelular (Schiffrin, 2005; Shepherd, 1990). As alterações funcionais incluem aumento da contratilidade ou diminuição do relaxamento, as quais refletem modificações no acoplamento excitação-contração, propriedades elétricas alteradas das células do músculo liso vascular e/ou disfunção endotelial. Esta última designa anormalidades na habilidade do endotélio de realizar uma ou mais de suas funções na manutenção da homeostasia vascular, assim, compreende basicamente na síntese predominante de fatores vasoconstritores e/ou redução da síntese e/ou da biodisponibilidade de fatores de relaxamento derivados do endotélio (Lüscher e Vanhoutte, 1986; Rubanyi, 1993). 
Um dos componentes responsáveis pela manutenção do tônus vascular é a atividade fisiológica da $\mathrm{Na}^{+} \mathrm{K}^{+}$-ATPase, ou bomba de sódio e potássio, e têm-se demonstrado que sua atividade encontra-se modificada com a hipertensão arterial, podendo este ser mais um fator associado à hiperreatividade vascular (Blaustein, 1993; Dos Santos et al., 2003; Marín e Redondo, 1999).

Sabendo-se que a homeostasia celular de sódio e o potencial de membrana são fatores essenciais para o controle do tônus vascular e, consequentemente, para a regulação da pressão arterial, e que estas duas variáveis também são controladas pela atividade da $\mathrm{Na}^{+} \mathrm{K}^{+}$-ATPase, alguns trabalhos sugerem que alteração na atividade dessa bomba pode ser um fator envolvido na gênese e/ou manutenção do processo hipertensivo (Blaustein, 1993; Dostanic-Larson et al., 2005; Kaplan, 2005; Marín e Redondo, 1999; Songu-Mize et al., 1982). Neste sentido, um novo fator, inibidor da $\mathrm{Na}^{+} \mathrm{K}^{+}$-ATPase, associado à gênese e a manutenção da hipertensão arterial foi identificado e purificado na circulação humana (Hamlym et al., 1989), o qual em 1991 foi caracterizado como ouabaína endógena (Bova et al., 1991).

\subsection{Ouabaína, Hipertensão arterial e sua fina relação com o sal}

Os seres humanos consumiam cerca de $700 \mathrm{mg} / \mathrm{dia}$ de sódio no final do período Paleolítico e começou a usar sal regularmente para preservação de alimentos cerca de 10.000 anos atrás. Deste então, desenvolveu um gosto hedonístico para o sal (Rodriguez-Iturbe et al., 2007).

A associação entre a quantidade de sal na dieta e pressão arterial foi sugerida pela primeira vez em 1904 (Ambard e Beaujard, 1904) e amplamente reconhecida após Kempner em 1948 ter demonstrado que a dieta de arroz, a qual continha menos de $0,5 \mathrm{~g}$ de sal, reduzia a pressão arterial e o tamanho do coração (Kempner, 1948).

De forma pioneira, De Wardener et al. (1961) demonstraram que a infusão de salina e expansão aguda de volume em cachorros, denominados de animais doadores, era capaz de promover natriurese em outros cachorros, denominados de animais receptores, ou seja, os animais que recebiam o plasma dos animais doadores. Com tais dados, esses pesquisadores sugeriram a presença de um fator natriurético circulante o qual era liberado após a expansão aguda de volume extra 
celular. Subsequente a este trabalho, Lewis Dahl (1969) foi um dos primeiros a inferir que a hipertensão arterial induzida pelo sal pode ser mediada por um fator humoral. Concomitante a esta sugestão, um trabalho apresentado no "Proceedings of the Fourth International Congress of Nephrology" em 1969 e intitulado como: "Third Factor: Inhibitor of Na-K-ATPase?" foi uma das primeiras referências a demonstrar que esse fator humoral natriurético era capaz de inibir a $\mathrm{Na}^{+} \mathrm{K}^{+}$-ATPase (Kramer et al., 1969).

Já na década de 80, Gruber et al. (1980) observaram que esse fator endógeno reagia com anticorpo anti-digoxina. Em 1989, Hamlyn et al. identificaram e purificaram o composto inibidor da $\mathrm{Na}^{+} \mathrm{K}^{+}$-ATPase na circulação humana e, em 1991, o mesmo passou a ser denominado como ouabaína endógena (Bova et al., 1991).

A ouabaína endógena é encontrada em concentrações nanomolares no plasma de mamíferos. Sua produção concentra-se no córtex da supra-renal (Hamlyn et al., 2003; Ludens et al, 1992; Nesher et al., 2009), no hipotálamo (De Wardener e Clarkson, 1985; Murrell et al., 2005) e na região anteroventral do terceiro ventrículo (Pamnani et al., 1981; Songu-Mize et al., 1982); e pode ser estimulada pelo aumento da concentração plasmática de sódio, pela expansão de volume extracelular (Blaustein, 1993; Yamada et al., 1997), pela ação dos hormônios adrenocorticotrófico e angiotensina II (Laredo et al., 1997), pelo exercício físico (Bauer et al., 2005) entre outros fatores.

Em humanos, algumas enfermidades apresentam aumento dos níveis plasmáticos de ouabaína, como a hipertensão arterial essencial (Hamlyn et al.,1982; Pierdomenico et al., 2001), a insuficiência cardíaca congestiva (Gottlieb et al., 1992; Pitzalis et al., 2006), a insuficiência renal crônica (Hamlyn et al., 1996), o "ouabaínoma primário" ou adenoma cortical adrenal (Hamilton et al. 1994), entre outras.

Em modelos animais de hipertensão arterial, também foi demonstrado alteração na concentração plasmática de ouabaína, no entanto, esta é dependente do modelo experimental estudado. Deste modo, em ratos espontaneamente hipertensos (SHR), não foi demonstrado alterações na concentração plasmática de ouabaína quando comparado a ratos Wistar (Doris, 1994). Por outro lado, em outros modelos experimentais de hipertensão arterial dependentes de volume, como DOCA-sal e um rim um clipe (1R1C), foi demonstrado que a ouabaína plasmática 
está aumentada (Kojima, 1984; Nakamura et al., 1987; Pamnani e Haddy, 1988; Park et al., 2004).

Recentemente, Nesher et al. (2009) demonstraram o papel fisiológico da ouabaína na ausência de condições que estimulam o aumento das concentrações plasmáticas de ouabaína, como o exercício físico (Bauer et al., 2005). Esses autores, demonstraram que ratos normais tratados cronicamente com anticorpo antiouabaína apresentam redução da natriurese e da contração induzida por fenilefrina em aorta de ratos, sugerindo um papel da ouabaína na homeostase do sódio e do tônus vascular. Além disso, neste mesmo estudo (Nesher et al., 2009) foi evidenciado que a redução crônica das concentrações plasmáticas de ouabaína não afeta o crescimento do coração e do rim e a pressão arterial sistólica.

Até o início da década de 1990, especulava-se sobre a participação da ouabaína no processo hipertensivo, entretanto, nenhum trabalho havia demonstrado a capacidade desse digitálico em desenvolver hipertensão arterial. Assim, em 1993, Yuan et al. demonstraram, pela primeira vez na literatura, que o tratamento crônico com ouabaína era capaz de induzir hipertensão arterial em ratos. Posteriormente, Manunta et al. (1994) caracterizaram esse modelo de hipertensão arterial, e encontraram aumento das concentrações de ouabaína no plasma, rins, hipotálamo e pituitária anterior.

Atualmente já está bem estabelecido que o tratamento crônico com ouabaína em ratos induz o desenvolvimento de hipertensão arterial (Briones et al., 2006; Hernanz et al., 2008; Kimura et al., 2000; Manunta et al., 1994; Rossoni et al., 2002a,b, 2006; Padilha et al., 2008; Cao et al., 2009; Wenceslau et al., 2011; Xavier et al. 2004a,b,c; Yuan et al., 1993). O efeito hipertensinogênico tem sido associado com aumento do tônus simpático (Huang et al., 1994) devido a uma ativação de sistemas regulatórios centrais, como o sistema renina-angiotensina (Huang e Leenen, 1999) e endotelina (Di Filippo et al., 2003). Embora, o sistema nervoso central pareça ser o maior contribuinte para gênese do efeito pressor da ouabaína, alguns estudos demonstraram que os mecanismos periféricos cardíacos (Ferrandi et al., 2004; Rossoni et al., 2006; Skoumal et al., 2007), renais (Cao et al., 2009; Kurashina et al., 1996) e vasculares (Briones et al., 2006; Kimura et al., 2000; Rossoni et al., 2002a,b; Padilha et al., 2008; Wenceslau et al., 2011; Xavier et al. 2004a,b,c) também contribuem para a gênese e/ ou manutenção da hipertensão arterial induzida pela administração crônica de ouabaína. 


\subsection{Ouabaína, hipertensão arterial e o sistema vascular}

Independente do tempo de administração de ouabaína seja ela aguda ou crônica, esse glicosídeo cardíaco promove alterações na função vascular, as quais são dependentes tanto da concentração de ouabaína quando do leito vascular estudado (Briones et al., 2006; Hernaz et al.,2008; Rossoni et al., 1999,2002a,b; Padilha et al., 2004,2008;2011; Wenceslau et al., 2011; Xavier et al. 2004a,b,c). As alterações observadas podem ser tanto ajustes compensatórios fundamentais para a manutenção da homeostasia do sistema como um todo, ou podem induzir uma desordem no sistema, às vezes irreversíveis, culminando desta forma na instalação de algumas enfermidades, dentre elas a hipertensão arterial.

Ouabaína administrada agudamente, em concentrações nanomolares, potencializa as ações de fenilefrina em preparações do leito vascular caudal (Rossoni et al., 1999). Já, em concentrações maiores (micromolar), a administração aguda de ouabaína induz contração por ação direta sobre o músculo liso vascular e/ ou pela liberação de noradrenalina das terminações adrenérgicas (Aarhus et al., 1983; Rodríguez-Mañas et al., 1994).

Em alguns modelos de hipertensão arterial, como SHR (Padilha et al., 2004), DOCA-sal, um rim um clipe (1R1C) e hipertensão arterial induzida pelo tratamento com o inibidor da óxido nítrico sintase, L-NAME (Rossoni et al., 2001,2003), a administração aguda de ouabaína aumenta a pressão arterial. Siman et al. (2010), demonstraram que a administração (i.v.) de doses baixas (picomolar) de ouabaína em SHR aumenta a pressão arterial sistólica e a diastólica por mecanismo que parece depender da ativação do sistema renina-angiotensina. No entanto, o efeito da ouabaína sobre a pressão arterial diastólica não foi bloqueado por canrenona, sugerindo um mecanismo de ação independente da inibição da $\mathrm{Na}^{+} \mathrm{K}^{+}$-ATPase (Siman et al., 2010).

Estudos prévios demonstraram que o tratamento por cinco semanas com ouabaína em ratos promove hipertensão arterial associada à redução da resposta vasoconstritora à agonista do receptor $\alpha$-adrenérgico em aorta e artéria mesentérica superior, aumento em artéria renal e não alteração em artéria caudal e em artéria mesentérica de resistência (Kimura et al., 2000; Rossoni et al., 2002a,b; Xavier et al. 2004a,b,c). Esta resposta é atribuída à modulação endotelial, devido a maior 
produção do óxido nítrico, via ativação das isoformas endotelial e neuronal da sintase de óxido nítrico (Rossoni et al., 2002b; Xavier et al., 2004a).

Em artéria coronária de ratos hipertensos devido ao tratamento com ouabaína por 5 semanas, o relaxamento induzido pela acetilcolina nos segmentos arteriais pré-contraídos com $\mathrm{KCl}$ ou com bloqueadores de canais para potássio ativados por cálcio (BKCa) está prejudicado. Entretanto, quando estes segmentos são précontraídos com serotonina, não há diferenças do relaxamento induzido pela acetilcolina entre os grupos normotensos e hipertensos (Briones et al., 2009). Neste mesmo trabalho, os autores sugeriram que o tratamento crônico com ouabaína aumenta o fluxo iônico do canal BKCa em artérias coronárias e, consequentemente, preserva a função endotelial nessas artérias (Briones et al., 2009). Em artérias cerebrais do mesmo modelo de hipertensão arterial, tanto a contração ao $\mathrm{KCl}$ quanto a contração à serotonina não diferiram das artérias dos animais controle (Hernanz et al., 2008). Por outro lado, o relaxamento induzido por bradicinina e L-arginina foi de maior magnitude nos segmentos de artéria basilar dos animais hipertensos induzidos pela ouabaína (Hernanz et al., 2008), o qual era dependente da maior biodisponibilidade do óxido nítrico via redução do ânion superóxido. Estes pesquisadores sugeriram que este seria um ajuste das artérias cerebrais em relação ao aumento da pressão arterial (Hernanz et al., 2008). Também foi observada alteração nos vasos que perfundem a medula renal, como a vasa recta descendente, após o tratamento crônico com ouabaína (Cao et al., 2008). Nesse sentido, o influxo de cálcio nas células endoteliais proveniente dos segmentos de vasa recta dos animais tratados com ouabaína é reduzido tanto em resposta à acetilcolina quanto à bradicinina quando comparado ao controle (Cao et al., 2009).

Em artérias mesentéricas de resistência, as alterações funcionais observadas, após o tratamento com ouabaína, são dependentes do tempo de exposição a este glicosídeo. Em relação a este parâmetro, os resultados obtidos por Xavier et al (2004b) e Wenceslau et al. (2011) sugerem que em períodos menores de tratamento, cinco e dez semanas, a resposta contrátil à noradrenalina não está alterada. Ao passo que, em período mais prolongado de tratamento, vinte semanas, ocorre redução na modulação nitrérgica sobre a resposta contrátil vascular, associada ao estresse oxidativo via ativação da COX-2, característicos de disfunção endotelial, acompanhada de aumento da resposta vasoconstritora (Wenceslau et al., 2011). Corroborando esses dados, Xavier et al. (2009) demonstraram que SHR 
tratados com ouabaína por 5 semanas apresentam incremento da pressão arterial acompanhado de aumento da resposta à fenilefrina em pequenas artérias devido à maior liberação do tromboxano $\mathrm{A}_{2}$ e/ou prostaglandina $\mathrm{H}_{2}$ via COX-2 (Xavier et al., 2009). Além de alterações sobre a função vascular, também foi demonstrado que o tratamento durante cinco semanas com ouabaína é capaz de modificar a estrutura das artérias mesentéricas de resistência promovendo remodelamento para dentro. Essa alteração na estrutura vascular é devido à diminuição do número de células do músculo liso vascular e aumento na deposição de colágeno na camada média (Briones et al., 2006).

\subsection{Ouabaína, hipertensão arterial e a $\mathrm{Na}^{+} \mathrm{K}^{+}$-ATPase}

A identificação da $\mathrm{Na}^{+} \mathrm{K}^{+}$-ATPase, em 1957, conferiu aos pesquisadores $\mathrm{Dr}$. Skou, Dr. Boyer e Dr. Walker o prêmio mais almejado do meio acadêmico e científico, o prêmio Nobel. Deste então a estrutura, o funcionamento e a regulação desta enzima têm sido caracterizados (Blanco e Mercer, 1998; Skou e Esmann, 1992; Sweadner, 1989; Xie e Cai, 2003).

A $\mathrm{Na}^{+} \mathrm{K}^{+}$-ATPase, ou bomba de sódio e potássio, é uma proteína integral de membrana e está presente na maioria das células eucarióticas. Esta enzima usa a energia da hidrólise da adenosina trifosfato (ATP) para realizar o transporte de sódio e potássio através da membrana plasmática (Skou e Esmann, 1992; Sweadner, 1989). É formada por três subunidades, a catalítica $\alpha$ e as regulatórias $\beta$ e $y$ ou FXYD (Blanco e Mercer, 1998; Sweadner, 1989; Xie e Cai, 2003). A subunidade catalítica a possui sítios de ligação para os íons $\mathrm{Na}^{+}$e $\mathrm{K}^{+}$, para o ATP e para os compostos digitálicos, dentre eles a ouabaína e a digoxina (Blanco e Mercer, 1998). Esta subunidade é composta de 6-7 domínios transmembrana e pode ser encontrada sob quatro isoformas distintas: $\alpha_{1}, \alpha_{2}, \alpha_{3}$ e $\alpha_{4}$, cuja expressão varia de acordo com o tecido estudado. Estas isoformas diferem pouco quanto ao seu peso molecular, mas são diferentes em relação à sensibilidade pelos compostos digitálicos em roedores. Desta forma, a isoforma que apresenta maior sensibilidade aos compostos digitálicos é a $\alpha_{3}$, seguida da $\alpha_{2}$, e por fim a $\alpha_{1}$ (Blanco e Mercer, 1998). Cabe ressaltar que no músculo liso vascular e no endotélio foi descrita a presença das três isoformas da subunidade $\alpha: \alpha_{1}, \alpha_{2}$ e $\alpha_{3}$ (Sahin-Erdemli et al., 1994). 
A subunidade $\beta$ possui três isoformas distintas identificadas: $\beta_{1}, \beta_{2}$ e $\beta_{3}$. A $\beta_{1}$ está presente em quase todos os tecidos, porém é predominantemente renal; a $\beta_{2}$ é encontrada no músculo esquelético, glândula pineal e sistema nervoso central; e a $\beta_{3}$ está presente no testículo, retina, fígado e pulmão (Blanco e Mercer, 1998). Já a expressão da subunidade $\mathrm{y}$ ou FXYD na fase embrionária do camundongo é importante para a formação do blastócito (Jones et al., 1997; Mobasheri et al., 2000). Sabe-se também que a subunidade y liga-se a aducina uma importante proteína do citoesqueleto (Ferrandi et al., 1999). Interessantemente, polimorfismos na sequência da aducina correlacionam-se com hipertensão arterial tanto em humanos quanto em ratos hipertensos de Milão (Ferrandi et al., 1999).

Em 1998 Blaustein et al. identificaram uma microrregião celular entre a membrana plasmática e a membrana do retículo sarcoplasmático, denominada por eles de plasmerosome, onde estão localizados o trocador $\mathrm{Na}^{+} / \mathrm{Ca}^{2+}$, o retículo sarcoplasmático e as isoformas $\alpha_{2}$ e $\alpha_{3}$ da $\mathrm{Na}^{+} \mathrm{K}^{+}$-ATPase (Figura 1). Nesta microrregião, os compostos digitálicos, como a ouabaína, possuem uma importante função sobre a mobilização de $\mathrm{Ca}^{2+}$ intracelular. Estes compostos digitálicos ao inibirem as subunidades $\alpha_{2}$ e $\alpha_{3}$ da $\mathrm{Na}^{+} \mathrm{K}^{+}$-ATPase aumentam a concentração de $\mathrm{Na}^{+}$ intracelular nesse microdomínio específico, o que resulta na redução da atividade do trocador $\mathrm{Na}^{+} / \mathrm{Ca}^{2+} \mathrm{e}$, consequente, aumento da concentração dos íons $\mathrm{Ca}^{2+}$ livres no interior da célula. Esse $\mathrm{Ca}^{2+}$ é captado pela $\mathrm{Ca}^{2+}$-ATPase do retículo sarcoplasmático e estocado no interior dessa organela citoplasmática. Desta forma, após o estímulo de um agonista vasoconstritor como a noradrenalina, a resposta contrátil resultante é amplificada em consequência de uma maior liberação de $\mathrm{Ca}^{2+}$ pelo retículo sarcoplasmático. Esse mecanismo ajuda a explicar, em parte, como concentrações nanomolares de ouabaína podem amplificar a resposta a um agente vasoconstritor e representa um mecanismo adicional pelo qual a ouabaína endógena pode contribuir para o processo hipertensivo. 
Figura 1 - Modelo do plasmerosome proposto por Blaustein e colaboradores

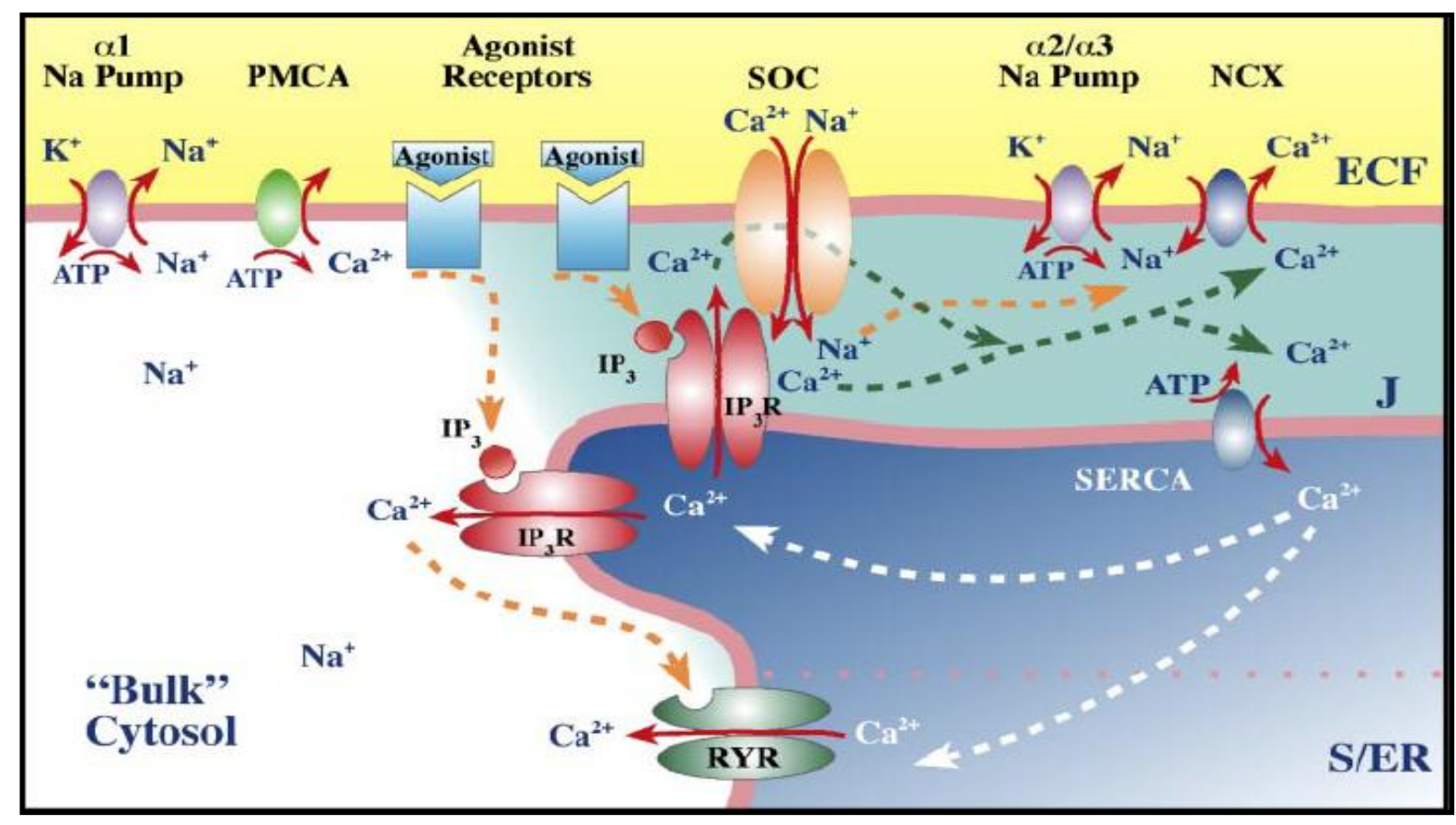

$\alpha_{1}$ Na pump: isoforma $\alpha_{1}$ da $\mathrm{Na}^{+} \mathrm{K}^{+}$-ATPase; PMCA: $\mathrm{Ca}^{2+}$-ATPase da Membrana Plasmática; Agonist Receptor: Receptor para Agonista; SOC: Canal Operado por Estoque; $\alpha_{2} / \alpha_{3} \mathrm{Na}$ pump: isoformas $\alpha_{2} / \alpha_{3}$ da $\mathrm{Na}^{+} \mathrm{K}^{+}$-ATPase; NCX: Trocador $\mathrm{Na}^{+} / \mathrm{Ca}^{2+}$; ECF: Fluído do Meio Extracelular; $I_{3}: 1$, 4, 5 Trifosfato Inositol; IP ${ }_{3} \mathrm{R}$ : receptor para 1, 4, 5 Trifosfato Inositol; SERCA: $\mathrm{Ca}^{2+}$-ATPase do Retículo Sarcoplasmático; RYR: Receptor para Rianodina; S/ER: Retículo Endoplasmático/ sarcoplasmático; Bulk Cytosol: Massa Plasmática.

Fonte: Blaustein et al. (2006).

Entretanto, trabalhos subsequentes (Xie et al., 1999, 2003) sugeriram uma função "binária" da $\mathrm{Na}^{+} \mathrm{K}^{+}$-ATPase. Esses autores observaram que além da função de transporte de íons, a $\mathrm{Na}^{+} \mathrm{K}^{+}$-ATPase atua como um receptor, tendo como agonista a ouabaína. Uma vez que o receptor $\mathrm{Na}^{+} \mathrm{K}^{+}$-ATPase é ativado pela ouabaína, inicia-se uma cascata de sinalização e transdução de sinais via caminhos múltiplos. Baseado nesse fenômeno, Xie e Cai (2003) denominaram este mecanismo de transdução de sinais, via o complexo ouabaína- $\mathrm{Na}^{+} \mathrm{K}^{+}$-ATPase, de signalosome (Figura 2).

O signalosome ocorre em um compartimento específico da membrana, a cavéola, a qual transfere sinais para o interior da célula no momento em que a ouabaína está acoplada a $\mathrm{Na}^{+} \mathrm{K}^{+}$-ATPase (Figura 2). A interação da $\mathrm{Na}^{+} \mathrm{K}^{+}$-ATPase com proteínas do citoesqueleto, como a aducina, parece ser essencial para a funcionalidade desta proteína e a transdução de sinais para o interior da célula (Ferrari et al., 2006). 
Sabe-se que o complexo ouabaína- $\mathrm{Na}^{+} \mathrm{K}^{+}-\mathrm{ATPase}$ leva à ativação das seguintes proteínas e moléculas: PI3-quinase; proteína quinase B (AKT); tirosina quinase não associada a receptor ( $\mathrm{cSrc}$ ); receptor para fator de crescimento epidermal (ERGF); ERK; espécies reativas derivadas do oxigênio, proteína quinase ativada por mitógeno (MAPK); fosfolipase C (PLC) e NFkB (Figura 2) (Xie et al., 1999, Aizman et al., 2001; Xie, Cai, 2003).

Figura 2 - Modelo do signalosome proposto por Xie e Cai (2003)

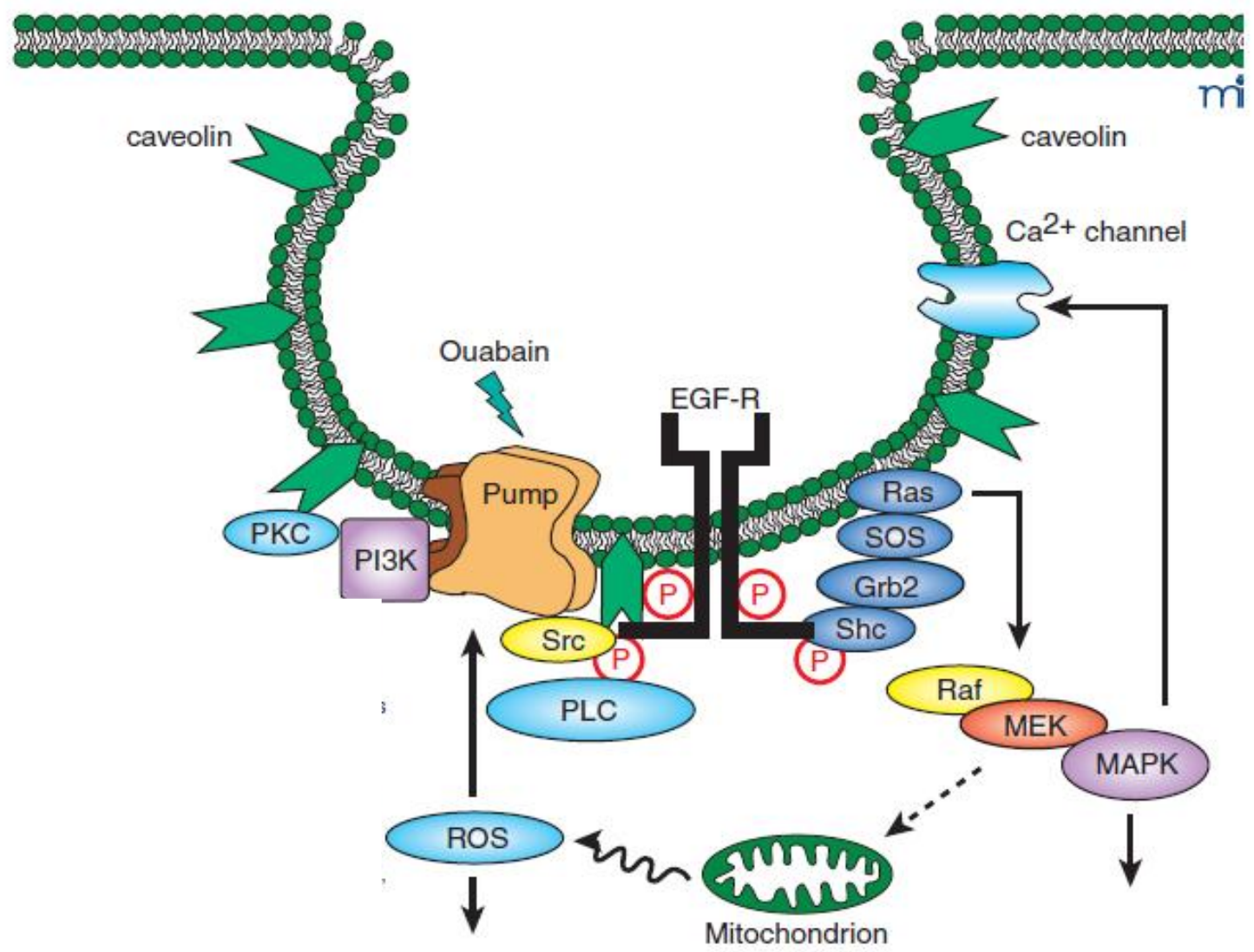

Pump: Na+K+-ATPase; EGFR: receptor para fator de crescimento epitelial; PKC: proteína quinase C; PI3K: proteína quinase 3' fosfoinositídeo; Grb2: proteína 2 ligada ao receptor de fator de crescimento; SOS: son of sevenless; PLC: fofolipase C, MAPK: proteína quinase ativada por mitógeno; ROS: espécies reativas derivadas do oxigênio.

Fonte: Modificado de Xie e Cai (2003). 


\subsubsection{Ouabaína, $\mathrm{Na}^{+} \mathrm{K}^{+}$-ATPase e cSRC}

A ligação da ouabaína com a $\mathrm{Na}^{+} \mathrm{K}^{+}$-ATPase causa rápida ativação da tirosina quinase da família cSRC em muitos tipos de células, incluindo miócito cardíaco, músculo liso vascular e epitélio renal (Aydemir-Koksoy et al., 2001; Xie e Cai, 2003).

As tirosinas quinases são importantes reguladoras da função celular, como: crescimento, proliferação, diferenciação, adesão, migração e sobrevivência (Thomas e Brugge, 1997). Elas são classificadas dentro de dois grupos: (1) tirosinas quinases associadas a receptores, como o receptor de fator de crescimento epidermal; e (2) tirosinas quinases não associadas a receptores, como a família da cSRC. A atividade catalítica da CSRC é controlada pela fosforilação em tirosina e interação proteína a proteína. Assim, a fosforilação CSRC $^{\text {Tyr529 }}$ mantém esta quinase na conformação inativa, enquanto que a fosforilação da cSRC $C^{\text {Tyr418 }}$ ativa esta quinase (Thomas e Brugge, 1997).

A ouabaína quando acoplada a $\mathrm{Na}^{+} \mathrm{K}^{+}$-ATPase estimula a fosforilação da $\mathrm{CSRC}^{\text {Tyr418}}$, mas não tem efeito na $\mathrm{CSRC}^{\text {Tyr529 }} \mathrm{em}$ diferentes tipos de células (Haas et al., 2002). Além disso, após a imunoprecipitação da subunidade $\alpha_{1}$ da $\mathrm{Na}^{+} \mathrm{K}^{+}-$ ATPase de células da linhagem LLC-PK1 (células epiteliais de rim de porco) tratadas agudamente com ouabaína, foi observado aumento da ligação da cSRC com a $\mathrm{Na}^{+} \mathrm{K}^{+}$-ATPase (Xie, 1999).

\subsection{Ouabaína, hipertensão arterial e o sistema nervoso simpático (SNS)}

A extensa inervação do sistema nervoso simpático (SNS) sobre os dois efetores do sistema cardiovascular, o coração e os vasos sanguíneos, faz com que este sistema tenha papel imperativo na regulação minuto a minuto da pressão arterial, por alterar a frequência, mecânica cardíaca e o tônus vascular.

A relação entre o SNS e hipertensão arterial é foco de ampla pesquisa clínica e experimental visto que $\mathrm{o}$ aumento da atividade simpática está fortemente associado à piora no prognóstico de pacientes hipertensivos e altas taxas de mortalidade (Esler, 2000). Neste sentido, evidências extraídas de diversas fontes (Esler, 2000; Huang e Leenen, 1999; Jacob et al., 2005; Leenen, 2002; Mueller e Ertel; 1983; Yemane et al., 2009; Zhang e Leenen, 2001), utilizando técnicas 
distintas, como eletrofisiologia e neuroquímica, fornecem informações convincentes de que a hiperatividade do sistema nervoso simpático está comumente presente em pacientes com enfermidades cardiovasculares, tais como hipertensão arterial e insuficiência cardíaca (Esler, 2000) e em modelos experimentais, como SHR (Mueller e Ertel; 1983), DOCA-sal (Jacob et al., 2005; Yemane et al., 2009), hipertensão dependente de ouabaína (Huang e Leenen, 1999; Zhang e Leenen, 2001), ratos Dahl sensíveis ao sal (Dahl-sal) (Leenen, 2002), entre outros.

As causas específicas do aumento da atividade simpática na hipertensão arterial são ainda desconhecidas, embora influências genéticas e fatores comportamentais e estilo de vida, como sedentarismo, tabagismo e hábitos alimentares, parecem estar envolvidos (Esler, 2000). Todavia, pesquisadores têm obtido cada vez mais dados sugerindo uma correlação positiva entre o aumento de ouabaína plasmática e/ ou tecidual e o aumento da atividade simpática na hipertensão arterial (D’Amico et al., 2003; Huang et al., 1994; Leenen, 2002). Assim, há grandes possibilidades desse glicosídeo ser um forte candidato, ao menos em parte, para a gênese e/ ou manutenção da simpatoexcitação observada na hipertensão arterial, visto que: (1) a administração aguda de ouabaína aumenta o tônus simpático (D’Amico et al., 2003; Leenen, 2002); (2) a administração intracerebroventricular de anticorpo anti-ouabaína abole a hiperatividade do nervo simpático renal em ratos sensíveis ao sal e em SHR, ambos expostos a alta dieta de sal (Leenen, 2002; Van Huysse, 2007); (3) ouabaína injetada intracerebroventricular promove resposta vasopressora dependente da dose e taquicardia acompanhada de aumento na atividade simpática do nervo lombar em DOCA-sal (Takahashi et al., 1987).

Também de maneira interessante, foi sugerido que 0 aumento da concentração de ouabaína central, concomitante à hiperatividade simpática, depende do influxo de sódio através de canais para sódio sensíveis a amilorida/ benzamil (Leenen, 2002). Além disso, em modelos genéticos de hipertensão arterial sensíveis ao sal, como o Dahl-sal sensível, o controle do sódio no líquido cefalorraquidiano está alterado associado à ativação da ouabaína central, levando assim, à hiperatividade simpática e hipertensão arterial, aparentemente independente do genótipo renal (Leenen, 2002).

A administração aguda, dependente da dose, de ouabaína em algumas regiões do sistema nervoso central, tais como o núcleo mediano preóptico 
(Budzikowski e Leenen, 1997;2001) e bulbo rostral ventrolateral (Teruya et al., 1997), promove aumento da atividade nervosa simpática, pressão arterial e frequência cardíaca. A hiperatividade simpática induzida por ouabaína e o consequente aumento da pressão arterial parecem envolver o sistema reninaangiotensina central, visto que a administração do antagonista do receptor $A T_{1}$ (Budzikowski, Leenen, 2001) bloqueia esta hiperatividade simpática. Além disso, a elevação da pressão arterial induzida pela administração aguda de ouabaína é atenuada em ratos transgênicos deficientes de angiotensinogênio central (Huang et al., 2001). Cabe ressaltar que a infusão de aldosterona aumenta os níveis ouabaína no hipotálamo e bloqueadores de receptores de mineralocorticóides e ligantes que inibem as ações da ouabaína previnem aumento da atividade simpática e pressão arterial (Wang et al., 2003).

Destarte, por meio dos trabalhos citados acima, é possível presumir que a ouabaína tenha um papel significativo no desenvolvimento e/ou manutenção da hiperatividade simpática e, assim, no desenvolvimento e/ou manutenção da hipertensão arterial.

\subsection{Ouabaína e o modelo de hipertensão DOCA-sal}

A desoxicorticosterona é um hormônio esteróide produzido pela glândula adrenal que possui atividade mineralocorticóide e atua como um precursor da aldosterona (Selye e Stone, 1946; Vinson, 2011). Na década de 30, a desoxicorticosterona foi isolada, estruturalmente identificada e sintetizada (Vinson, 2011). Selye et al. $(1946 ; 1957)$ foram os primeiros a demonstrarem que a administração de acetato de desoxicorticosterona (DOCA) induz hipertensão arterial em ratos.

O modelo DOCA-sal é um modelo de hipertensão arterial dependente de volume, onde a administração de DOCA aumenta a reabsorção de sódio e água nos túbulos distais (Guyton et al. 1972; Selye e Stone, 1946; Vinson, 2011). Além disso, para induzir hipertensão arterial em ratos, concomitante a administração de DOCA, os animais são mantidos em uma dieta com níveis altos de $\mathrm{NaCl}$ e submetidos a redução da massa renal (devido indução de nefrectomia unilateral). Todos esses 
fatores contribuem para a hipervolemia, levando a um quadro de hipertensão arterial maligna (Vinson, 2011).

Há evidências que a ouabaína está aumentada no plasma e encéfalo do modelo de hipertensão DOCA-sal (Kojima, 1984; Park et al., 2004; Ferrari et al., 2006).

Em 1981, após Pamnani et al. terem demonstrado que a atividade da $\mathrm{Na}^{+} \mathrm{K}^{+}-$ ATPase estava reduzida em artérias de animais DOCA-sal, trabalhos subsequentes sugeriram a participação da ouabaína neste modelo de hipertensão arterial. Neste sentido, em 1982 Songu-Mize et al. demonstraram que ratos DOCA-sal com lesão na região AV3V apresentaram redução na pressão arterial que estava relacionada, ao menos em parte, com a interrupção da secreção, transporte ou síntese de uma substância humoral, a qual reduzia a atividade da $\mathrm{Na}^{+} \mathrm{K}^{+}$-ATPase. Neste mesmo período, corroborando os dados de Songu-Mize et al. (1982), Kojima et al. (1982) sugeriram que o fator inibidor da $\mathrm{Na}^{+} \mathrm{K}^{+}$-ATPase contribuía com a hipertensão arterial presente nos animais DOCA-sal, visto que estes autores observaram uma queda significativa na pressão arterial desses animais após a infusão do anticorpo antidigoxina, o qual inibe o fator digitalis-like. Posteriormente, comprovou-se que este fator era o glicosídeo ouabaína, e que estava presente em maiores concentrações tanto no hipotálamo quanto na glândula adrenal em animais DOCAsal (Kojima, 1984; Park et al., 2004).

No modelo DOCA-sal há alterações tanto funcionais quanto estruturais no território vascular, o qual se questiona, no presente estudo, a plausível participação da ouabaína neste cenário.

Neste sentido, as mudanças observadas, em artérias dos animais DOCA-sal, são: (1) aumento da resposta vasoconstritora e/ ou redução da resposta vasodilatadora via prejuízo da síntese e/ ou biodisponibilidade do óxido nítrico (Cordellini et al., 1990; Ko et al., 2007; Lima et al., 2009; Nunes et al., 2000; Somers et al., 2000; White et al., 1996); (2) aumento do tônus miogênico, o qual é abolido na presença de um bloqueador de canal para $\mathrm{Ca}^{2+}$, do inibidor da NADPH oxidase e do inibidor da COX (Glosh et al., 2004); (3) aumento de espécies reativas derivadas do oxigênio, principalmente o ânion superóxido (Callera et al., 2006), tendo como principais fontes a NADPH oxidase (Beswick et al., 2001), a xantina oxidase e/ ou a mitocôndria (Viel et al., 2008); (4) redução da atividade Cu/Zn SOD (Wu et al., 2001); (5) aumento de citocinas proinflamatórias, do fator de transcrição nuclear (NF-KB) e 
infiltração de macrófago (Beswick et al., 2001; Ko et al., 2007; Schiffrin, 2005); e, (6) durante a fase maligna da hipertensão arterial, ocorre remodelamento hipertrófico das artérias de resistência (Ko et al., 2007; Yemane et al., 2009).

Além das alterações no território vascular, o modelo DOCA-sal apresenta hiperatividade simpática, visto que: (1) a desnervação renal reduz a elevação da pressão arterial e retenção de sódio (Katholi et al., 1980); (2) a aguda normalização dos níveis de $\mathrm{NaCl}$ no plasma dos animais DOCA-sal diminui a atividade do nervo simpático lombar (O'Donaughy e Brooks; 2006); e (3) há aumento das catecolaminas plasmáticas no estágio inicial da hipertensão arterial (Yemane et al., 2009).

Como mencionado no presente texto, sabendo que no modelo de hipertensão arterial induzido por ouabaína também ocorrem alterações funcionais e estruturais no território arterial e ativação do sistema nervoso simpático, comparáveis àquelas descritas na hipertensão arterial do modelo DOCA-sal, é cabível presumir que haja uma correlação positiva entre o aumento das concentrações plasmáticas e/ ou teciduais da ouabaína e as alterações da função vascular e da atividade simpática do modelo DOCA-sal.

\subsection{Ouabaína: Um possível alvo para o tratamento da Hipertensão arterial?}

Visto que algumas enfermidades cursam com um aumento das concentrações plasmáticas de ouabaína, entre elas a hipertensão arterial, parece razoável sugerir que um anti-hipertensivo capaz de antagonizar os efeitos da ouabaína endógena possa representar uma nova e específica intervenção farmacológica para o tratamento dessa enfermidade.

De fato, Ferrari et al. (1998) desenvolveram uma nova molécula com estas características. Esta molécula denominada de rostafuroxina (PST 2238) (17 $\beta$-(3furil)-5 $\beta$-androstana- $3 \beta, 14 \beta, 17 \alpha$-triol) é um derivado de digitoxigenina que desloca in vitro a ligação específica da ouabaína com a $\mathrm{Na}^{+} \mathrm{K}^{+}$-ATPase com $\mathrm{IC}_{50}$ de $2 \times 10^{-6} \mathrm{M} \mathrm{e}$ afeta a atividade enzimática em $10^{-5} \mathrm{M}$ (Ferrari et al., 2006; 2010). A toxicidade oral aguda da rostafuroxina em ratos é $L_{50}>2.000 \mathrm{mg} / \mathrm{kg}$. Estudos toxicológicos crônicos, um e três meses de tratamento com rostafuroxina, realizados em ratos e macacos, indicam que o composto não induz mortalidade ou qualquer alteração 
toxicológica em doses até $100 \mathrm{mg} / \mathrm{kg}$ (v.o.) para ratos e $180 \mathrm{mg} / \mathrm{kg}$ (v.o.) para macacos (Ferrari et al., 2000; 2006). A rostafuroxina não tem atividade diurética, não interage in vitro com outros receptores envolvidos no controle da pressão arterial e não causa qualquer efeito cardíaco quando testado tanto em preparações in vitro quanto in vivo (Ferrari et al., 2000; Quadri et al., 1997). Além disso, este composto é desprovido de efeitos androgênicos, estrogênicos e corticomiméticos in vivo, não altera o hormônio adrenocorticotrófico (ACTH) e a secreção de prolactina e não afeta motilidade gastrointestinal (Quadri et al., 1997).

Por antagonizar os efeitos da ouabaína endógena, a rostafuroxina reduz a pressão arterial sem afetar a frequência cardíaca em ratos hipertensos de Milão, em ratos DOCA-sal e em ratos hipertensos induzidos pelo tratamento crônico com ouabaína (Ferrari et al., 2006; 2010). Além disso, tratamento com rostafuroxina restaura a atividade aumentada da $\mathrm{Na}^{+} \mathrm{K}^{+}$-ATPase encontrada em ratos hipertensos de Milão e em ratos tratados com ouabaína (Ferrari et al., 1998;2006). No entanto, este composto não tem efeito sobre a pressão arterial de animais SHR (Ferrari et al., 1993).

A eficácia da rostafuroxina em antagonizar o efeito da ouabaína também foi observada no território vascular (Ferrari et al., 2006; Zhang et al., 2005). Nesse sentido, foi visto que o aumento da resposta contrátil ao $\mathrm{KCl}$, encontrado em artérias mesentéricas isoladas de animais tratados com ouabaína, é completamente normalizado pelo tratamento por quatro semanas com rostafuroxina (Ferrari et al., 2006). Além disso, foi demonstrado que o aumento da resposta miogênica, em artéria mesentérica de resistência de camundongo, induzido pela administração aguda de ouabaína, é antagonizado pela rostafuroxina (Zhang et al., 2005). Esses resultados reforçam a ideia que esse fármaco é um inibidor das ações desse glicosídeo.

É digno de nota que, o efeito anti-hipertensivo da rostafuroxina em humanos está sob análise em um ensaio clínico no estudo multicêntrico para Intervenção Específica do Sódio na Hipertensão Arterial (OASIS-HT). A fase II do ensaio clínico, a qual objetivou estudar a eficácia da rostafuroxina no tratamento da hipertensão arterial essencial, foi finalizada em 2011 (Staessen et al., 2011) e os resultados demonstraram que a rostafuroxina não reduziu a pressão arterial significativamente em humanos. A conclusão principal da ineficiência do fármaco foi que os pacientes estudados já recebiam tratamento para hipertensão arterial e que a retirada do 
medicamento por um período de 4 semanas foi insuficiente (Staessen et al., 2011). Por outro lado, um importante objetivo secundário do estudo da OASIS-HT foi investigar a redução da pressão arterial pelo tratamento com rostafuroxina em pacientes com determinada variação genética, ou seja, os pacientes que apresentam no fenótipo alteração nas enzimas envolvidas na síntese e degradação de ouabaína. Em suma, o estudo revelou que a farmacogenômica de portadores desse perfil genético, os quais representaram $23 \%$ dos pacientes randomizados pela OASIS-HT, mostraram diminuição significativa da pressão arterial (Staessen et al., 2011). Com base nesses resultados preliminares da farmacogenômica, a OASIS-HT iniciou uma forma mais focada de ensaio clínico de fase II comparando os efeitos do rostafuroxina e losartan em pacientes hipertensos com perfil genético específico. Esta pesquisa está em andamento e o perfil do estudo encontra-se no site do clinicaltrials. 


\section{HIPÓTESE E OBJETIVO}

Embora muitos trabalhos tenham demonstrado os mecanismos envolvidos na gênese e/ ou manutenção da hipertensão arterial induzida por ouabaína em ratos, pouco se sabe sobre os efeitos da elevação das concentrações plasmáticas de ouabaína durante a instalação e/ ou manutenção dessa enfermidade. Assim, é relevante estudar a interferência de fármacos que atenuem ou até mesmo revertam os efeitos da ouabaína sobre o processo hipertensivo e que atestem a sua real contribuição para instalação e/ou manutenção da hipertensão arterial.

Baseado em tais fatos ou premissas expostos até o momento, a hipótese da presente tese foi que ratos do modelo de hipertensão arterial DOCA-sal tratados com o antagonista da ouabaína, a rostafuroxina, teriam melhora significativa sobre o sistema cardiovascular. Confirmada tal hipótese, o papel prejudicial da ouabaína na hipertensão arterial seria demonstrado.

Portanto, o presente estudo teve como objetivo avaliar os valores pressóricos, a função vascular em artérias de resistência isoladas do leito mesentérico e a atividade simpática do nervo esplâncnico após o tratamento por 3 semanas com o antagonista da ouabaína, a rostafuroxina, de ratos DOCA-sal. 


\section{MATERIAIS E MÉTODOS}

\subsection{Animais experimentais}

Neste estudo foram utilizados ratos Wistar $(n=200)$ inicialmente com seis semanas de idade e pesando aproximadamente $140 \mathrm{~g}$, os quais foram comprados do biotério central do Instituto de Ciências Biomédicas da Universidade de São Paulo e mantidos em gaiolas, sob condições controladas de temperatura e ciclo claro-escuro defenido de 12/12 horas, respecticamente, com livre acesso à água e alimentação no biotério de experimentação animal do Departamento de Fisiologia e Biofísica, ICB/USP.

Os protocolos utilizados na presente tese para experimentação animal estão de acordo com os Princípios Éticos de Experimentação Animal adotado pelo Colégio Brasileiro de Experimentação Animal (COBEA) e foram aprovados pela Comissão de Ética em Experimentação Animal (CEEA) e registrados sob $n^{\circ} 023$ nas fls. 55 do livro 02.

\subsection{Obtenção dos modelos animais experimentais}

Após completarem sete semanas de idade, os ratos foram anestesiados com uma mistura contendo ketamina, xilazina e acetopromazina $(64,9 ; 3,20$ e 0,78 mg/Kg respectivamente, i.p.). Subsequente confirmação do plano anestésico, foi feita uma incisão dorso lateral para a remoção do rim direito e na sequência foi feita sutura e um analgésico ketoprofeno (Ketofen 1\%, Brasil, $2 \mathrm{mg} / \mathrm{Kg} / \mathrm{dia} \mathrm{s.c}$ ) durante três dias consecutivos foi aplicado. Estes animais permaneceram em repouso durante sete dias para total recuperação e o início da indução da hipertensão DOCA-sal.

\subsubsection{Indução da hipertensão DOCA-sal}

Para indução da hipertensão arterial, os animais foram separados de forma aleatória em dois grupos experimentais: I) grupo de ratos uninefrectomizados (SHAM) e II) grupo de ratos uninefrectomizados submetidos à hipertensão DOCAsal. 
Os animais DOCA-sal receberam semanalmente uma injeção subcutânea de acetato de desoxicorticosterona (Sigma Aldrich Co., Steinheim, Alemanha). Cada animal recebeu uma dose de $20 \mathrm{mg} / \mathrm{kg}$ na primeira semana, de $12 \mathrm{mg} / \mathrm{kg}$ na segunda e terceira semanas e $6 \mathrm{mg} / \mathrm{kg}$ até o final do tratamento (Carneiro, 2006). $O$ veículo utilizado para a solubilização da droga foi uma mistura (1:1) de propilenoglicol (Labsynth, Diadema, Brasil) com óleo mineral. As doses de desoxicorticosterona foram administradas em um volume de 0,2 $\mathrm{mL}$. Além disso, os animais deste grupo receberam água contendo $1 \%$ de cloreto de sódio $(\mathrm{NaCl})$ e $0,2 \%$ de cloreto de potássio $(\mathrm{KCl})$. Aos animais do grupo controle foi administrado semanalmente $0,2 \mathrm{~mL}$ de veículo pela via subcutânea, no período de 8 semanas.

\subsubsection{Tratamento terapêutico com Rostafuroxina}

Posteriormente à confirmação da estabilização da hipertensão arterial no grupo DOCA-sal, a qual ocorreu após a 5 semana de tratamento, os animais foram aleatoriamente subdivididos em dois grupos experimentais: DOCA-sal e DOCA-sal tratados com rostafuroxina ( $1 \mathrm{mg} / \mathrm{kg} / \mathrm{dia}$, doação da Sigma-Tau, Milão, Itália), por gavagem, por um período de três semanas. $O$ veículo utilizado para a solubilização da droga foi carboximetilcelulose 0,5\% (Center Fórmula, São Paulo, Brasil). Os animais do grupo controle receberam somente o veículo diariamente por gavagem.

\subsection{Avaliação das variações de pressão arterial sistólica, do peso corporal e taxa de mortalidade}

A pressão arterial caudal, medida pela técnica de pletismografia de cauda (LE 5001, Panlab s.l. Barcelona, Espanha), e o peso corporal foram determinados semanalmente iniciados antes da cirurgia de nefrectomia sendo avaliados ao longo do período de tratamento. Os valores semanais de pressão arterial de cauda (pressão arterial sistólica) para cada animal representam a média aritmética de 10 medidas coletadas após aquecimento dos animais à $\sim 35^{\circ} \mathrm{C}$ e acomodação dos mesmos em meio para contenção (Oanlab s.l. Barcelona, Espanha).

Para avaliar a taxa de mortalidade, a contagem dos animais que morreram ao longo do tratamento iniciou-se apenas a partir da quinta semana, ou seja, quando os 
animais foram divididos em subgrupos DOCA-sal e DOCA-sal tratados com rostafuroxina.

\subsection{Registro e análise da atividade do nervo simpático esplâncnico}

Após o período de tratamento, os animais foram inicialmente anestesiados com halotano $5 \%$ em $100 \%$ de oxigênio de ar inspirado e, posteriormente, traqueostomizados e colocados em ventilação artificial com 1,4 - 1,5\% de halotano em 100\% de oxigênio para continuação dos procedimentos cirúrgicos.

Para o registro das variáveis cardiovasculares, os animais foram submetidos à cateterização da artéria femoral com cateter de polietileno (PE-10 conectado a um PE-50) para registro da pressão arterial pulsátil (sistólica e diastólica) e calculada a pressão arterial média. O cateter da artéria femoral foi conectado a um transdutor de pressão (Physiological Pressure Transducer mod. MLT844, ADInstruments, USA) acoplado a um pré-amplificador (Bridge Bio Amplifier mod. ML221, ADInstruments, USA) e ao sistema de registro computadorizado de 8 canais (modelo Powerlab 8SP ADInstruments, USA). As veias femorais, direita e esquerda, também foram cateterizadas (PE-10 conectado a um PE-50) para a infusão de drogas e anestésico. Após a cateterização da veia femoral, o anestésico halotano foi substituído pelo anestésico uretana (1,2 g/kg, i.v.).

$\mathrm{Na}$ sequência, os animais foram colocados em um aparelho estereotáxico (modelo Kopf 1760) e receberam uma sonda retal para monitorização da temperatura corpórea mantida em $37^{\circ} \mathrm{C}$, utilizando-se um colchão com resistência interna para aquecimento (Moreira et al., 2011). O índice de $\mathrm{CO}_{2}$-expirado foi monitorado durante todo o experimento por meio de um capnômetro (Columbus Instruments, Ohio, USA).

Por meio de um modelo de abertura retroperitoneal, o nervo esplâncnico esquerdo foi exposto na saída do gânglio supra-renal e, com o auxílio de uma lupa (n. 0959, D.F. Vasconcellos, Brasil), cuidadosamente dissecado para colocação de um eletrodo em forma de gancho em configuração monopolar (Moreira et al., 2011). Os nervos e os eletrodos de registro foram cobertos com óleo mineral (Synth, Brasil).

O eletrodo bipolar em que o nervo foi colocado foi conectado a um conversor analógico-digital de 4 canais (modelo CED-1401, Cambridge, UK). Este aparelho possui filtro passa-baixo, ligação AC-DC (corrente direta-alternada), filtro de corte, 
variação do ganho e possibilita correção da linha de base. A partir deste aparelho, o sinal era copiado para um sistema de aquisição de dados versão 5 do Spike 2 software (CED). A atividade simpática do nervo esplâncnico foi filtrada de 100 a $3000 \mathrm{~Hz}$ (Moreira et al., 2011).

O nível da anestesia foi sempre monitorado testando a ausência de resposta no reflexo de retirada, ausência de mudanças na pressão arterial e na atividade do nervo esplâncnico após o pinçamento da pata do animal. Satisfeito esses critérios, o relaxante muscular (pancurônio) foi administrado endovenosamente em uma dose de $1 \mathrm{mg} / \mathrm{kg}$.

Após período de 30 min de estabilização se iniciou o registro basal da pressão arterial pulsátil e da atividade do nervo simpático esplâncnico por 10 min. $\mathrm{Na}$ sequência foi administrado fenilefrina em uma única dose (5 $\mu \mathrm{g} / \mathrm{kg})$. Esse mesmo procedimento foi repetido por mais duas vezes com um intervalo de 15 min, obtendos-se uma média dos valores. Após estabilização por 15 min, o respirador, ao qual o animal estava conectado foi desligado por 20 segundos (apneia), para obtenção do estímulo máximo da atividade simpática. Depois de estabilização da atividade do nervo simpático esplâncnico e da pressão arterial pulsátil foi feita a infusão endovenosa de hexametônio $(30 \mu \mathrm{g} / \mathrm{g})$ para bloqueio ganglionar da cadeia paravertebral simpática e obtenção do nível de ruído, o qual foi subtraído dos valores de atividade do nervo simpático esplâncnico.

\subsubsection{Análise da atividade basal do nervo simpático esplâncnico}

A captação dos biopotenciais da atividade do nervo simpático esplâncnico e da pressão arterial foram registrados simultaneamente seguindo o protocolo:

1-Basal: o registro foi realizado durante $10 \mathrm{~min}$ com o animal anestesiado;

2-Estimulado: o registro foi realizado após o respirador artificial ser desligado por 20 segundos (apnéia), para obtenção do estímulo máximo e saturação da atividade do nervo simpático. O padrão de atividade simpática estimulada foi considerado como máximo de atividade registrada para cada registro, ou $100 \%$;

3-Inibido: foi administrado o bloqueador ganglionar hexametônio (30 $\mu \mathrm{g} / \mathrm{g}$ i.v.) para bloqueio da atividade simpática ganglionar. Este registro foi utilizado como mínimo de atividade neural, ou 0\%; 
4-Ruído: após a morte do animal, por excesso de uretana injetada (2 g/kg, i.v.) no cateter inserido na veia femoral, foi registrada a atividade simpática durante 10 min. O registro deste sinal foi considerado como ruído do sistema e foi subtraído durante a análise dos registros eletroneurográficos. A atividade nervosa simpática foi analizada "off-line" usando um programa de computador (Spike 2, Cambridge Electronic Design, Cambridge, UK), como um roreiro pré-determinado (Antunes et al., 2006) e expressa como a média da voltagem $(\mu \mathrm{V})$ por unidade de tempo subtraindo desses valores o ruído do sistema.

Para avaliação da atividade foram selecionados aleatoriamente períodos, com o mesmo tempo, para a atividade basal (2 períodos diferentes e não simultâneos), estimulado, inibido e ruído. O valor do ruído foi subtraído dos valores de atividade basal, estimulado e inibido. Para atingir o valor da atividade basal foi realizada a seguinta fórmula:

Atividade basal $=[($ basal - inibido $) \times 100 \%] /($ estimulado - inibido $)$

A média dos valores percentuais dos dois períodos de atividade basal registrados foi considerada como valores de atividade basal.

A análise do registro com múltiplas fibras da atividade simpática é uma limitação metodológica desta técnica uma vez que um diferente número de fibras pode entrar em contato com o eletrodo e assim modificar o resultado da atividade. Entretanto, por meio da normalização da qualidade das preparações e registros com múltiplas fibras, expressando a porcentagem máxima (100\%) e mínima (0\%), estas limitações são minimizadas e este recurso tem sido frequentemente utilizado com sucesso para análise comparativa da atividade nervosa simpática de animais.

\subsubsection{Análise da sensibilidade barorreflexa}

Após a infusão endovenosa de pancurônio $(1 \mathrm{mg} / \mathrm{Kg})$ e um período de estabilização da atividade do nervo simpático esplâncnico e da pressão arterial pulsátil foi feita a administração de fenilefrina em uma única dose $(5 \mu \mathrm{g} / \mathrm{kg})$ para avaliar a sensibilidade do barorreceptor em reduzir a atividade simpática frente ao aumento da pressão arterial. Esse mesmo procedimento foi repetido por mais duas vezes com um intervalo de $15 \mathrm{~min}$, obtendo-se uma média dos valores. De cada registro, tanto para o aumento da pressão arterial quanto para a queda da atividade 
simpática, após à administração de fenilefrina, foram obtidos nove pontos para a construção da reta, pela equação $y=a x+b$ e, assim, obtenção do slope da reta.

\subsection{Quantificação de malondialdeído no plasma pelo método da reação de substâncias com o ácido tiobarbitúrico (TBARS)}

Em outro grupo de animais, após o período de tratamento os ratos foram anestesiados com uma mistura contendo ketamina, xilazina e acetopromazina $(64,9$; 3,20 e 0,78 mg/Kg respectivamente, i.p.). Foi feita uma incisão na pata esquerda e a artéria femoral foi cateterizada utilizando um cateter de polietileno (PE-10 conectado a um PE-50) e uma seringa contendo $20 \mu \mathrm{L}$ de heparina (1:10) foi adicionada no cateter para coleta de $1 \mathrm{~mL}$ de sangue. Imediatamente à coleta, os tubos contendo o sangue foram centrifugados a $5200 \mathrm{rpm}$ por $20 \mathrm{~min}$ a $4{ }^{\circ} \mathrm{C}$. O plasma foi separado e estocado a $-80^{\circ} \mathrm{C}$ para análises posteriores.

Para a medida de malondialdeído (MDA), produto da peroxidação lipídica, utilizou-se o kit para análise de TBARS (cód. 10009055; Cayman, USA). Para isso, $25 \mu \mathrm{L}$ do plasma foram misturados a uma solução contendo dodecil sulfato de sódio (SDS, cód. 10009055; Cayman, USA) e o reagente de cor contendo o ácido tiobarbitúrico (TBA; cód. 10009055; Cayman, USA) o qual, por sua vez, reage com o MDA. Após agitação, para mistura adequada da solução, os tubos contendo as amostras foram perfurados, lacrados e adicionados a um banho contendo água na temperatura de $100{ }^{\circ} \mathrm{C}$ por 1 hora, visto que a reação do MDA com o TBA só ocorre em temperatura alta. Imediatamente, após o período de incubação os tubos foram colocados no gelo por $10 \mathrm{~min}$ para cessar a reação. Na sequência foram centrifugados a $5400 \mathrm{rpm}$ por $10 \mathrm{~min}$ a $4{ }^{\circ} \mathrm{C}$ e $150 \mu \mathrm{L}$ do sobrenadante foi extraído e aplicado, em duplicata, em placa transparente para ELISA. A intensidade da cor (absorvida em $530 \mathrm{~nm}$ ) foi captada pelo espectrofotômetro.

\subsection{Estudo de reatividade vascular em artérias de resistência do leito vascular mesentérico}

Para estudar a reatividade vascular em artérias mesentéricas de resistência, foi utilizado o método descrito inicialmente por Mulvany e Halpern (1977). Para isso, 
o leito mesentérico foi removido, acondicionado em uma placa de petri contendo solução de Krebs-Henseleit a $4^{\circ} \mathrm{C}$ (composição em mM: $\mathrm{NaCl} 118 ; \mathrm{KCl} 4,7$; $\mathrm{NaHCO}_{3} 25 ; \mathrm{CaCl}_{2} .2 \mathrm{H}_{2} \mathrm{O}$ 2,5; $\mathrm{KH}_{2} \mathrm{PO}_{4}$ 1,2; $\mathrm{MgSO}_{4} .7 \mathrm{H}_{2} \mathrm{O}$ 1,2; EDTA 0,01 e glicose 11) e o terceiro ramo da artéria mesentérica superior foi dissecado e cortado em segmentos de 2,0 mm de comprimento com um auxílio de um microscópio de dissecação (Nikon, SMZ 645, USA). Dois fios de tungstênio (40 $\mu \mathrm{m}$ de diâmetro) foram inseridos no lúmen das artérias e montados em miógrafo para vasos de resistência (Danish Myo Tech, modelo 610M, JP-Trading I/S, Aarhus, Dinamarca) para estudo de tensão isométrica (Figura 3). O miógrafo estava conectado a um sistema para aquisição de dados (PowerLab / 8SP, ADinstruments, Austrália) e este a um computador (PC Pentium IV).

Figura 3 - Esquema da preparação montada nas placas que compõem o miógrafo para medida de tensão em vasos de resistência

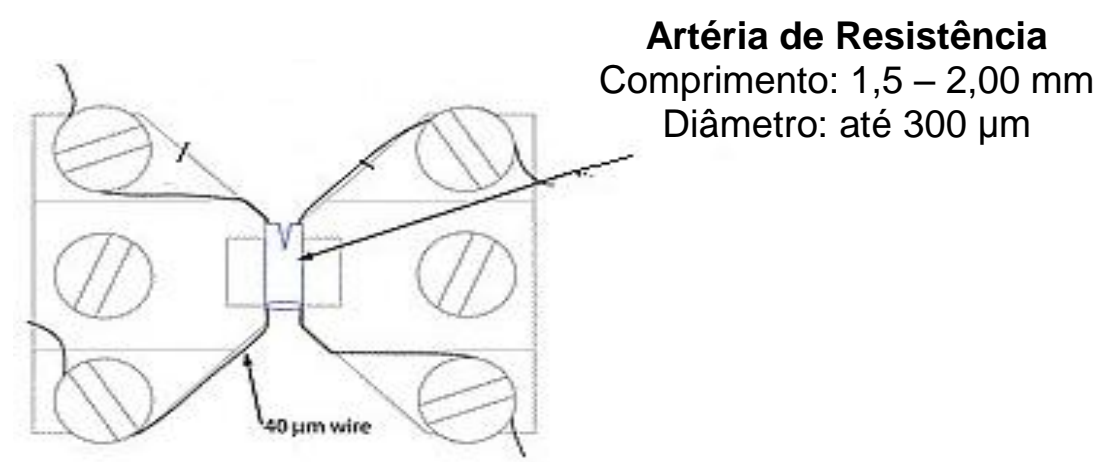

Fonte: Modficado de Mulvany e Halpern (1977).

\subsubsection{Normalização das artérias de resistência}

Após período de estabilização de 15 minutos em solução de Krebs-Henseleit $\left(\mathrm{pH} 7,4\right.$ e a $\left.37^{\circ} \mathrm{C}\right)$, a artéria foi estirada a uma tensão de repouso considerada ótima em relação ao seu diâmetro interno. Para isso, em cada segmento arterial, a relação tensão/diâmetro foi calculada a uma circunferência interna que corresponde a uma pressão transmural de $100 \mathrm{mmHg}$ para um vaso relaxado in situ (L100) (Mulvany e Halpern, 1977). Para a realização dos experimentos, as artérias foram mantidas com circunferência interna $L 1$, calculada por meio da fórmula $L 1=0,90 \times L 100$, na qual o 
desenvolvimento de força é máximo, como previamente descrito por Mulvany e Halpern (1977). O diâmetro luminal efetivo foi determinado de acordo com a equação $I 1=L 1 / \pi$, utilizando o software específico para normalização de artérias de resistência (DMT Normalization Module, ADInstruments, Austrália). Após 15 minutos do processo de normalização, as artérias foram contraídas com administração de cloreto de potássio $(\mathrm{KCl} 120 \mathrm{mM}$ ), objetivando avaliar a integridade funcional das preparações. A administração de $\mathrm{KCl}$ repetiu-se por mais duas vezes com intervalo de 15 min entre cada administração, até alcançar uma estabilidade na resposta de despolarização do músculo liso ao $\mathrm{KCl}$. Os segmentos arteriais que responderam à contração ao $\mathrm{KCl}$ com tensão vascular ativa (aumento da força a partir da tensão basal dividida por duas vezes o comprimento de cada segmento arterial, $\mathrm{mN} / \mathrm{mm}$ ) abaixo de $1,5 \mathrm{mN} / \mathrm{mm}$ foram excluídos.

\subsection{Protocolos experimentais}

3.7.1 Avaliação da resposta à agonistas contráteis

Para avaliar a contração vascular, os anéis foram inicialmente submetidos ao teste para confirmação da integridade funcional do endotélio. Para isso, os anéis foram pré-contraídos com noradrenalina $(10 \mu \mathrm{M})$ até alcançar um platô da resposta contrátil e na sequência foi administrado acetilcolina $(10 \mu \mathrm{M})$. Os anéis que relaxaram acima de $80 \%$ para o grupo SHAM, foram utilizados para a avaliação das curvas concentração-resposta à noradrenalina (1 $\mathrm{nM}-300 \mu \mathrm{M})$, à serotonina $(0,1$ $\mathrm{nM}-30 \mu \mathrm{M})$ e ao $\mathrm{KCl}(5 \mathrm{mM}-140 \mathrm{mM})$ de forma cumulativa. Embora o protocolo acima descrito também foi empregado para os anéis vasculares do grupo DOCA-sal e do grupo ROSTA, os segmentos arteriais que relaxaram abaixo de $80 \%$ não foram descartados devido a presença de disfunção endotelial.

\subsubsection{Análise do papel do cálcio intracelular e extracelular na resposta vasoconstritora à noradrenalina}

A resposta contrátil à noradrenalina mediada pela liberação de cálcio dos estoques intracelulares foi avaliada por meio da contração induzida por este agonista em solução de Krebs livre de cálcio (composição em mM: $\mathrm{NaCl}$ 119,3; 
$\mathrm{NaHCO}_{3}$ 25; $\mathrm{KH}_{2} \mathrm{PO}_{4}$ 1,2; $\mathrm{MgSO}_{4} .7 \mathrm{H}_{2} \mathrm{O}$ 1,2; EDTA 0,01; EGTA 1 e glicose 11). Na solução sem cálcio, o $\mathrm{NaCl}$ substituiu o $\mathrm{CaCl}_{2}$ por igual concentração, para manter a osmolaridade. Neste experimento, 60 minutos após a avaliação da integridade do endotélio observada pelo relaxamento à acetilcolina (10 $\mu \mathrm{M})$, os segmentos foram incubados durante 10 minutos com solução de Krebs livre de cálcio e contendo EGTA (1 mM), em seguida, foi adicionada noradrenalina (10 $\mu \mathrm{M})$ no banho. A adição de noradrenalina induziu contração transiente e de pequena magnitude. Após o retorno da tensão ao basal, foi avaliada a resposta contrátil mediada pelo influxo de cálcio por meio da administração de $\mathrm{CaCl}_{2}(2,5 \mathrm{mM})$.

\subsubsection{Avaliação da resposta à agonistas vasodilatadores}

Após 30 min da contração induzida pela terceira administração de $\mathrm{KCl}$ (120 $\mathrm{mM}$ ), foi avaliado, em alguns segmentos de artérias mesentéricas de resistência, o relaxamento dependente do endotélio induzido pela administração cumulativa de concentrações crescentes de acetilcolina $(0,01 \mathrm{nM}-30 \mu \mathrm{M})$. Para isso, alguns anéis foram pré-contraídos com U-46619, um mimético do tromboxano A2, com noradrenalina ou com serotonina em uma concentração capaz de induzir $\sim 100 \%$ da resposta contrátil máxima induzida pelo $\mathrm{KCl}(120 \mathrm{mM})$. Em outros segmentos, précontraídos com U-46619, foi avaliado o relaxamento independente do endotélio induzido ou pelo nitroprussiato de sódio $(0,1 \mathrm{nM}-300 \mu \mathrm{M})$ ou pela papaverina (10 $\mathrm{nM}-300 \mu \mathrm{M})$.

\subsubsection{Avaliação das vias envolvidas na resposta vasodilatadora dependente do endotélio}

Para avaliar as possíveis vias envolvidas na resposta vasodilatadora à acetilcolina, todas as artérias após incubação de $30 \mathrm{~min}$ com os inibidores específicos (descritos abaixo) foram pré-contraídas com serotonina em uma concentração capaz de induzir $\sim 100 \%$ da resposta contrátil máxima induzida pelo $\mathrm{KCl}(120 \mathrm{mM})$. Entre os agentes pré-contráteis utilizados para avaliar a função endotelial, a serotonina foi selecionada, pois foi o agonista que melhor manteve o tônus vascular no período de platô após incubação com os inibidores descritos 
abaixo e que não possue o seu mecanismo de ação via estimulação com o receptor TP.

3.7.3.1.1 Efeito do bloqueio da síntese de óxido nítrico e das espécies reativas derivadas do oxigênio sobre a resposta vasodilatadora à acetilcolina

Alguns anéis vasculares após a averiguação da integridade do endotélio, foram incubados por 30 min com L-NAME (100 $\mu \mathrm{M}$, inibidor não seletivo da sintase de óxido nítrico) ou Tiron (1 mM, varredor do ânion superóxido) ou catalase (1000 U/ $\mathrm{mL}$, varredor do peróxido de hidrogênio). Após o período de incubação os anéis foram pré-contraídos com serotonina $(10 \mu \mathrm{M})$ até alcançar $\sim 100 \%$ da contração ao $\mathrm{KCl}$ (120 mM). Após atingir o platô, foi administrado cumulativamente acetilcolina em concentração crescente $(0,01 \mathrm{nM}-30 \mu \mathrm{M})$.

3.7.3.1.2 Efeito do inibidor da NADPH oxidase e da ciclooxigenase-2 (COX-2) sobre a resposta vasodilatadora à acetilcolina

Para avaliar a participação NADPH e da COX-2 sobre o relaxamento induzido pela acetilcolina, alguns anéis vasculares foram incubados, após a averiguação da integridade endotelial, com apocinina (10 $\mu \mathrm{M}$, inibidor da NADPH oxidase) ou com NS-398 (10 $\mu \mathrm{M}$, inibidor específico da COX-2) por $30 \mathrm{~min}$. Após o período de incubação os anéis foram pré-contraídos com serotonina (10 $\mu \mathrm{M})$ até uma tensão ativa próxima a $100 \%$ da contração ao $\mathrm{KCl}(120 \mathrm{mM})$. Alcançado o platô, foi administrado cumulativamente acetilcolina em concentração crescente $(0,01 \mathrm{nM}-30$ $\mu \mathrm{M})$.

\subsection{Atividade funcional da $\mathrm{Na}^{+} \mathrm{K}^{+}$-ATPase sensível à ouabaína}

Para este estudo foi utilizada a técnica de relaxamento induzida por potássio, como previamente descrita por Webb e Bohr (1978). Após 30 minutos de estabilização em solução normal de Krebs-Henseleit, a preparação foi incubada por mais 30 min com solução nutridora livre de potássio. Em seguida foi realizada a précontração com noradrenalina (100\% da resposta máxima induzida por $120 \mathrm{mM}$ de $\mathrm{KCl})$ até atingir um platô. A partir desse ponto, foi adicionado $\mathrm{KCl}(1,2,5$ e $10 \mathrm{mM})$ 
no banho com intervalos de dois minutos e meio entre cada concentração. A resposta de relaxamento na presença de concentrações crescentes de potássio é um indicador da atividade funcional da $\mathrm{Na}^{+} \mathrm{K}^{+}$-ATPase (Webb e Bohr, 1978). Em seguida as preparações foram lavadas, esperou-se que a tensão voltasse ao basal e na sequência reincubadas com solução nutridora livre de potássio por $30 \mathrm{~min}$ em presença de ouabaína agudamente adicionada ao banho $(100 \mu \mathrm{M})$ e então uma nova curva ao $\mathrm{KCl}$ foi realizada.

\subsection{Medida de tromboxano $B_{2}\left(T_{x} B_{2}\right)$ do sobrenadante de artérias mesentéricas de resistência}

A medida de $T x B_{2}$, metabólito estável do tromboxano $A_{2}\left(T x A_{2}\right)$, foi realizada utilizando o kit para ensaio bioquímico (Cayman, EUA). Para isso, os terceiros e quartos ramos da artéria mesentérica superior foram dissecados e colocados em um tubo transparente contendo $200 \mu \mathrm{L}$ de solução de Krebs (composição em mM: NaCl 118; $\mathrm{KCl} 4,7 ; \mathrm{NaHCO}_{3} 25 ; \mathrm{CaCl}_{2} .2 \mathrm{H}_{2} \mathrm{O}$ 2,5; $\mathrm{KH}_{2} \mathrm{PO}_{4}$ 1,2; $\mathrm{MgSO}_{4} .7 \mathrm{H}_{2} \mathrm{O}$ 1,2; EDTA 0,01 e glicose 11 ), previamente gaseificada a $37^{\circ} \mathrm{C}$. Após $30 \mathrm{~min}$ de estabilização, a solução de Krebs foi descartada e substituída por uma nova solução de Krebs e as amostras permanaceram sendo gaseificadas a $37^{\circ} \mathrm{C}$ por $10 \mathrm{~min}$. Após o período de incubação, a solução, a qual foi considerada situação basal, foi coletada e imediatamente congelada a $-80^{\circ} \mathrm{C}$. Esse processo repetiu-se por mais duas vezes, obtendo, desta forma, um total de três situações basais. Após a última coleta do basal, as amostras foram novamente incubadas com solução de Krebs e, após 10 min de estabilização, foi administrado noradrenalina $(10 \mu \mathrm{M})$ e depois de 2 min foi realizada uma curva concentração-resposta à acetilcolina de forma cumulativa $(0,01$ $\mathrm{nM}-30 \mu \mathrm{M})$ com intervalo de 2 min entre as concentraçãoes. Após 10 min da última concentração de acetilcolina administrada, o Krebs foi coletado e imediatamente congelado no freezer $-80^{\circ} \mathrm{C}$.

Para a medida do $\mathrm{TxB}_{2}$ foram utilizadas duas diluições (absoluto e 1:10) dos sobrenadantes, tanto para a situação basal, quanto para a situação estimulação. As diluições foram adicionadas na placa para ELISA (cód. 10004023; Cayman, USA) contendo $\mathrm{o}$ anticorpo monoclonal para $\mathrm{TxB}_{2}$ e $\mathrm{o}$ anticorpo imunoglobulina IgG anticamundongo. A placa foi incubada por duas horas em temperatura ambiente em 
agitador orbital. Após o período de incubação, a placa foi esvaziada e lavada 5 vezes com solução contendo Tris e Tween 20 (cód. 10004023; Cayman, USA). Na sequência foi adicionado em cada poço o reagente Ellman (cód. 10004023Cayman, USA), o qual promoveu uma coloração amarela decorrente da reação do corante com o traçador. A placa foi novamente incubada, sob agitação em shaker orbital, e protegida da luz por $20 \mathrm{~min}$. A intensidade da cor (absorvida em $420 \mathrm{~nm}$ ) foi captada pelo espectrofotômetro.

\subsection{Avaliação da expressão proteica pela técnica de Western Blot}

O conteúdo proteico foi avaliado pela técnica de Western Blot. Para isso, os terceiros ramos da artéria mesentérica superior foram homogeneizados em solução RIPA (Upstate, EUA), a qual era composta de: 0,5 M Tris- $\mathrm{HCl}, \mathrm{pH} 7,4 ; 1,5 \mathrm{M} \mathrm{NaCl}$; 2,5\% ácido desóxicolato, 10\% NP-40, 10 mM EDTA. Para reduzir a degradação das proteínas, foi adicionado ao tampão RIPA inibidores de proteases e fosfatases: PMSF (1 mM); $\mathrm{Na}_{3} \mathrm{VO}_{4}(10 \mathrm{mM}) ; \mathrm{FNa}(100 \mathrm{mM}) ; \mathrm{Na}_{4} \mathrm{P}_{2} \mathrm{O}_{7}(10 \mathrm{mM})$; coquetel inibitor de protease (1:1000, PIC, Sigma-Aldrich, Alemanha).

Os homogenatos (50 - $75 \mu \mathrm{g}$ de proteína) e os controles positivos para nNOS, Cu/Zn-SOD e Mn-SOD (homogenatos de encéfalo de rato), da eNOS (HUVEC), da EC-SOD e catalase (homogenatos de pulmão de rato), da NOX-1/2 e da p-22 phox (extrato de membrana de neutrófilo), da p-67phox e da p-47phox (neutrófilo total) da COX-1, COX-2 e TXA 2 (homogenatos de pulmão de rato com LPS), da c-SRC e da phopho-cSRC ${ }^{\text {Tyr418 }}$ (homogenatos de tumor de rato) foram diluídos em solução de Laemmli (Bio-rad, EUA) contendo Ditiotreitol (DTT, $350 \mathrm{mM}$ ).

Em seguida, as alíquotas foram fervidas a $100{ }^{\circ} \mathrm{C}$ por 5 min para desnaturação das proteínas. Após, as amostras foram aplicadas nos geles contendo SDS-PAGE 7,5\% (Bio-Rad, EUA) para as proteínas com maior peso molecular (eNOS, nNOS, COX-1, COX-2, NOX-1/2, p-67, cSRC e phospho-cSRC ${ }^{\text {Tyr418, }}$, catalase, $\mathrm{TxA}_{2}$ ) e $12 \%$ para as proteínas com menor peso molecular (isoformas da SOD, p-22phox e p-47phox). Para o devido controle do peso molecular, nos geles também foi adicionado o padrão de peso molecular junto às amostras (Bio-rad, EUA). Na sequência, as amostras foram submetidas à eletroforese em um sistema Mini Protean durante $\sim 2$ horas, com voltagem constante de $80 \mathrm{mV}$. 
Após eletroforese, as amostras foram transferidas para uma membrana de polivinil difluorida (Amersham Biosciences, EUA), previamente ativada com metanol. Para a transferência, o gel, a membrana e papel Whatman foram colocados em um sistema de sanduíche e imersos em uma cuba do sistema Mini Trans-Blot Cell (Biorad, EUA) contendo a solução de transferência (Tris 25 mM; glicina 190 mM; metanol $20 \%$ e SDS $0,05 \%$ ). A transferência foi confirmada pela coloração do gel durante 1 hora com azul de coomassie e pela coloração das membranas durante 20 min com Ponceau $0,1 \%$ em ácido acético $1 \%$.

Em seguida, as membranas foram bloqueadas com leite desnatado $5 \%$ dissolvido em tampão Tris (Tris 10 mM; NaCl 100 mM e Tween 20 0,1\%) por 1 hora e 30 min em temperatura ambiente. Após, as membranas foram incubadas por toda noite e sob agitação com solução de bloqueio (albumina 3\% ou leite desnatado 5\%) contendo os anticorpos primários específicos para as proteínas estudadas: anticorpo primário contra a isoforma nNOS (1:1000, cód. 610329; BD Transduction Laboratories, KY); contra a isoforma eNOS (1:1000, cod. 610297; BD Transduction Laboratories, KY); contra a isoforma CuZn-SOD (1:1500, cód. S-2147; SigmaAldrich, USA); contra a isoforma Mn-SOD (1:2000, cód. SOD-110; Stressgen, USA) e contra a isoforma EC-SOD (1:1000, cód. SOD-116; Stressgen, USA); contra a NOX 1/2 (1:1000, cód. 07-024; Upstate, USA); contra a isoforma p-47phox (1:500, cód. 3923; Millipore, USA); contra a isoforma p-67phox (1:1000, cód. 3923; Cell Signaling, USA); contra a isoforma p-22phox (1:1000, cód. 11712; Santa Cruz, USA); contra a catalase (1:2000, cód. 0979; Sigma, USA); contra isoforma COX-1 (1:500; cód. MAB5586; Chemicon, USA); contra isoforma COX-2 (1:500; cód. 160116; Cayman, USA); contra $\operatorname{TxA}_{2}$ (1:1000; cód. ab-39362; abcam, USA); contra cSRC (1:1000; cód. 05-184; Millipore, USA); contra phospho-cSRC Tyr418 (1:1000; cód. 44660; Invitrogen, USA).

Após 12 horas, as membranas foram lavadas quatro vezes (4X) por $10 \mathrm{~min}$ com solução de Tris, sob agitação. Posteriormente, estas foram incubadas com anticorpos secundários específicos para as proteínas estudadas: imunoglobulina lgG anti-camundongo conjugado à peroxidase de rabanete (1:1500, cód. 170-6516; BioRad, USA) para as isoformas eNOS, nNOS, Cu/Zn-SOD, COX-1, c-SRC, catalase; imunoglobulina IgG anti-coelho conjugado a peroxidase de rabanete (1:5000, cód. NA934; Amersham International) para as isoformas EC-SOD, Mn-SOD, NOX-1/2, p47phox, p67phox, phospho-cSRC ${ }^{\text {Tyr418 }}, \mathrm{TxA}_{2}$, COX-2 e imunoglobulina IgG anti- 
cabra conjugado a peroxidase de rabanete (1:2000, cód. 705-035-003; Jackson Immuno Reserch, USA) para a p22phox.

Ao final, o excesso dos anticorpos secundários foi lavado $4 \mathrm{X}$ por $10 \mathrm{~min}$ com solução de Tris. Os imunocomplexos foram detectados por um sistema de detecção de quimioluminescência para peroxidase (ECL Plus, Amersham International, Inglaterra) seguida de autoradiografia (Hyperfilm ECL, Amersham International, Inglaterra).

As bandas das proteínas foram quantificadas mediante análise densitométrica. Para tal, os filmes com as bandas proteicas impregnadas foram gravados por um scanner conectado a um computador e os blots de proteínas foram quantificados pelo programa Scion Image (EUA). A mesma membrana foi usada para detectar a expressão da proteína $\beta$-actina (1:10000, cód. A5316; Sigma, Alemanha), a qual foi usada como controle interno para a normalização da expressão protéica das isoformas nNOS, eNOS, Cu/Zn-SOD, Mn-SOD, EC-SOD, NOX-1/2, p-22phox, p47phox, p-67phox, COX-1 e 2, TxA 2 , catalase, cSRC, phopho-

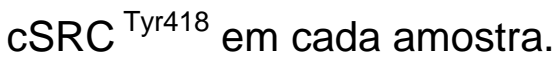

Para tal, primeiramente foi necessário retirar o imunocomplexo da membrana. Para isso, a membrana foi incubada com solução para limpeza (Tris- $62,5 \mathrm{mM}$, SDS$10 \%$, $\beta$-Mercaptoetanol- $100 \mathrm{mM}$ ) por 30 minutos a $50^{\circ} \mathrm{C}$ e lavada com TBS-T $(\mathrm{NaCl}$ $0,5 \mathrm{M}$, Tris- $\mathrm{HCl} 20 \mathrm{mM}$, Tween-20 0,1\%) por 30 minutos. Posteriormente, a membrana foi incubada com a solução bloqueante por 1 hora e 30 min e todo o processo foi repetido, como descrito anteriormente.

\subsection{Determinação da produção das espécies reativas derivadas do oxigênio pelo método de oxidação da dihidroetidina (DHE)}

Após a dissecação das artérias de resistência do leito vascular mesentérico, alguns segmentos foram imersos em um meio para congelamento (OCT, Electron Microscopy Science, EUA) e guardados em freezer $-80 \stackrel{\circ}{\circ}$. No período dos experimentos, inicialmente, foram feitos cortes transversais de $10 \mu \mathrm{m}$ em criostato (Leica, Alemanha) e colocados em lâminas silanizadas (Star Frost, Alemanha). Os cortes foram incubados com tampão fosfato durante 10 min a $37^{\circ} \mathrm{C}$. Na sequência, foi adicionado sobre os cortes tampão fosfato contendo dihidroetidina (5 $\mu \mathrm{M}$, 
Invitrogen, EUA), os quais permaneceram incubados por $30 \mathrm{~min}$, a $37^{\circ} \mathrm{C}$ em câmara úmida e protegidos da luz. Para avaliar a participação da sintase de oxido nítrico endotelial (NOS), da NADPH oxidase, da COX-1 e da COX-2 como possíveis fontes de geração das ROS, em alguns cortes de artérias mesentérica de resistência dos três grupos estudados foram incubados, concomitantemente ao DHE, com L-NAME (inibidor inespecífico da NOS, $100 \mu \mathrm{M}$ ), apocinina (inibidor da NADPH oxidase, 10 $\mu \mathrm{M}$ ), NS-398 (inibidor específico da COX-2, $10 \mu \mathrm{M}$ ) ou SC-560 (inibidor específico da COX-1, 9 nM). Após $30 \mathrm{~min}$, as lâminas foram observadas em microscópio óptico equipado com filtro padrão para rodamina e câmera fotográfica, utilizando uma objetiva para fluorescência de 20X. A análise das imagens foi feita no programa Image J 1,4 g (Wayne Rasband, National Institutes of Health, EUA), medindo-se densidade óptica média da fluorescência observada no corte. A fluorescência foi avaliada em pelo menos três locais em cada imagem e feita a media das medidas.

\subsection{Medida da produção de NO em artérias de resistência}

Para determinar a produção de $\mathrm{NO}$ foi utilizado 0 acetado 4,5diaminofluoresceína (DAF-2, Sigma, USA) um fluorescente sensível ao NO. Após a dissecação das artérias de resistência do leito vascular mesentérico, alguns segmentos foram imersos em um meio para congelamento (OCT, Electron Microscopy Science, EUA) e guardados em freezer $-80^{\circ} \mathrm{C}$. Em seguida, foram feitos cortes transversais de $10 \mu \mathrm{m}$ em criostato (Leica, Alemanha) e colocados em lâminas silanizadas (Star Frost, Alemanha). Os cortes foram incubados em tampão fosfato $(0,1 \mathrm{M}, \mathrm{pH} 7,4)$ contendo $\mathrm{CaCl}_{2}(0,45 \mathrm{mM})$. Na sequência foi adicionado DAF$2(8 \mu \mathrm{M})$ durante 30 minutos a $37^{\circ} \mathrm{C}$ em câmara úmida e protegidos da luz. Após incubação, os cortes foram estimulados com acetilcolina $(10 \mu \mathrm{M})$ por $15 \mathrm{~min}$ e as lâminas foram observadas em um microscópio óptico (Nikon eclipse 80i, Japão) equipado com filtro padrão para fluoresceína e câmera fotográfica, utilizando uma objetiva para epifluorescência de 20X. A análise das imagens foi feita no programa Image J 1,4 g (Wayne Rasband, National Institutes of Health, EUA), medindo-se densidade óptica média da fluorescência observada no endotélio. A fluorescência foi avaliada em pelo menos três locais em cada imagem. 


\subsection{Apresentação dos resultados e análise estatística}

Para analisar o papel da rostafuroxina sobre a mortalidade dos animais DOCA-sal, foi feita a contagem dos animais mortos a partir da quinta semana (quando os animais foram subdivididos em grupo DOCA-sal e DOCA-sal tratado com rostafuroxina). Assim, os resultados foram expressos como porcentagem (\%) dos animais mortos em relação ao número de animais no início do tratamento com rostafuroxina. A análise estatística dos resultados foi realizada pelo método de Wilcoxon-Gehan. Os resultados foram considerados estatisticamente significantes para valores de $\mathrm{p}<0,05$.

Nos anéis vasculares dos três grupos estudados (SHAM, DOCA-sal e ROSTA) a resposta contrátil foi calculada como tensão vascular ativa (aumento da força a partir da tensão basal dividida por duas vezes o comprimento de cada segmento arterial, $\mathrm{mN} / \mathrm{mm}$ ) (Mulvany e Halpern, 1977). Os resultados das curvas concentração-resposta aos agentes vasodilatadores (acetilcolina, nitroprussiato de sódio e papaverina) foram expressos como porcentagem de contração residual em relação ao valor da pré-contração.

Para avaliar a atividade funcional da $\mathrm{Na}^{+} \mathrm{K}^{+} \mathrm{ATPase}$, os resultados foram expressos como diferença percentual da área abaixo da curva (dAUC \%). As áreas abaixo da curva (AUC) foram calculadas das curvas concentração-resposta (individuais) ao $\mathrm{KCl}$ na presença e na ausência de ouabaína adiministrada agudamente e as diferenças foram expressas como porcentagem da AUC do controle correspondente.

Os resultados de expressão proteica foram expressos como razão entre 0 sinal obtido para as proteínas analisadas pela banda correspondente de $\beta$-actina na mesma amostra.

Os resultados da fluorescência emitida pelo DHE e DAF foram expressos como porcentagem da intensidade de fluorescência observada nos cortes transversais das artérias mesentéricas de resistência.

Os resultados dos animais dos grupos SHAM, DOCA-sal e ROSTA foram expressos como média \pm EPM. A análise estatística dos resultados foi realizada por análise de variância (ANOVA), uma ou duas vias, completamente randomizada, de acordo com a necessidade. Quando a ANOVA apresentou significância estatística, o 
teste post-hoc de Bonferroni foi aplicado (GraphPad Prism Software, EUA). Os resultados foram considerados estatisticamente significantes para valores de $p<0,05$.

\subsection{Reagentes e Diluições}

Todos os sais utilizados no preparo da solução de Krebs-Henseleit e no preparo do tampão fosfato foram adquiridos da Synth (Brasil). Os demais fármacos utilizados no presente estudo: cloridrato de acetilcolina (cód. A-6625), nitroprussiato de sódio (cód. S-0501), noradrenalina (cod. A-5276), L-NAME (cód. N5751), papaverina (cód. P3510), acetato de desoxicorticosterona (cód. D7000), apocinina (cod. W508454), DAF-2 (D-225), fenilefrina (P-6126), U-46619 (D-8174), serotonina (H9523), uretana (U-2500), hexametônio (cód. 52605) foram adquiridos da SigmaAldrich (EUA). Dihidroetidina (cód. D23107) foi adquirido da Invitrogen (EUA). Pancurônio (cód. 20.1586) e halotano (cód. 03243) foram adquiridos da Cristália (Brasil). Rostafuroxina foi doada pela Sigma-Tau (Itália). Todas as drogas foram diluídas em água destilada, exceto para desoxicorticosterona (mistura 1:1 de propilenoglicol e óleo mineral); para U-46619 e apocinina diluídas em etanol e para rostafuroxina, a qual foi diluída em carboximetilcelulose $(1 \mathrm{mg} / \mathrm{mL})$. As soluçõesestoque foram mantidas a $-20 \stackrel{\circ}{\mathrm{C}}$ e as diluições utilizadas foram preparadas antes de cada lote de experimentos.

Os kits para determinação de TBARS (n. do catálogo 10009055) e medida de $\mathrm{TxB}_{2}$ (n. do catálago 10004023) foram adquiridos da Cayman (EUA) e as soluções presentes no kit foram diluídas, quando necessário, em água ultra pura. 


\section{RESULTADOS}

\subsection{Avaliação da taxa de mortalidade, dos valores de pressão arterial de cauda e do peso corporal}

No presente estudo foi avaliada a capacidade da rostafuroxina de reduzir a taxa de mortalidade dos animais DOCA-sal. A partir da quinta semana de tratamento, quando os animais foram subdivididos em dois grupos (DOCA-sal e DOCA-sal tratados com rostafuroxina) dos 52 animais submetidos à hipertensão DOCA-sal 23 não sobreviveram, resultando em uma taxa de mortalidade de $43 \%$ ao final do tratamento (Figura 4). Dos 47 animais tratados com ROSTA, 21 não sobreviveram tendo uma taxa de mortalidade de $44 \%$. Não houve morte no grupo SHAM de um total de 45 animais (Figura 4).

Figura 4 - Taxa de mortalidade de ratos controle (SHAM), submetidos à hipertensão DOCA-sal ou DOCA-sal tratados com rostafuroxina (ROSTA)

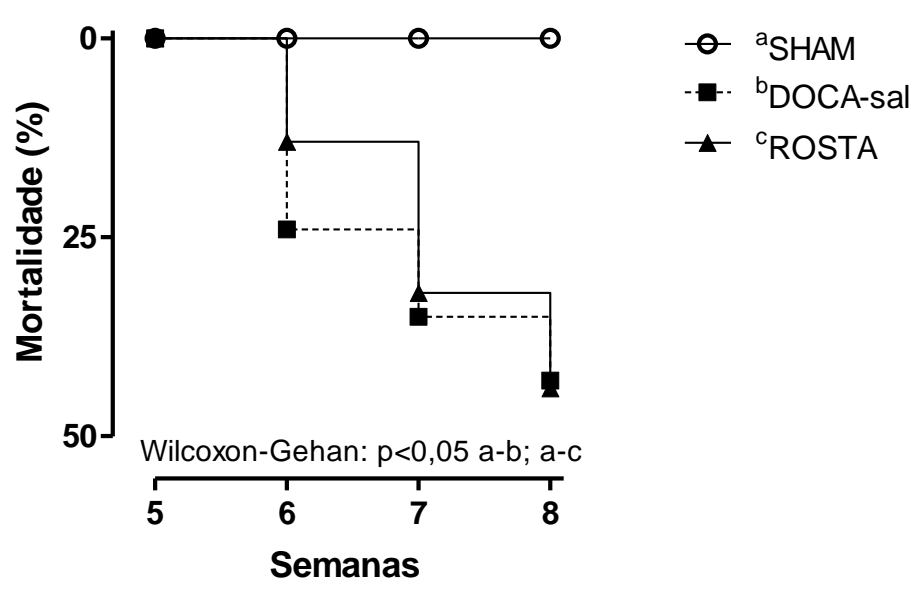

Os animais DOCA-sal e ROSTA receberam desoxicorticosterona e $\mathrm{NaCl}(1 \%)$ e $\mathrm{KCl}(0,2 \%)$ por oito semanas; o grupo ROSTA recebeu rostafuroxina $(1 \mathrm{mg} / \mathrm{kg} /$ dia) a partir da quinta semana por um período de três semanas. Os resultados estão expressos como porcentagem (\%) dos animais mortos em relação ao número de animais no início a partir da quinta semana. Wilcoxon-Gehan.

Fonte: Wenceslau (2012)

Uma semana após a cirurgia de nefrectomia não foi observada alteração na pressão arterial de todos os animais estudados, como evidenciado na semana 0 (Figura 5A). O tratamento com DOCA-sal foi efetivo em elevar a pressão arterial a partir da primeira semana de tratamento e a mesma se manteve estável a partir da 
quarta semana de tratamento (Figura 5A). Após cinco semanas de tratamento com desoxicorticosterona e solução contendo $\mathrm{NaCl}(1 \%)$ e $\mathrm{KCl}(0,2 \%)$ iniciou-se o tratamento com a rostafuroxina (1 $\mathrm{mg} / \mathrm{kg} / \mathrm{dia})$. A rostafuroxina promoveu queda significativa da pressão arterial dos animais DOCA-sal, desde a primeira semana de tratamento, a qual se manteve até o fim do tratamento (Figura 5A). Entretanto, esta queda não alcançou valores de pressão arterial similares aos observados no grupo SHAM (Figura 5A).

Ao longo do tratamento, os animais dos três grupos (SHAM, DOCA-sal e ROSTA) apresentaram aumento significativo no peso corporal (Figura 5B). Os animais do grupo DOCA-sal tiveram uma redução no peso corporal a partir da terceira semana e ao final do tratamento essa redução foi de $30 \%$ quando comparado ao grupo SHAM (Figura 5B). O tratamento com rostafuroxina restabeleceu o ganho de peso no grupo DOCA-sal tratado com rostafuroxina, embora em magnitude menor que o grupo SHAM e ao final do tratamento apresentaram ganho de 78\% quando comparado ao grupo DOCA-sal (Figura 5B). 
Figura 5 - Valores de pressão arterial sistólica $(A)$ e do peso corporal $(B)$ de ratos controle (SHAM), submetidos à hipertensão DOCA-sal ou DOCA-sal tratados com rostafuroxina (ROSTA)

A)
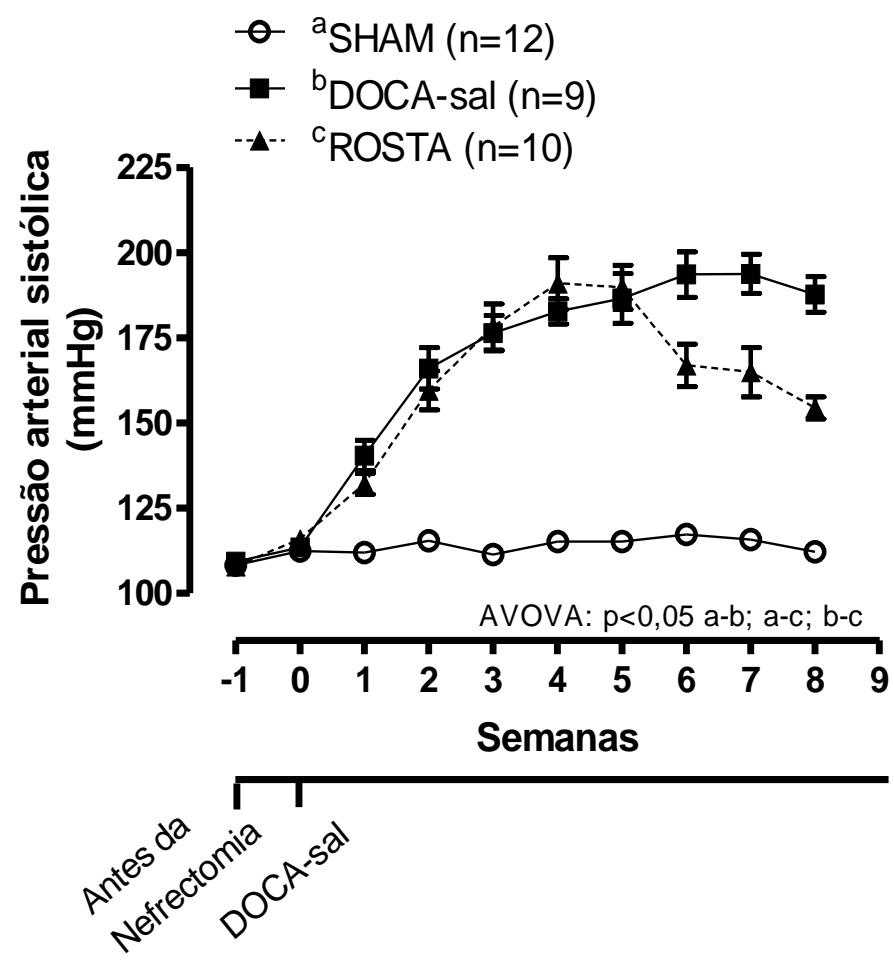

B)

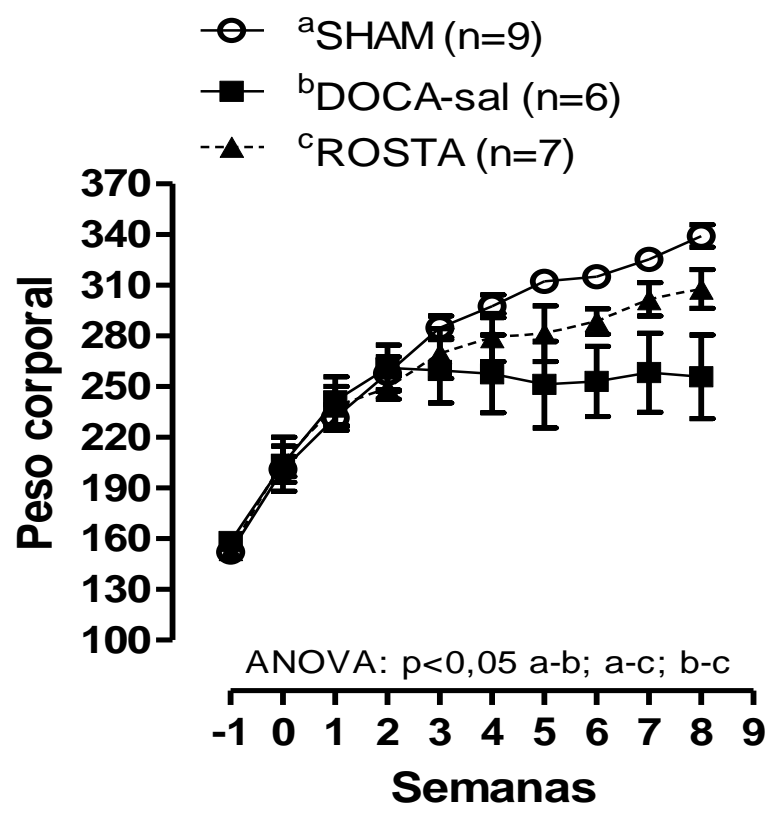

Os animais DOCA-sal e ROSTA receberam desoxicorticosterona e $\mathrm{NaCl}(1 \%)$ e $\mathrm{KCl}(0,2 \%)$ por oito semanas; o grupo ROSTA recebeu rostafuroxina $(1 \mathrm{mg} / \mathrm{kg} /$ dia) a partir da quinta semana por um período de três semanas. O número de animais está indicado em parênteses. Resultados estão expressos como média \pm EPM para o número de animais usados. ANOVA (2-vias).

Fonte: Wenceslau (2012) 


\subsection{Medida de Atividade Simpática e Sensibilidade barorreflexa}

A pressão arterial pulsátil registrada nos animais anestesiados com uretana foi maior nos grupos DOCA-sal $(145 \pm 15 \mathrm{mmHg})$ e ROSTA $(165 \pm 13 \mathrm{mmHg})$ quando comparados ao grupo SHAM $(83 \pm 16 \mathrm{mmHg})$. Este parâmetro não diferiu entre os grupos DOCA-sal e ROSTA.

A atividade simpática, medida pelo registro do número de potências de ação por segundo no nervo esplâncnico antes e após a administração de hexametônio foi maior nos animais DOCA-sal quando comparado ao grupo SHAM (Figura 6). Os animais ROSTA não diferiram do grupo SHAM (Figura 6).

A sensibilidade do barorreceptor em reduzir a atividade simpática frente ao aumento da pressão arterial, pela administração aguda de fenilefrina, não diferiu entre os grupos tratados (Figura 7). 
Figura 6 - Painel representa o registro típico da atividade simpática do nervo esplâncnico (ASNE) antes e após a administração de hexametônio (seta). O gráfico representa os níveis da ASNE basais comparados entre os ratos controle (SHAM), submetidos à hipertensão DOCA-sal ou DOCA-sal tratados com rostafuroxina (ROSTA).

SHAM

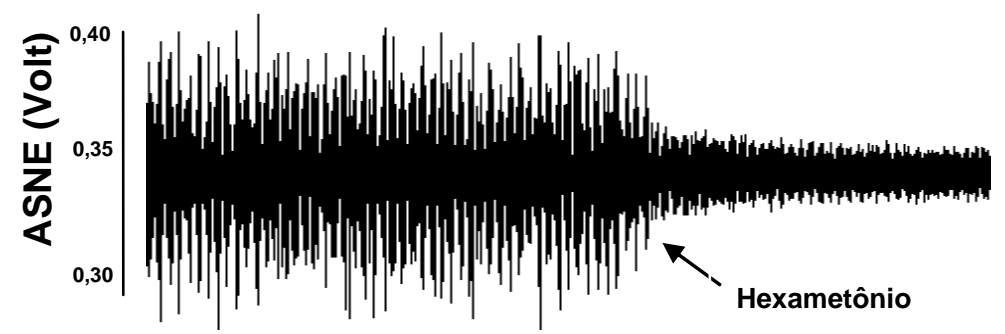

DOCA-sal

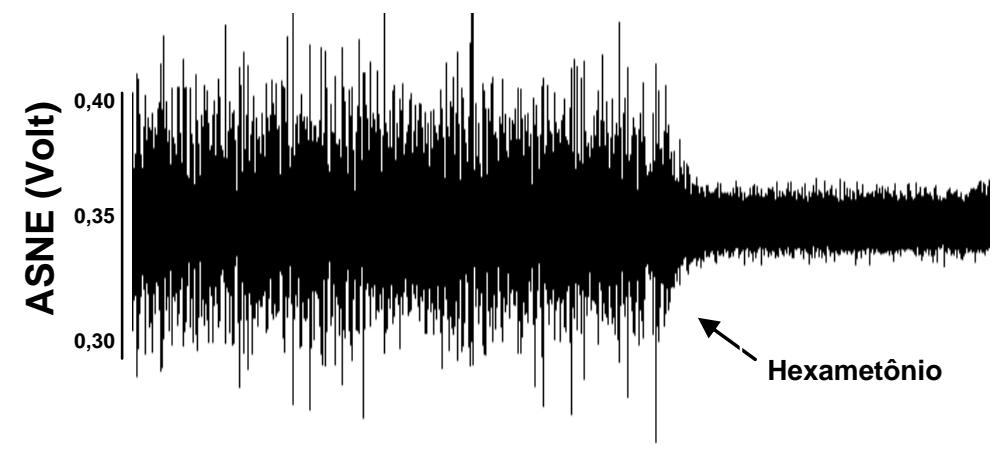

ROSTA

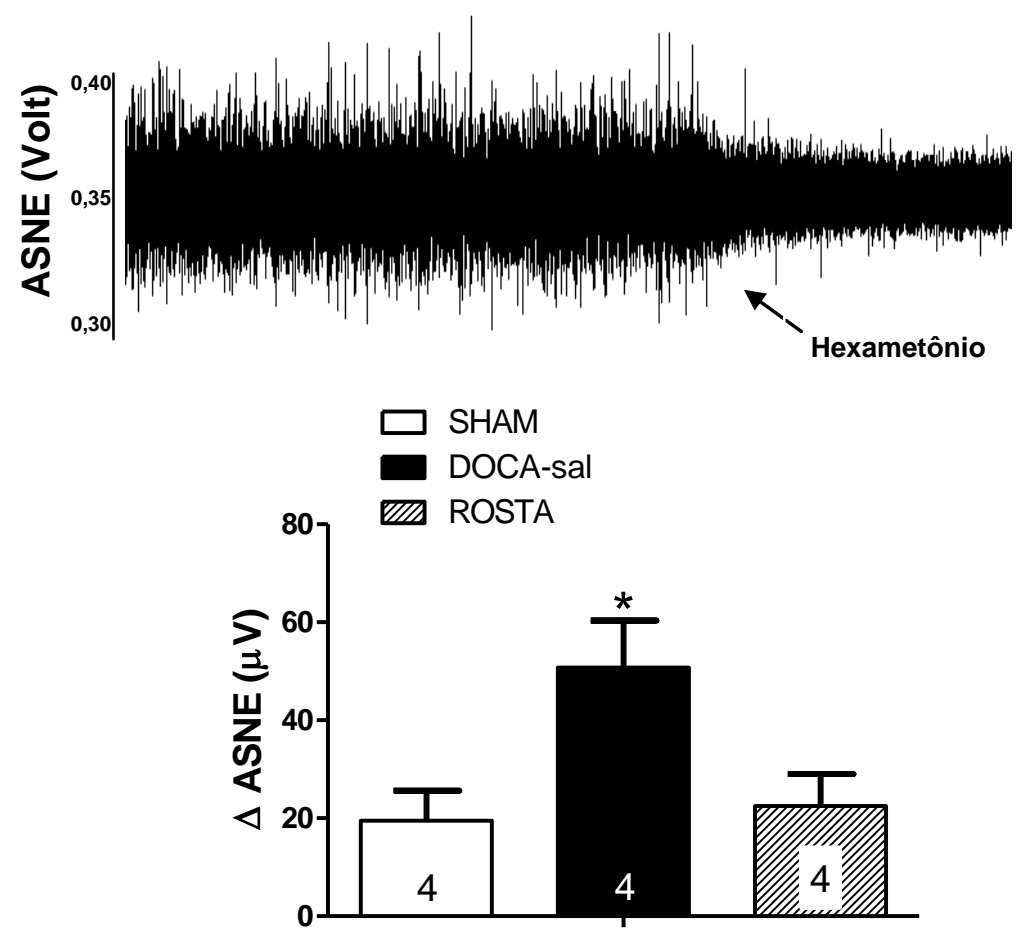

O número de animais está dentro das barras. Resultados estão expressos como média \pm EPM para o número de animais usados. ANOVA 1-via: $\mathrm{P}<0,05$ ${ }^{*}$ vs. SHAM.

Fonte: Wenceslau (2012) 
Figura 7- Painel superior representa o registro típico da atividade simpática do nervo esplâncnico (ASNE) e da pressão alterial pulsátil (PAP) antes e após a administração de fenilefrina (seta). O gráfico representa a sensibilidade do barorreflexo em ratos controle (SHAM), submetidos à hipertensão DOCA-sal ou DOCA-sal tratados com rostafuroxina (ROSTA) durante a ativação dos barorreceptores com fenilefrina.
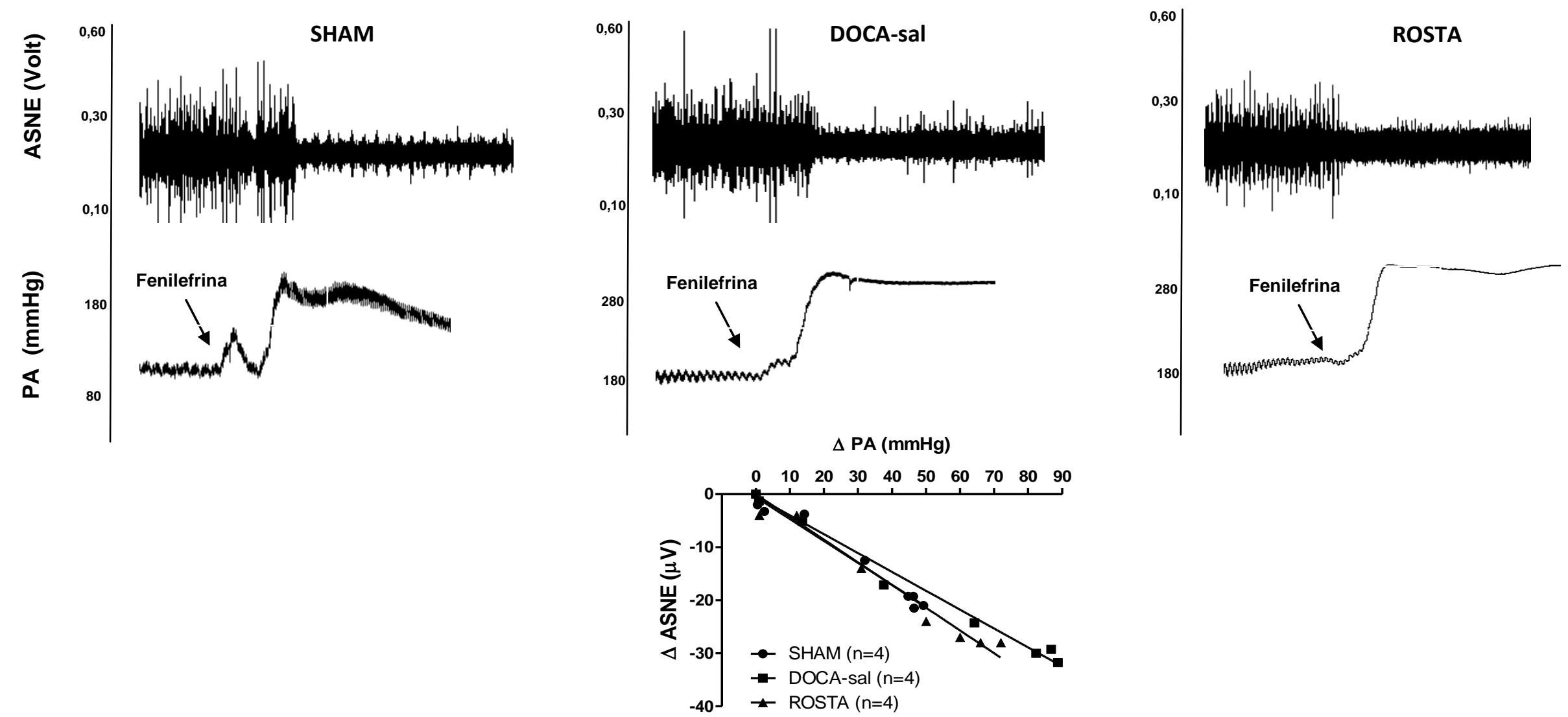

O número de animais está indicado entre parênteses. Resultados estão expressos como média \pm EPM para o número de animais usados. Regressão linear: Slopes não são significamente diferentes.

Fonte: Wenceslau (2012) 


\subsection{Quantificação de malondialdeído no plasma pela técnica TBARS}

A coloração detectada pelo espetrofotômetro resultante da reação do ácido tiobarbitúrico com o produto da peroxidação lipídica, o malondialdeído (MDA), apresentou maior intensidade no plasma do grupo DOCA-sal quando comparado ao grupo SHAM (Figura 8). O grupo ROSTA não diferiu do grupo SHAM, porém a intensidade da coloração foi significamente menor quando comparado ao grupo DOCA-sal (Figura 8).

Figura 8 - Concentração plasmática de malondialdeído (MDA) de ratos controle (SHAM), submetidos à hipertensão DOCA-sal ou DOCA-sal tratados com rostafuroxina (ROSTA)

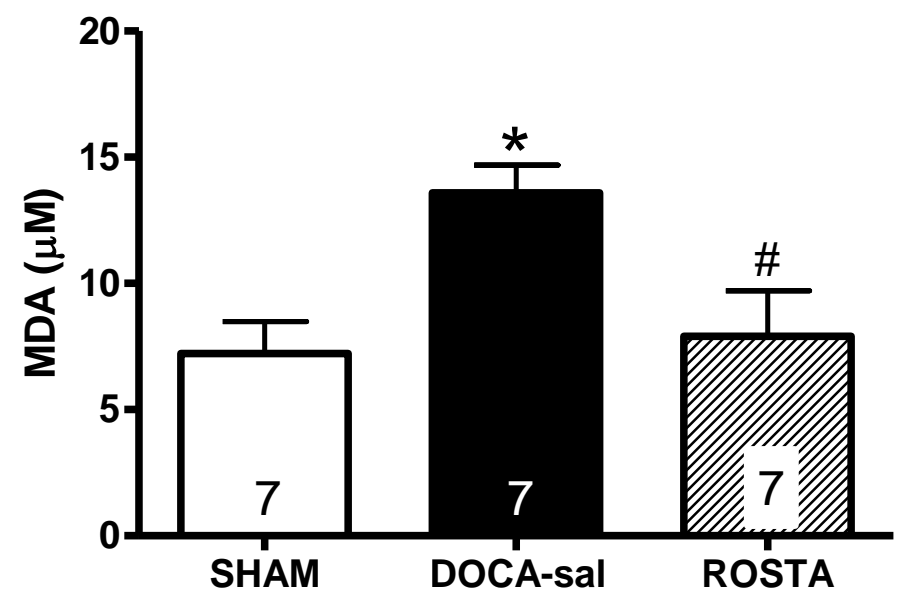

O número de animais está indicado dentro das barras. Resultados estão expressos como média \pm EPM para o número de animais usados. ANOVA (1 via): $P<0,05 *$ vs. SHAM; ${ }^{\sharp}$ vs. DOCA-sal.

Fonte: Wenceslau (2012)

\subsection{Reatividade vascular em artérias mesentéricas de resistência}

4.4.1 Diâmetro luminal e tensão vascular ativa

O diâmetro interno das artérias mesentéricas de resistência dos animais DOCA-sal foi menor quando comparado ao grupo SHAM (Tabela 2). Não houve 
diferença entre o grupo DOCA e ROSTA (Tabela 2) e entre o grupo ROSTA e SHAM.

Não foram observadas alterações significativas na tensão vascular ativa das artérias mesentéricas de resistências dos animais utilizados no presente estudo (Tabela 2).

Tabela 2 - Valores do diâmetro interno e da tensão ativa das artérias mesentéricas de resistência do grupo SHAM, DOCA-sal e DOCA-sal tratados com rostafuroxina (ROSTA)

\begin{tabular}{|c|c|c|c|}
\hline & SHAM & DOCA-sal & ROSTA \\
\hline $\begin{array}{l}\text { Diâmetro } \\
\text { interno }(\mu \mathrm{m})\end{array}$ & $256 \pm 4(n=38)$ & $230 \pm 4^{*}(n=34)$ & $243 \pm 6(n=29)$ \\
\hline $\begin{array}{l}\text { Tensão Ativa } \\
(\mathrm{mN} / \mathrm{mm})\end{array}$ & $2,7 \pm 0,1(n=30)$ & $2,3 \pm 0,1(n=30)$ & $2,4 \pm 0,1(n=26)$ \\
\hline
\end{tabular}

4.4.2 Resposta vasocontritora à noradrenalina, à serotonina e ao $\mathrm{KCl}$

A noradrenalina, a serotonina e $\circ \mathrm{KCl}$ induziram contração de maneira dependente da concentração, em segmentos de artérias mesentéricas de resistência dos animais SHAM, DOCA-sal e ROSTA (Figura 9 A, B e C).

A contração induzida pelo $\mathrm{KCl}$ foi significativamente reduzida em artérias mesentérica de resistência do grupo DOCA-sal quando comparada ao grupo SHAM (Figura 9 A, Tabela 3). Não houve diferenças nem na sensibilidade nem na resposta máxima à contração induzida pelo $\mathrm{KCl}$ entre os grupos SHAM e ROSTA (Figura $9 \mathrm{~A}$, Tabela 3).

A hipertensão DOCA-sal promoveu aumento da resposta máxima à noradrenalina e da sensibilidade à serotonina em artérias mesentéricas de resistência quando comparado ao grupo SHAM (Figura 9 B e C, Tabela 3). O tratamento com rostafuroxina por 3 semanas não foi eficiente em modificar estas respostas em relação ao grupo DOCA-sal (Figura 9 B e C, Tabela 3). 
Figura 9 - Curva concentração-resposta ao $\mathrm{KCl}(\mathrm{A})$, à noradrenalina $(\mathrm{B})$ à serotonina $(\mathrm{C})$ em anéis de artérias mesentéricas de resistência dos animais SHAM, DOCA-sal e DOCA-sal tratados com rostafuroxina (ROSTA)

A)

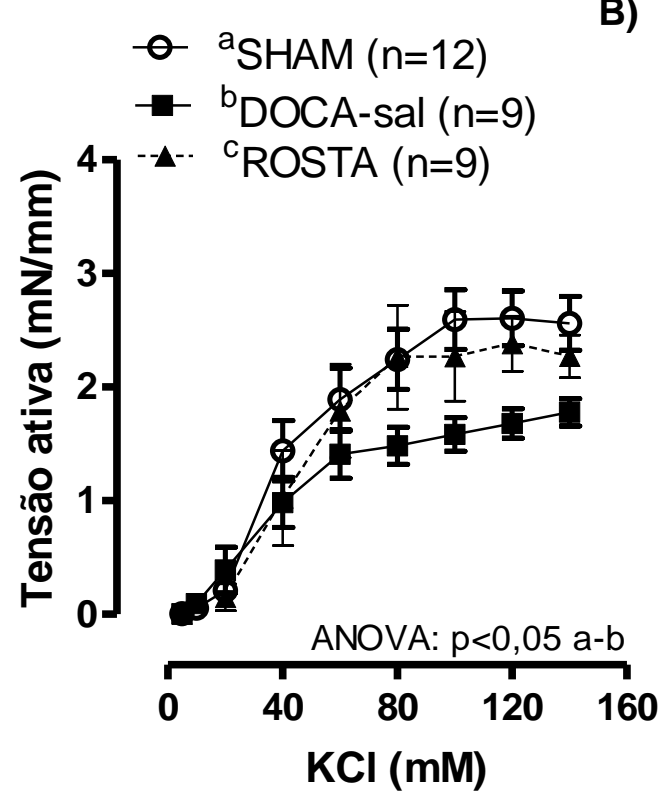

B)

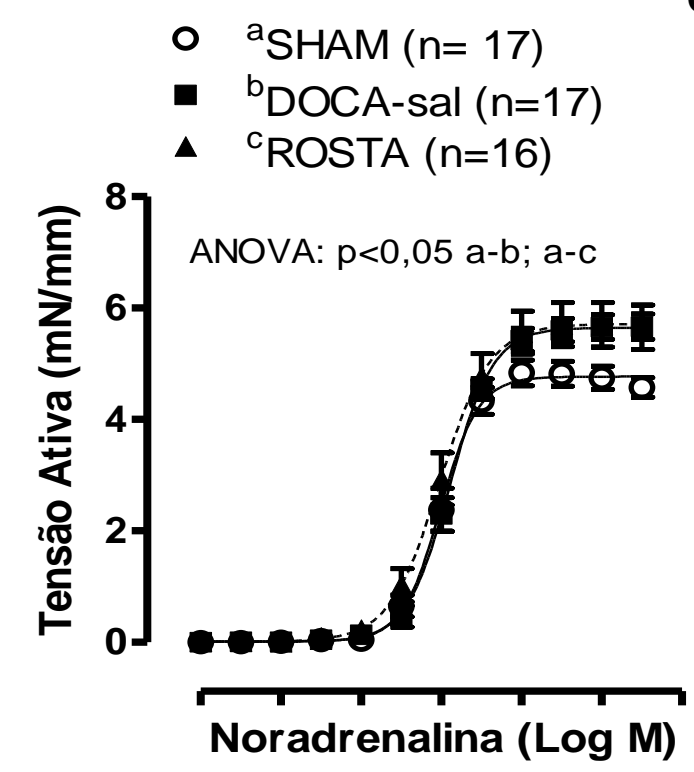

C)

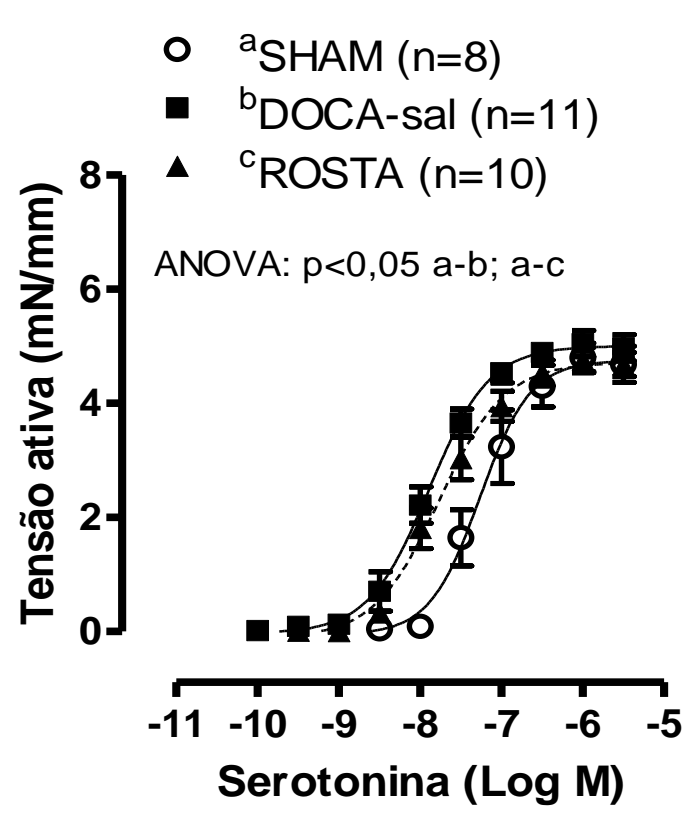

O número de animais analisados em cada grupo experimental (n) está entre parênteses. Os resultados são expressos como média \pm EPM. ANOVA (2 vias).

Fonte: Wenceslau (2012) 
Tabela 3 - Valores de sensibilidade $\left(p D_{2}\right)$ e resposta máxima $(R m a x, \mathrm{mN} / \mathrm{mm})$

\begin{tabular}{|c|c|c|c|c|c|c|}
\hline & \multicolumn{2}{|c|}{ SHAM } & \multicolumn{2}{|c|}{ DOCA-sal } & \multicolumn{2}{|c|}{ ROSTA } \\
\hline & $p D_{2}$ & $R \max$ & $p D_{2}$ & $R \max$ & $p D_{2}$ & $R \max$ \\
\hline$K C I$ & $41 \pm 5,36(12)$ & $2,56 \pm 0,21(12)$ & - & $1,77 \pm 0,11^{*}(9)$ & $50 \pm 6,64(9)$ & $2,27 \pm 0,11(9)$ \\
\hline Noradrenalina & $5,99 \pm 0,17(17)$ & $4,57 \pm 0,17$ (17) & - & $5,66 \pm 0,22 *(17)$ & - & $5,65 \pm 0,39 *(16)$ \\
\hline Serotonina & $7,23 \pm 0,15$ (8) & 4,68 $\pm 0,31(8)$ & $7,95 \pm 0,09 *(11)$ & $4,97 \pm 0,23(11)$ & $7,78 \pm 0,11^{*}(13)$ & $4,67 \pm 0,21(16)$ \\
\hline
\end{tabular}

Curvas concentração-resposta ao cloreto de potássio $(\mathrm{KCl})$, à noradrenalina e à serotonina nas artérias mesentéricas de resistência dos animais SHAM, DOCA-sal e DOCA-sal tratado com rostafuroxina (ROSTA). O número de animais utilizado em cada grupo experimental $(n)$ está entre parênteses. Os valores são expressos como média \pm EPM. ANOVA ( 1 via): * $p<0,05$ vs. SHAM.

Fonte: Wenceslau (2012) 
4.4.3 Papel do cálcio intracelular e extracelular na resposta vasoconstritora à noradrenalina

Como esperado, a noradrenalina $(10 \mu \mathrm{M})$ promoveu contração fásica de pequena magnitude em anéis de artérias mesentéricas de resistência do grupo SHAM em solução livre de cálcio contendo EGTA (1mM). Essa pequena contração refletiu a liberação de cálcio dos estoques intracelulares (EI) (Figura 10). Entretanto, a liberação de cálcio dos EI nos anéis vasculares do grupo DOCA-sal e ROSTA, promoveu maior contração vascular em relação ao grupo SHAM (Figura 10).

$A$ adição de $\mathrm{CaCl}_{2}(2,5 \mathrm{mM})$ nas preparações previamente incubadas com solução livre de cálcio contendo EGTA $(1 \mathrm{mM})$ e na presença da noradrenalina (10 $\mu \mathrm{M}$ ), para avaliar o influxo de cálcio (IF) nas células musculares lisas das artérias analisadas, aumentou a tensão ativa dos três grupos em questão: SHAM, DOCA-sal e ROSTA (Figura 10). A contração pelo IF foi maior nos anéis vasculares do grupo DOCA-sal em relação ao grupo SHAM e ao grupo ROSTA (Figura 10). Não houve diferenças para o IF entre o grupo SHAM e ROSTA (Figura 10).

Figura 10 - Tensão ativa à noradrenalina na ausência ou presença de $\mathrm{Ca}^{2+}$

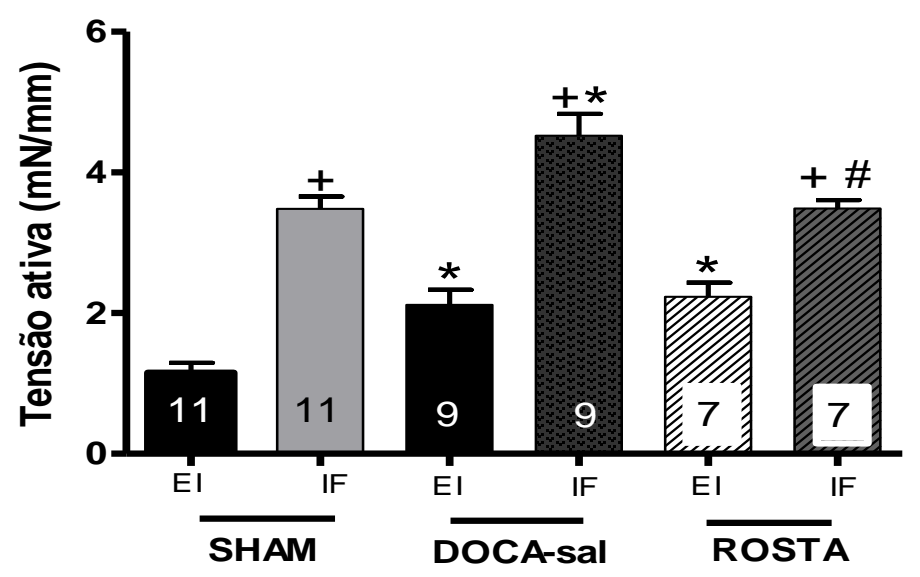

Tensão ativa das artérias mesentéricas de resistência do grupo SHAM, DOCAsal e DOCA-sal tratado com rostafuroxina (ROSTA) após a adição de noradrenalina $(10 \mu \mathrm{M})$ incubadas previamente em solução livre de cálcio para avaliar a liberação dos estoques intracelulares (EI) e após a adição de $\mathrm{CaCl}_{2}(2,5$ $\mathrm{mM}$ ) (IF, influxo). Os resultados são expressos como média \pm EPM. O número de animais analisados em cada grupo experimental (n) está no interior das barras. ANOVA (2 vias): $p<0,05^{+} v s$. Ausência de cálcio (EI); *vs. SHAM; " $v s$. DOCA-sal.

Fonte: Wenceslau (2012) 
4.4.4 Avaliação da resposta aos agentes vasodilatadores

4.4.4.1 Resposta de relaxamento independente do endotélio

O nitroprussiato de sódio e a papaverina promoveram relaxamento dependente da concentração utilizada nos segmentos de artérias mesentéricas de resistência pré-contraídas com U-46619 $(1 \mu \mathrm{M})$ dos animais estudados (Figura 11 A e B). Não foram observadas diferenças significativas nem na sensibilidade e nem na resposta máxima do relaxamento induzido pelo nitroprussiato de sódio ou pela papaverina entre as artérias dos animais SHAM, DOCA-sal e ROSTA (Figura $11 \mathrm{~A} \mathrm{e}$ B, Tabela 4). 
Figura 11 - Curva concentração-resposta a papaveriana (A) e ao nitroprussiato de sódio (NPS, B) em anéis de artérias mesentéricas de resistência précontraídos com U-46619 $(1 \mu \mathrm{M})$ dos animais SHAM, DOCA-sal e ROSTA

A

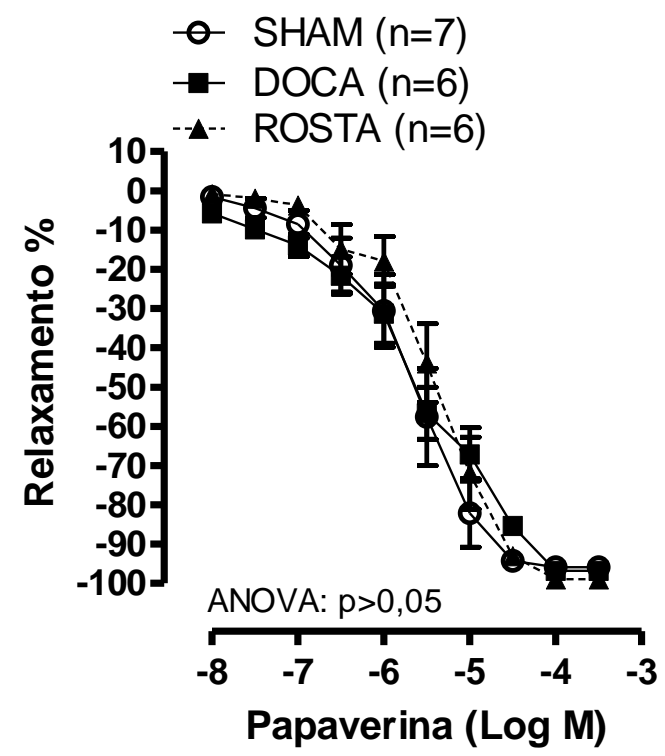

B

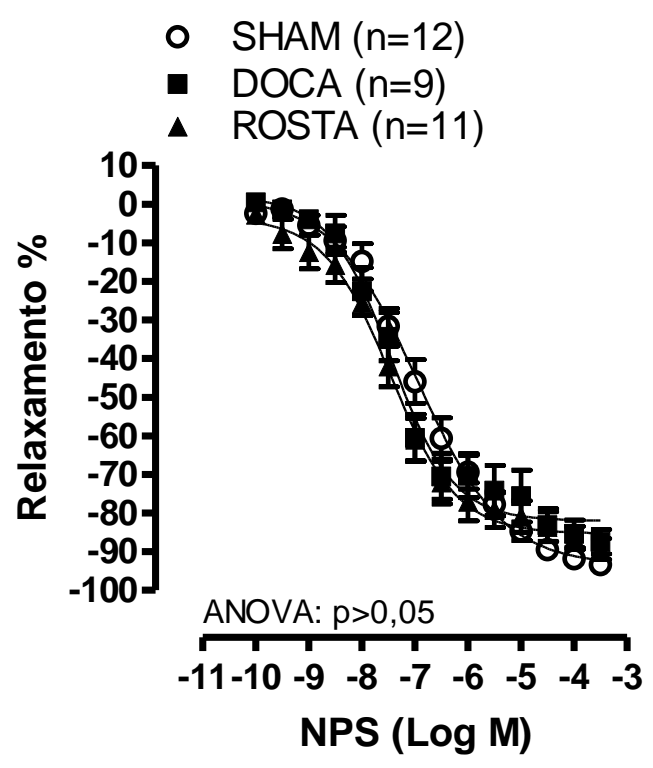

Os resultados são expressos como média \pm EPM. O número de animais analisados em cada grupo experimental ( $n$ ) está entre parênteses. ANOVA (2 vias): $p>0,05$

Fonte: Wenceslau (2012) 
Tabela 4 - Valores de sensibilidade $\left(\mathrm{pD}_{2}\right)$ e resposta máxima $(\mathrm{Rmax})$

\begin{tabular}{lcccccc}
\hline & \multicolumn{2}{c}{ SHAM } & \multicolumn{2}{c}{ DOCA-sal } & \multicolumn{2}{c}{ ROSTA } \\
\hline & \multicolumn{1}{c}{$\boldsymbol{p \boldsymbol { D } _ { 2 }}$} & $\boldsymbol{R m a x}$ & $\boldsymbol{p \boldsymbol { D } _ { 2 }}$ & $\boldsymbol{R m a x}$ & $\boldsymbol{p \boldsymbol { D } _ { 2 }}$ & $\boldsymbol{R}$ max \\
\cline { 2 - 7 } & & & & & & \\
Papaverina & $5,70 \pm 0,20(7)$ & $95 \pm 12(7)$ & $5,52 \pm 0,14(6)$ & $96 \pm 15(6)$ & $5,39 \pm 0,16(6)$ & $98 \pm 14(6)$ \\
NPS & $6,98 \pm 0,19(12)$ & $86 \pm 61(12)$ & $7,43 \pm 0,17(9)$ & $87 \pm 37(9)$ & $7,48 \pm 0,33(11)$ & $89 \pm 25(11)$ \\
\hline
\end{tabular}

Curva concentração-resposta a papaverina e ao nitroprussiato de sódio (NPS) nas artérias mesentéricas de resistência dos animais SHAM, DOCA-sal e DOCA-sal tratados com rostafuroxina (ROSTA). O número de animais utilizado em cada grupo experimental $(n)$ está entre parênteses. Os valores são expressos como média \pm EPM. ANOVA (1 via): $p>0,05$.

Fonte: Wenceslau (2012) 


\subsubsection{Resposta de relaxamento dependente do endotélio}

Em anéis de artérias mesentéricas de resistência dos três grupos em questão, previamente contraídos com U-46619 $(1 \mu \mathrm{M})$, com noradrenalina $(10 \mu \mathrm{M})$ ou com serotonina $(10 \mu \mathrm{M})$, a acetilcolina foi eficaz em induzir relaxamento na dependência da concentração utilizada (Figura 12 A, B e C, Tabela 5). Nos anéis vasculares das artérias mesentéricas de resistência pré-contraídas com U-46619 foram observadas diferenças significativas entre as curvas concentração-resposta à acetilcolina do grupo SHAM, DOCA-sal e ROSTA (Figura 12 A., Tabela 5). Neste sentido, foi observado que os anéis de artérias mesentéricas de resistência do grupo DOCA-sal apresentaram redução significativa na resposta máxima comparado ao grupo SHAM e ao grupo ROSTA. A resposta vasodilatadora à acetilcolina do grupo ROSTA não diferiu do grupo SHAM (Figura 12 A, Tabela 5).

Nos segmentos de artérias mesentéricas de resistência pré-contraídos com noradrenalina ou serotonina, observou-se significativa redução do relaxamento à acetilcolina do grupo DOCA-sal comparado ao grupo SHAM (Figura 12 B e C, Tabela 5). O grupo ROSTA também apresentou redução de relaxamento induzido pela acetilcolina comparado ao grupo SHAM. Entretanto, essa foi de menor magnitude quando comparado ao grupo DOCA-sal (Figura 12 B e C, Tabela 5). 
Figura 12 - Curvas concentração-resposta à acetilcolina em anéis de artérias mesentéricas de resistência dos animais SHAM, DOCA-sal e DOCA-sal tratados com rostafuroxina (ROSTA)

A)

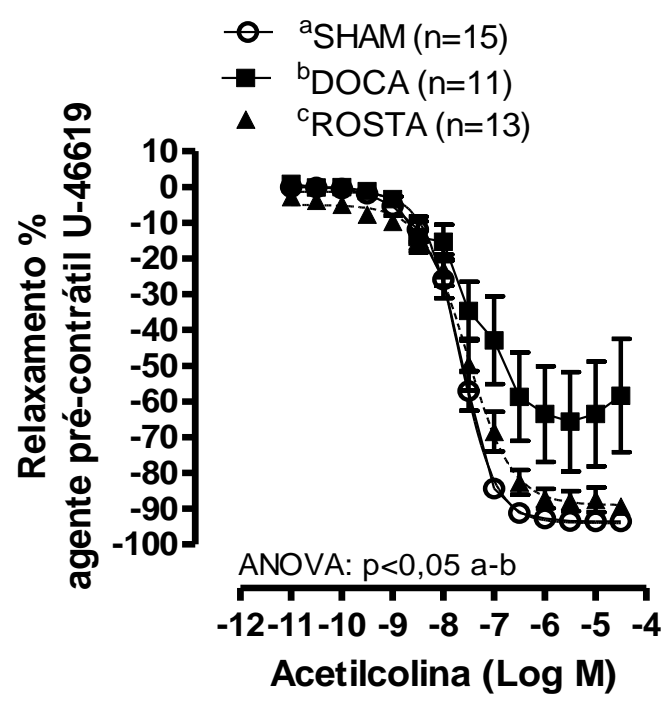

B)

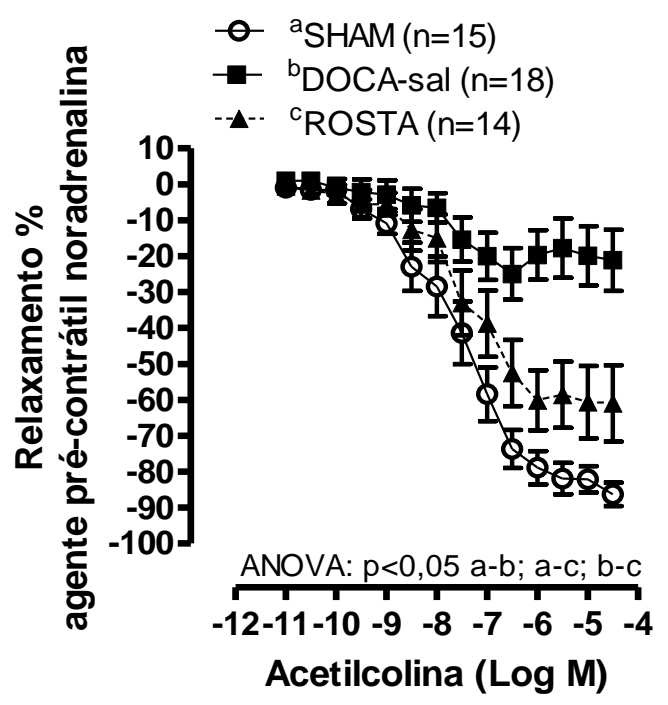

C)

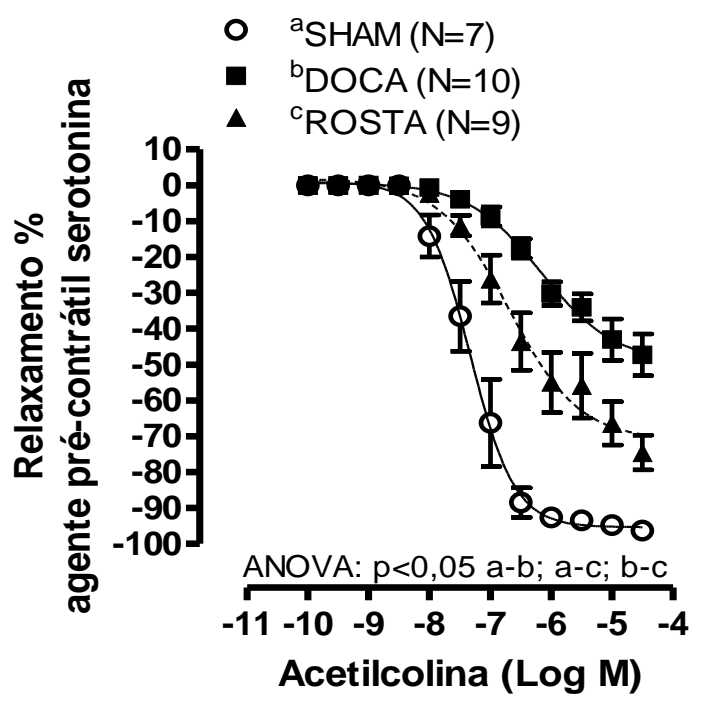

As artérias foram pré-contraídas com o mimético do tromboxano $A_{2}$, U-46619 (A), com noradrenalina (B) ou com serotonina (C) Os resultados são expressos como média \pm EPM. O número de animais analisados em cada grupo experimental $(n)$ está entre parênteses. ANOVA (2 vias).

Fonte: Wenceslau (2012) 
Tabela 5 - Valores de sensibilidade $\left(\mathrm{pD}_{2}\right)$ e resposta máxima (Rmax) obtidos por meio de curvas concentração-resposta à acetilcolina nas artérias mesentéricas de resistência.

\begin{tabular}{|c|c|c|c|c|c|c|}
\hline \multirow[b]{3}{*}{$\begin{array}{l}\text { Fator } \\
\text { pré-contrátil }\end{array}$} & \multicolumn{5}{|c|}{ Relaxamento à Acetilcolina } & \\
\hline & $\mathrm{SH}$ & AM & & CA-sal & \multicolumn{2}{|c|}{ ROSTA } \\
\hline & $p D_{2}$ & $R \max (\%)$ & $p D_{2}$ & $R \max (\%)$ & $p D_{2}$ & $\operatorname{Rmax}(\%)$ \\
\hline U-46619 & $7,71 \pm 0,08(15)$ & $93 \pm 0,98(15)$ & - & $58 \pm 15,85^{*}(11)$ & - & $89 \pm 2,31^{\#}(13)$ \\
\hline Noradrenalina & $7,30 \pm 0,21(15)$ & $86 \pm 3,23$ (15) & - & $21 \pm 8,48^{*}(18)$ & - & $60 \pm 10,66^{\#}(14)$ \\
\hline Serotonina & $7,44 \pm 0,10(7)$ & $96 \pm 3,01(7)$ & - & $47 \pm 5,30 *(10)$ & - & $74 \pm 4,11^{\star \#}(9)$ \\
\hline
\end{tabular}

As artérias foram pré-contraídas com o mimético do tromboxano $A_{2}$ (U-46619), com noradrenalina ou com serotonina dos animais SHAM, DOCA-sal e DOCA-sal tratados com rostafuroxina (ROSTA). O número de animais utilizado em cada grupo experimental $(n)$ está entre parênteses. Os valores são expressos como média \pm EPM. ANOVA (1 via): $p<0,05{ }^{*} v s$. SHAM; ${ }^{\#} v s$. DOCA-sal.

Fonte: Wenceslau (2012) 
4.4.4.3 Efeito do bloqueio da síntese de óxido nítrico e das espécies reativas derivadas do oxigênio sobre a resposta vasodilatadora à acetilcolina

A incubação com L-NAME $(100 \mu \mathrm{M})$ reduziu de maneira significativa o relaxamento à acetilcolina em anéis de artérias mesentéricas de resistência do grupo SHAM (Figura $13 \mathrm{~A}$, Tabela 6), porém, não teve efeito sobre a resposta vasodilatadora à acetilcolina nos anéis do grupo DOCA-sal (Figura 13 B, Tabela 6). De maneira similar ao grupo SHAM, a adiministração de L-NAME reduziu o relaxamento à acetilcolina dos anéis vasculares do grupo ROSTA (Figura $13 \mathrm{C}$, Tabela 6). 
Figura 13 - Curvas concentração-resposta à acetilcolina

A)

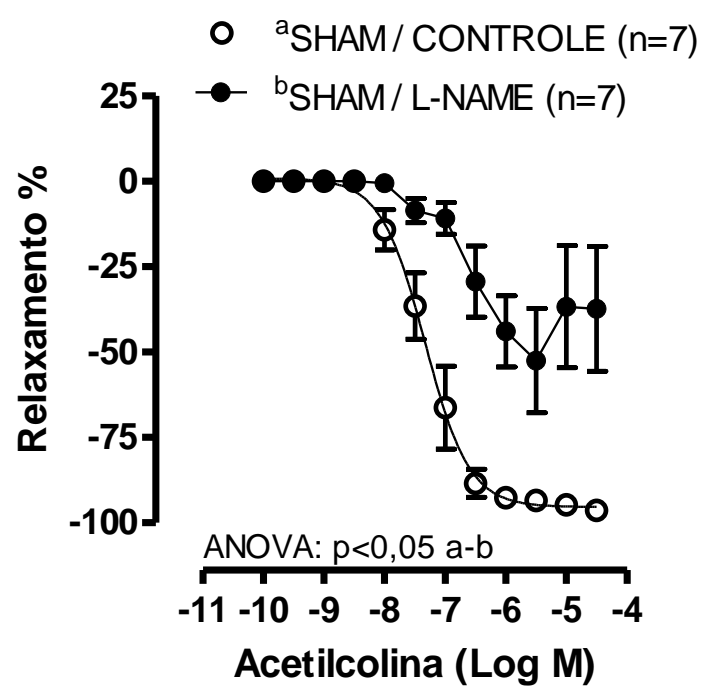

B)

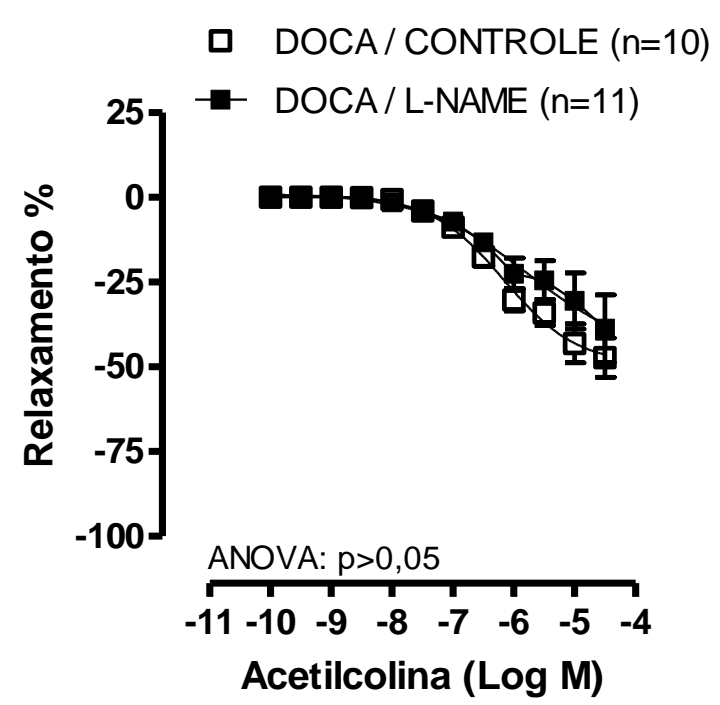

C)

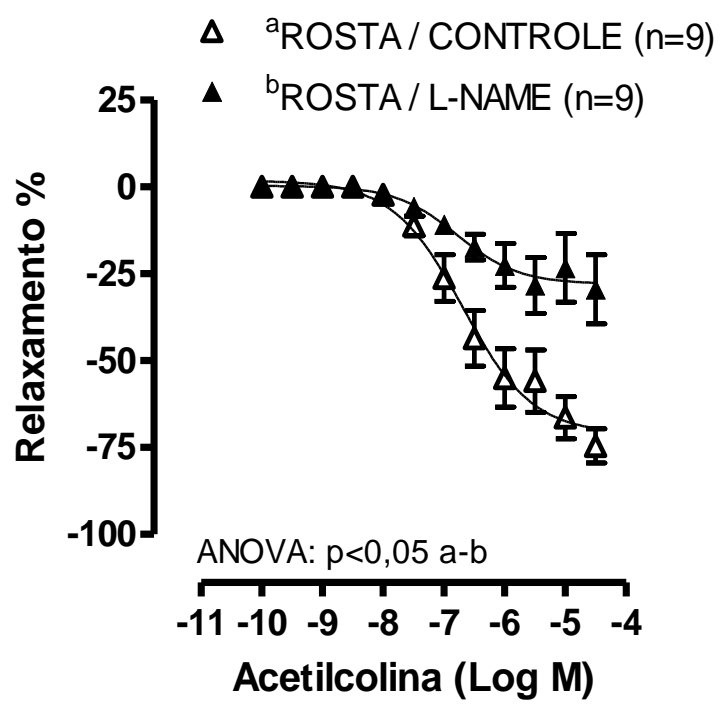

Presença (símbolo cheio) ou ausência (símbolo vazio) do inibidor inespecífico da NOS (L-NAME, 100 $\mu$ M) em anéis de artérias mesentéricas de resistência dos animais SHAM (A), DOCA-sal (B) e DOCA-sal tratados com rostafuroxina (ROSTA) (C) précontraídos com serotonina $(10 \mu \mathrm{M})$ Os resultados são expressos como média \pm EPM. O número de animais analisados em cada grupo experimental (n) está entre parênteses. ANOVA (2 vias).

Fonte: Wenceslau (2012) 
A incubação com tiron $(1 \mathrm{mM})$ não não alterou a resposta vasodilatadora à acetilcolina em segmentos arteriais do grupo SHAM e grupo ROSTA (Figura $14 \mathrm{~A} \mathrm{e}$ C, Tabela 6). Entretanto, aumentou esta resposta nas artérias do grupo DOCA-sal (Figura $14 \mathrm{~B}$, Tabela 6), fazendo com que a mesma alcançasse o mesmo nível de vasodilatação observada nas artérias dos animais ROSTA (Tabela 6).

A incubação com catalase (1000 U/ mL) não alterou a resposta vasodilatadora à acetilcolina das artérias dos grupos SHAM, DOCA-sal e ROSTA (Figura 14 D, E e F, Tabela 6). 
Figura 14 - Curvas concentração-resposta à acetilcolina

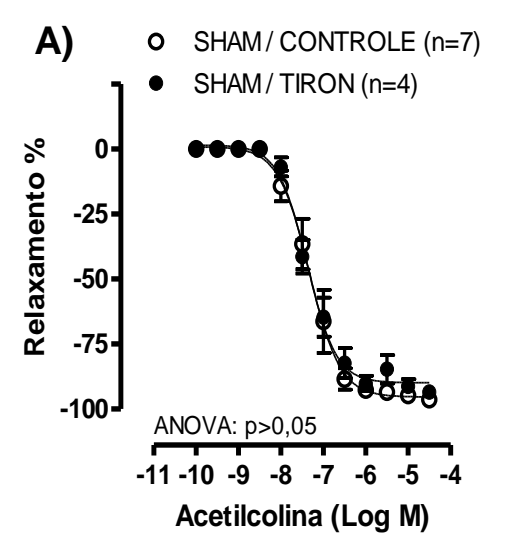

D)

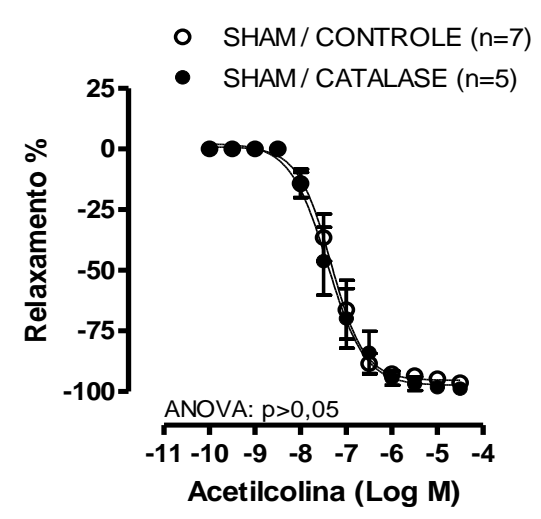

B)

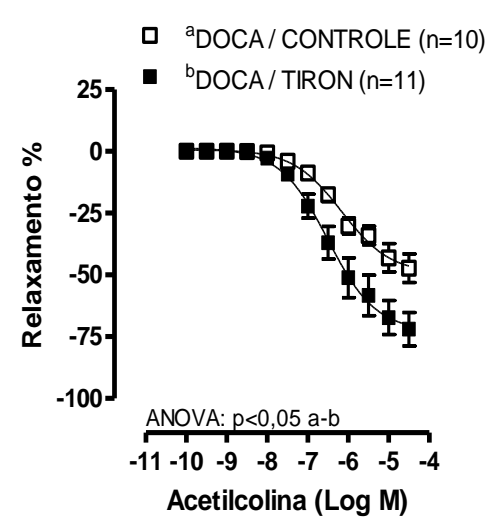

E)

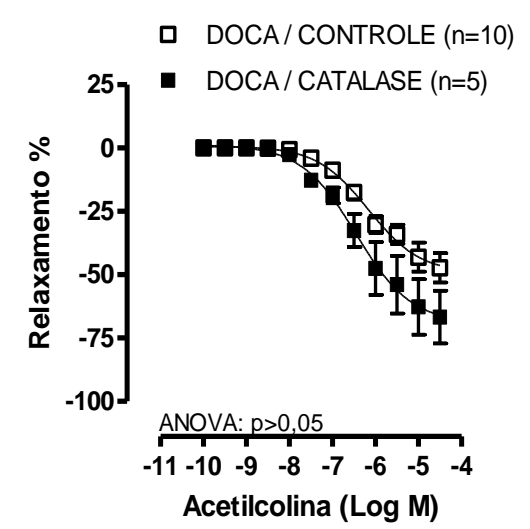

C) ROSTA/ CONTROLE $(\mathrm{n}=9)$ ROSTA / TIRON ( $n=10)$

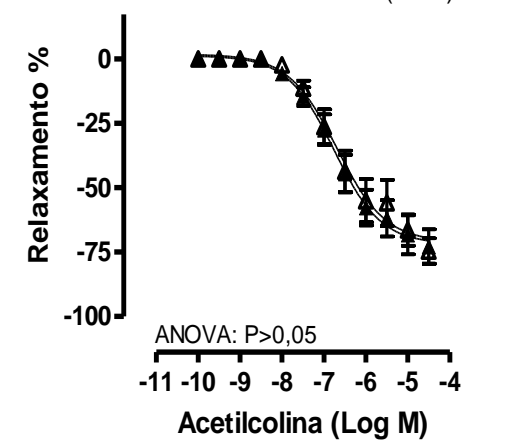

F)

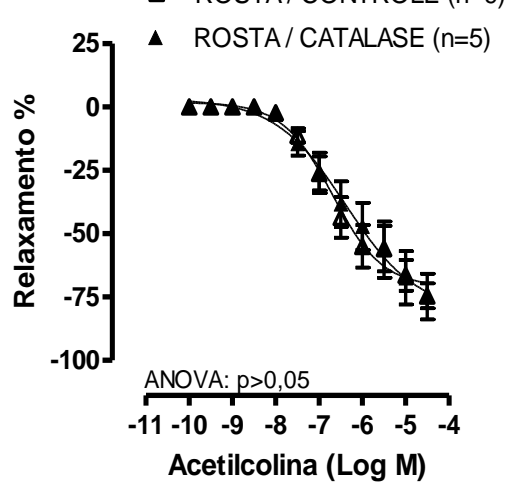

Presença (símbolo cheio) ou na ausência (símbolo vazio) do inibidor do ânion superóxido (TIRON, $1 \mathrm{mM}$, gráficos superiores) ou do inibidor do peróxido de hidrogênio (CATALASE, $1000 \mathrm{U} / \mathrm{mL}$, gráficos inferiores) em anéis de artérias mesentéricas de resistência dos animais SHAM (A e D), DOCA-sal (B e E) e DOCA-sal tratados com rostafuroxina (ROSTA) (C e F) pré-contraídos com serotonina. Os resultados são expressos como média \pm EPM. O número de animais analisados em cada grupo experimental ( $\mathrm{n}$ ) está entre parênteses. ANOVA (2 vias).

Fonte: Wenceslau (2012) 
4.4.4.4 Efeito do bloqueio da NADPH oxidase e da ciclooxigenase-2 (COX-2) sobre a resposta vasodilatadora à acetilcolina

A incubação com apocinina $(1 \mu \mathrm{M})$ não alterou a resposta de relaxamento à acetilcolina em artérias mesentérica de resistência do grupo SHAM e do grupo ROSTA (Figura 15 A e C, Tabela 6). Já em artérias do grupo DOCA-sal observou-se aumento da resposta máxima a este agente vasodilatador (Figura 15 B, Tabela 6).

De maneira similar, a administração de NS-398 (1 $\mu \mathrm{M})$ não alterou a resposta de relaxamento à acetilcolina em segmentos arteriais do grupo SHAM e do grupo ROSTA (Figura 16 A e C, Tabela 6), mas em artérias do grupo DOCA-sal observouse aumento da resposta máxima à acetilcolina (Figura $16 \mathrm{~B}$, Tabela 6). Tanto a incubação dos anéis vasculares com apocinina ou com NS-398 fez com que a vasodilatação induzida pela acetilcolina alcançasse os níveis observados nos anéis vasculares do grupo ROSTA (Tabela 6). 
Figura 15 - Curvas concentração-resposta à acetilcolina

A)

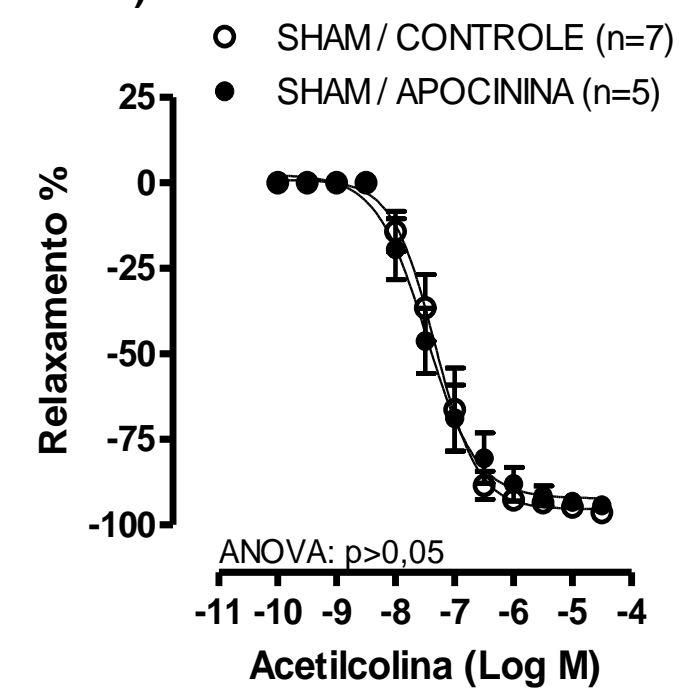

B)

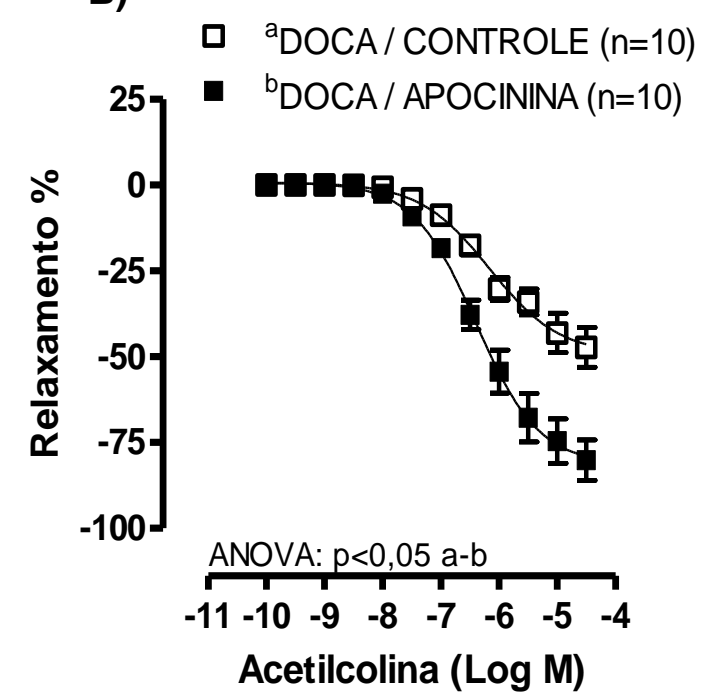

C)

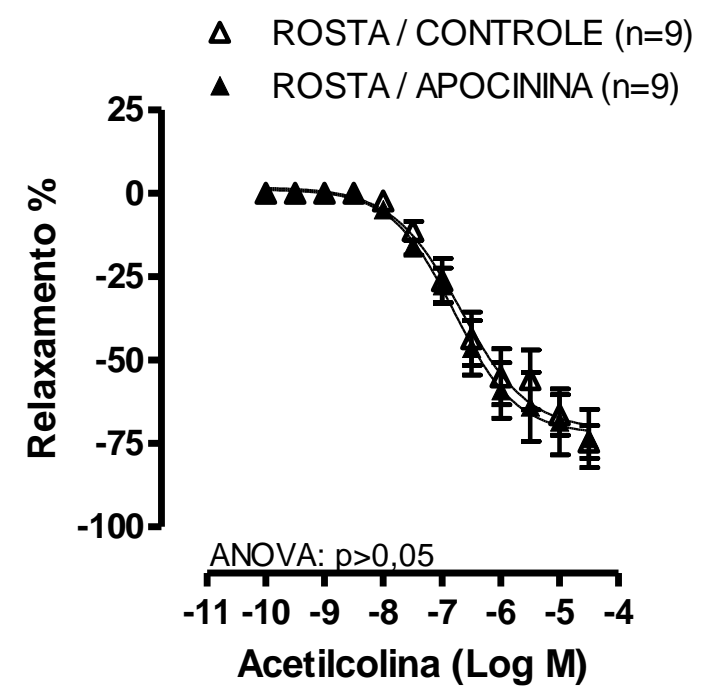

Presença (símbolo cheio) ou ausência (símbolo vazio) do inibidor da NAD(P)H oxidase (apocinina, $10 \mu \mathrm{M}$ ) em anéis de artérias mesentéricas de resistência dos animais SHAM (A), DOCA-sal (B) e DOCA-sal tratados com rostafuroxina (ROSTA) (C). As artérias foram pré-contraídas com serotonina $(10 \mu \mathrm{M})$. Os resultados são expressos como média \pm EPM. $O$ número de animais analisados em cada grupo experimental (n) está entre parênteses. ANOVA (2 vias).

Fonte: Wenceslau (2012) 
Figura 16 - Curvas concentração-resposta à acetilcolina

A)

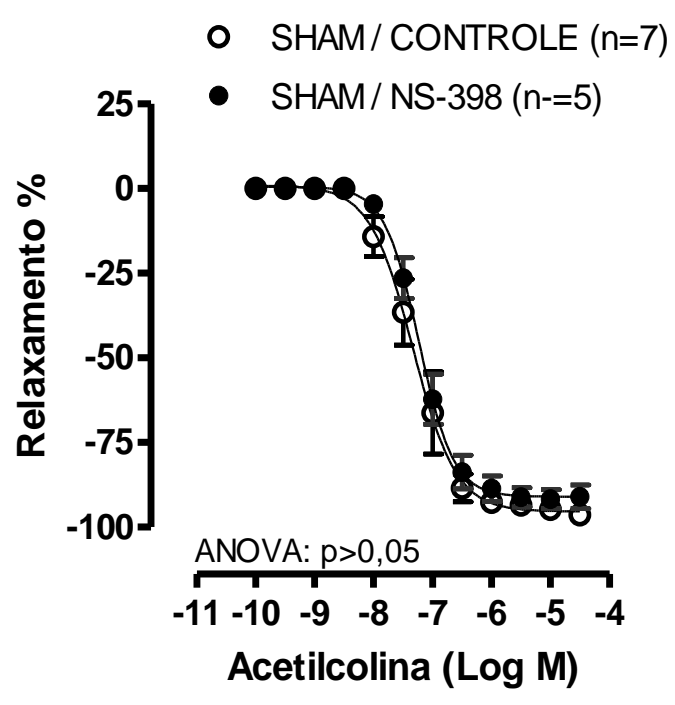

B)

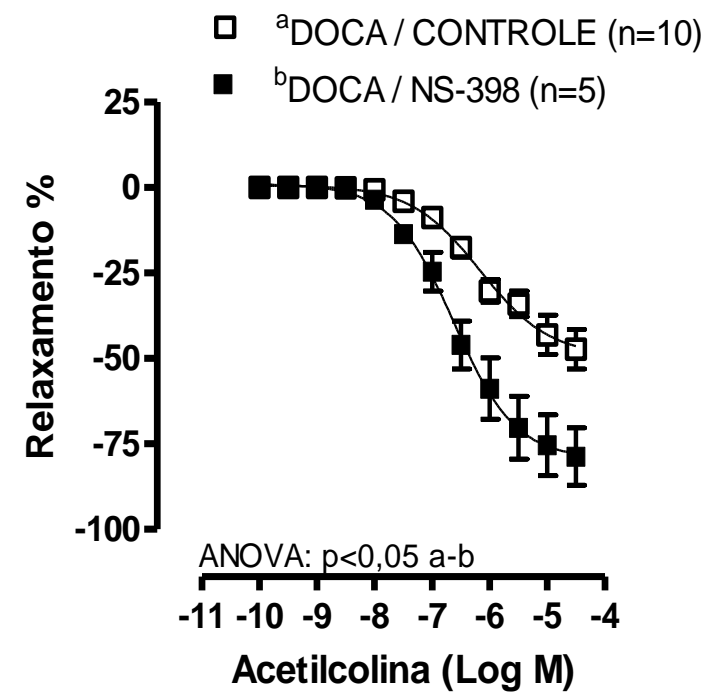

C)

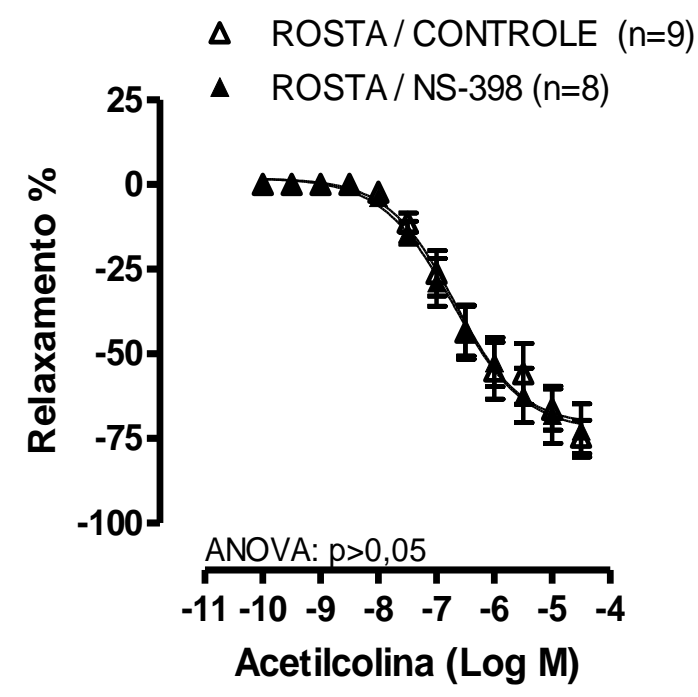

Presença (símbolo cheio) ou a ausência (símbolo vazio) do inibidor da cliclooxigenase-2 (COX-2, NS-398, $1 \mu \mathrm{M}$ ) em anéis de artérias mesentéricas de resistência dos animais SHAM (A), DOCA-sal (B) e DOCA-sal tratados com rostafuroxina (ROSTA) (C) pré-contraídos com serotonina $(10 \mu \mathrm{M})$. Os resultados são expressos como média \pm EPM. O número de animais analisados em cada grupo experimental (n) está entre parênteses. ANOVA (2 vias).

Fonte: Wenceslau (2012) 
Tabela 6 - Valores de sensibilidade $\left(\mathrm{pD}_{2}\right)$ e resposta máxima (Rmax)

\begin{tabular}{|c|c|c|c|c|c|c|}
\hline \multicolumn{7}{|c|}{ Relaxamento à Acetilcolina } \\
\hline & \multicolumn{2}{|c|}{ SHAM } & \multicolumn{2}{|c|}{ DOCA-sal } & \multicolumn{2}{|c|}{ ROSTA } \\
\hline & $p D_{2}$ & $\operatorname{Rmax}(\%)$ & $p D_{2}$ & $\operatorname{Rmax}(\%)$ & $p D_{2}$ & $\operatorname{Rmax}(\%)$ \\
\hline CONTROLE & $7,44 \pm 0,10(7)$ & $96 \pm 3,11(7)$ & - & $47 \pm 5,01^{*}(10)$ & - & $74 \pm 4,02^{\star \#}(9)$ \\
\hline L-NAME & - & $37 \pm 1,40^{+}(7)$ & - & $38 \pm 9,21(11)$ & - & $29 \pm 4,12^{+}(9)$ \\
\hline TIRON & $7,42 \pm 0,06(7)$ & $93 \pm 4,32(7)$ & - & $71 \pm 6,03^{+}(14)$ & - & $72 \pm 6,42(10)$ \\
\hline CATALASE & $7,37 \pm 0,27(5)$ & $98 \pm 2,01$ (5) & - & $66 \pm 1,02(9)$ & - & $74 \pm 9,04$ (8) \\
\hline APOCININA & $7,50 \pm 0,15(8)$ & $94 \pm 1,61(8)$ & - & $80 \pm 5,03^{+}(10)$ & - & $73 \pm 8,10(9)$ \\
\hline NS-398 & $7,23 \pm 0,09(7)$ & $91 \pm 3,84(7)$ & - & $78 \pm 8,21^{+}(11)$ & - & $72 \pm 7,81$ (8) \\
\hline
\end{tabular}

Curva concentração-resposta à acetilcolina na ausência ou na presença dos inibidores da sintase de óxido nítrico, (L-NAME, 100 $\mu \mathrm{M}$ ); do ânion superóxido (TIRON, $1 \mathrm{mM}$ ); do peróxido de hidrogênio (catalase, $1000 \mathrm{U} / \mathrm{mL}$ ), da NAD(P)H oxidade (APOCININA $10 \mu \mathrm{M}$ ) e da ciclooxigenase-2 (NS-398, $1 \mu \mathrm{M}$ ) em artérias mesentéricas de resistência dos animais SHAM, DOCA-sal e DOCA-sal tratados com rostafuroxina (ROSTA). O número de animais utilizado em cada grupo experimental (n) está entre parênteses. Os valores são expressos como média \pm EPM. ANOVA (1via): $p<0,05{ }^{*} v s$. SHAM; \# $v s$. DOCA; ${ }^{+} v s$. ausência do inibidor (situação CONTROLE).

Fonte: Wenceslau (2012) 
4.4.5 Avaliação da atividade funcional da $\mathrm{Na}^{+} \mathrm{K}^{+}$-ATPase sensível à ouabaína

Como é possível observar na figura $17 \mathrm{~A}, \mathrm{~B}$ e $\mathrm{C}$, o potássio administrado às preparações que foram incubadas com solução de Krebs livre de potássio, na ausência da ouabaína $(100 \mu \mathrm{M})$, foi capaz de reduzir a contração induzida pela noradrenalina nos segmentos arteriais dos três grupos avaliados (Figura $17 \mathrm{~A}, \mathrm{~B}$ e C). A incubação aguda dos anéis vasculares com ouabaína $(100 \mu \mathrm{M})$ aboliu o relaxamento induzido pelo potássio nos segmentos de artérias mesentéricas de resistência do grupo SHAM, DOCA-sal e ROSTA. Porém, como observado no gráfico que expressa a diferença percentual da área abaixo da curva (dAUC \%) a atividade funcional sensível a ouabaína foi menor quando comparado com o grupo SHAM nas artérias mesentéricas de resistência do grupo DOCA-sal (Figura 17 D). 0 tratamento com rostafuroxina não alterou essa resposta (Figura $17 \mathrm{D}$ ). 
Figura 17 - Os gráficos superiores representam a avaliação da atividade funcional da $\mathrm{Na}^{+} \mathrm{K}^{+} \mathrm{ATPase}$ sensível a ouabaína pela curva de relaxamento ao $\mathrm{KCl}$ na ausência e na presença de ouabaína (OUA, $100 \mu \mathrm{M})$ incubada agudamente às preparações em anéis de artérias mesentéricas de resistência de ratos SHAM $(A)$, DOCA-sal (B) ou DOCA-sal tratados com rostafuroxina (ROSTA) (C). D representa a diferença percentual da área abaixo da curva (dAUC \%) de relaxamento ao $\mathrm{KCl}$ na ausência e na presença de ouabaína (OUA, $100 \mu \mathrm{M})$.

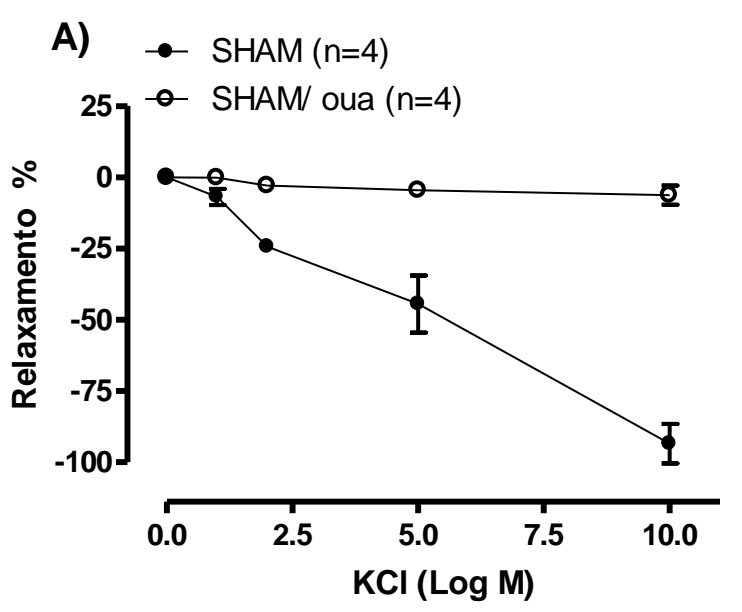

B)

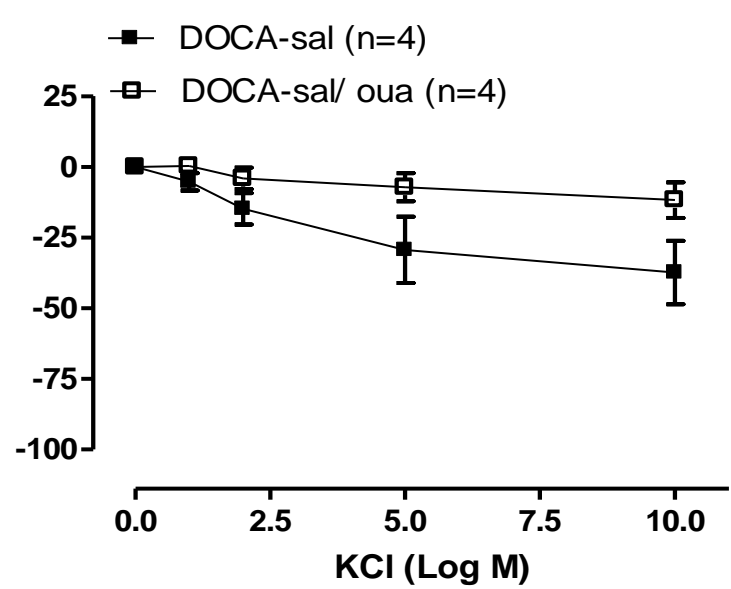

C)

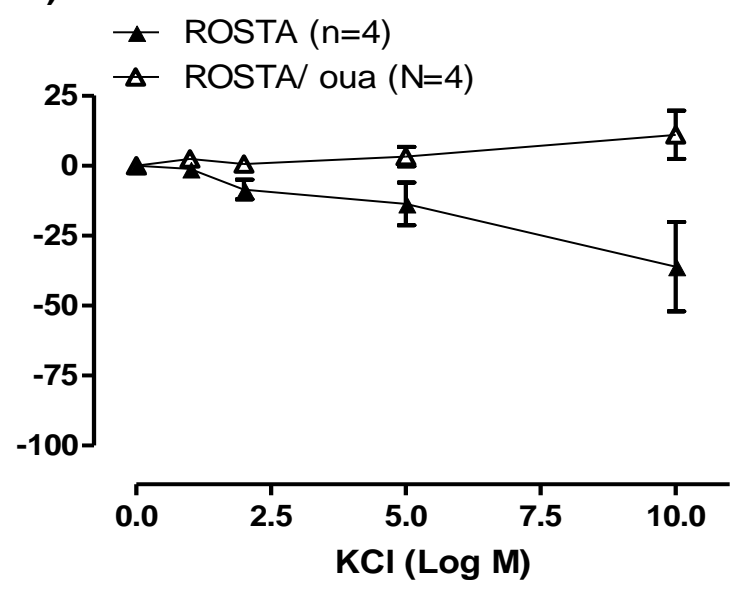

D)

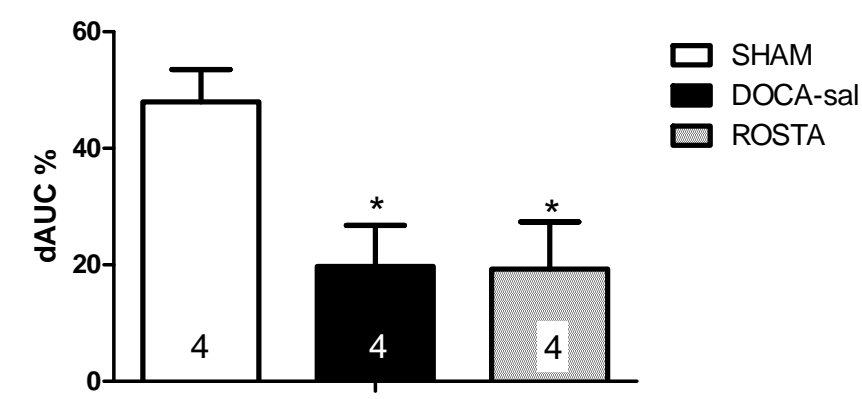

O número de animais utilizado em cada grupo experimental $(n)$ está entre parênteses ou no interior das barras. Os valores são expressos como média \pm EPM. ANOVA 1 via. ${ }^{*} p<0,05$ vs. SHAM.

Fonte: Wenceslau (2012) 
4.5 Medida de tromboxano $\mathrm{B}_{2}\left(\mathrm{TxB}_{2}\right)$ no sobrenadante de artérias mesentéricas de resistência

A concentração basal de $\mathrm{TxB}_{2}$ no sobrenadante não diferiu entre os grupos (Figura 18). A administração cumulativa de acetilcolina em concentrações crescentes $(0,01 \mathrm{nM}-30 \mu \mathrm{M})$ promoveu aumento significativo de $\mathrm{TxB}_{2}$ no sobrenadante nos três grupos avaliados (Figura 18). Entretanto, este aumento foi maior no grupo DOCA-sal e ROSTA quando comparado ao grupo SHAM (Figura 18). O grupo ROSTA não diferiu do DOCA-sal após o estímulo com acetilcolina (Figura 18).

Figura 18 - Dosagem de tromboxano $B_{2}\left(T x B_{2}\right)$ antes (Basal) e após a curva de acetilcolina (ACh) no sobrenadante de artérias mesentéricas de resistência de ratos SHAM, DOCA-sal e DOCA-sal tratados com rostafuroxina (ROSTA).

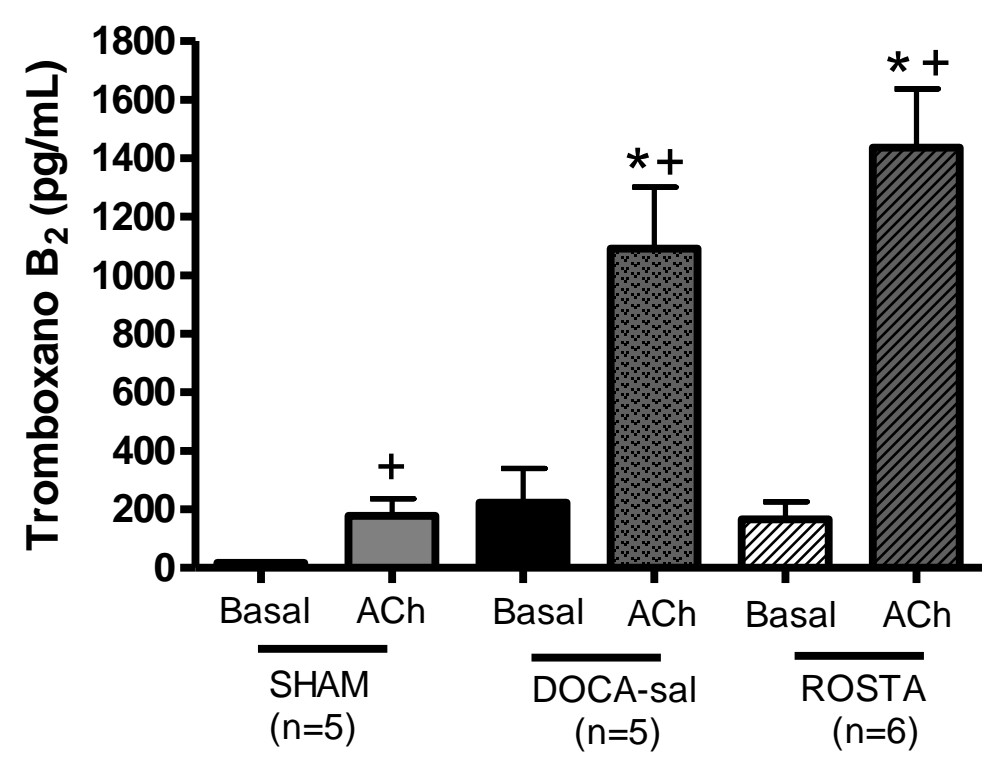

O número de animais analisado em cada grupo experimental está entre parênteses. ANOVA 2 vias: ${ }^{*} p<0,05$ vs. SHAM; + vs. Basal.

Fonte: Wenceslau (2012) 


\subsection{Medida da produção de NO em artérias de resistência}

Para avaliar a viabilidade da técnica na detecção da produção de $\mathrm{NO}$ em cortes transversais de artérias mesentéricas em ratos SHAM, alguns cortes foram previamente incubados com L-NAME $(1 \mathrm{mM})$ por $30 \mathrm{~min}$ ou nitroprussiato de sódio (NPS, $100 \mu \mathrm{M}$ ) por $15 \mathrm{~min}$. Na figura 19 (Painel superior), observou-se redução da fluorescência emitida pelo acetado 4,5-diaminofluoresceína (DAF-2) após a incubação com L-NAME. Por outro lado, o NPS aumentou a fluorescência ao DAF-2. Este dado confirmou a viabilidade da técnica em determinar a produção de NO.

Como pode ser observada na figura 19 (Painel inferior e gráfico), a administração de acetilcolina $(10 \mu \mathrm{M})$ em cortes transversais de artérias mesentéricas de resistência do grupo SHAM aumentou a fluorescência emitida pelo marcador sensível ao óxido nítrico, o DAF-2 em relação ao basal. Entretanto, a administração de acetilcolina não alterou a fluorescência em cortes de artérias no grupo DOCA-sal. O aumento da fluorescência emitida após o estímulo com acetilcolina nos cortes das artérias do grupo ROSTA não diferiru do grupo SHAM e do grupo DOCA-sal (Figura 19). 
Figura 19 - Produção de Óxido Nítrico

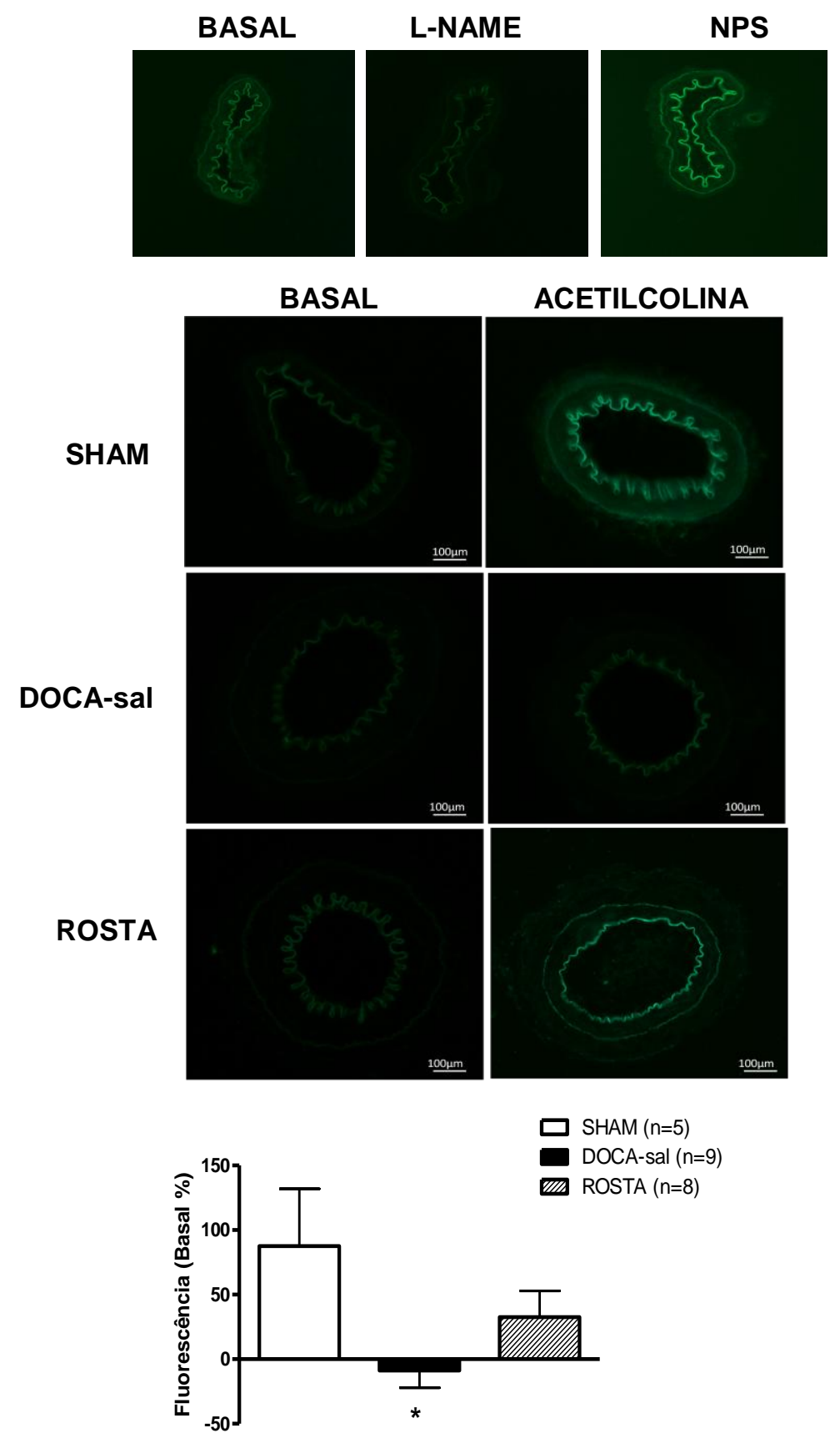

Painel superior mostra imagens representativas do efeito do L-NAME $(1 \mathrm{mM})$ e do nitroprussiato de sódio (NPS, $100 \mu \mathrm{M}$ ) na produção de NO emitida pelo marcador sensível ao óxido nítrico, o acetado 4,5-diaminofluoresceína (DAF-2) em cortes de artérias mesentéricas de resistência de ratos SHAM. Painel inferior (imagens representativas) e gráfico (análise densitométrica) da fluorecência emitida pelo DAF-2 antes (Basal) e após o estímulo com acetilcolina $(10 \mu \mathrm{M})$ em cortes transversais de artérias mesentéricas de resistência de animais SHAM, DOCA-sal e DOCA-sal tratados com rostafuroxina (ROSTA). Os resultados estão expressos como média \pm EPM. O número de animais analisados em cada grupo experimental está entre parênteses. ANOVA 1 via: $p<0,05$ *vs. SHAM.

Fonte: Wenceslau (2012) 


\subsection{Produção das espécies reativas derivadas do oxigênio}

Como pode ser observada na figura 20 , a fluorescência emitida pela oxidação da DHE em cortes transversais de artérias mesentérica de resistência foi maior no grupo DOCA-sal quando comparado ao grupo SHAM. O tratamento com rostafuroxina reduziu significativamente a fluorescência para o mesmo patamar do grupo SHAM (Figura 20).

Figura 20 - Fluorescência emitida pela oxidação da DHE

SHAM

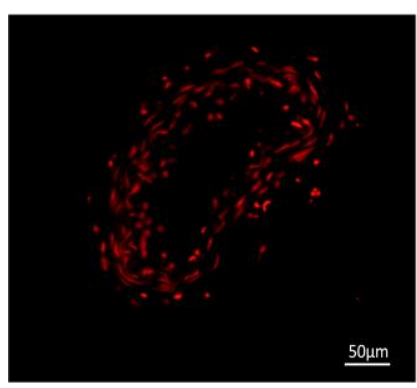

DOCA-sal

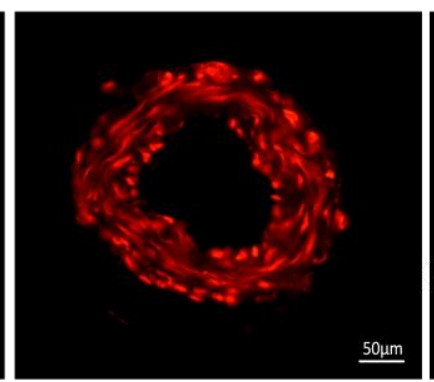

ROSTA

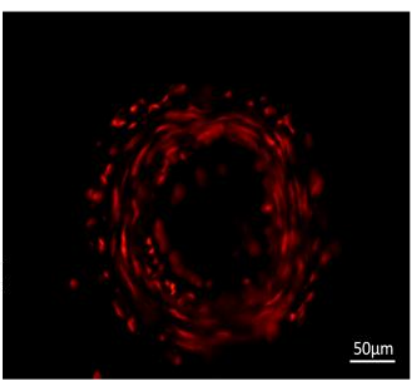

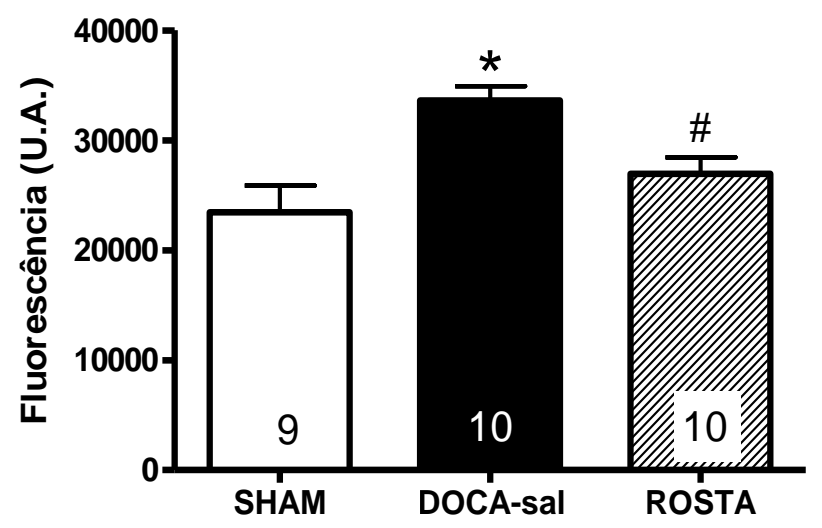

Painel superior demonstra imagens da fluorescência emitida pela oxidação da DHE em cortes transversais de artérias mesentéricas de resistência de animais SHAM, DOCA-sal e DOCA-sal tratados com rostafuroxina (ROSTA). Os gráficos representam a análise densitométrica da intensidade da fluorescência emitida pela oxidação da DHE. Os resultados estão expressos como média \pm EPM. O número de animais analisados em cada grupo experimental está indicado dentro das barras. ANOVA 1 via: $\mathrm{p}<0,05^{*} v s$. SHAM; ${ }^{*}$ vs. DOCA-sal. Fonte: Wenceslau (2012) 
Para avaliar a participação da óxido nítrico sintase (NOS), da $N A D(P) H$ oxidase, da COX-1 e da COX-2 como possíveis fontes de geração das ROS, em alguns cortes de artérias mesentérica de resistência dos três grupos estudados foi adicionado L-NAME (inibidor inespecífico da NOS, $100 \mu \mathrm{M}$ ) (Figura 21), apocinina (inibidor da NADPH oxidase, $10 \mu \mathrm{M}$ ) (Figura 22), SC-560 (inibidor específico da COX-1, 9 nM) (Figura 23) ou NS-398 (inibidor específico da COX-2, $10 \mu \mathrm{M}$ ) (Figura 24).

A administração de L-NAME aumentou a intensidade de fluorescência nos cortes das artérias do grupo SHAM e não alterou esta resposta nem para o grupo DOCA-sal nem para o grupo ROSTA (Figura 21).

$\mathrm{Na}$ figura 22 é possível observar que a apocinina reduziu o aumento da fluorescência em cortes de artérias mesentéricas de resistência do grupo DOCA-sal. Porém, não modificou a intensidade de fluorescência nos cortes das artérias nem do grupo SHAM nem do grupo ROSTA (Figura 22).

A incubação do inibidor da COX-1 não promoveu significativamente alteração na intensidade de fluorescência em nenhum dos grupos avaliados (Figura 23).

A incubação com NS-398 não alterou a intensidade de fluorescência dos cortes das artérias do grupo SHAM (Figura 24). Entretanto, reduziu de maneira significativa a intensidade de fluorescência dos cortes das artérias do grupo DOCAsal e do grupo ROSTA, mas a redução foi de maior magnitude para o grupo DOCAsal (Figura 24). 
Figura 21 - Fluorescência emitida pela oxidação da DHE

A)

BASAL
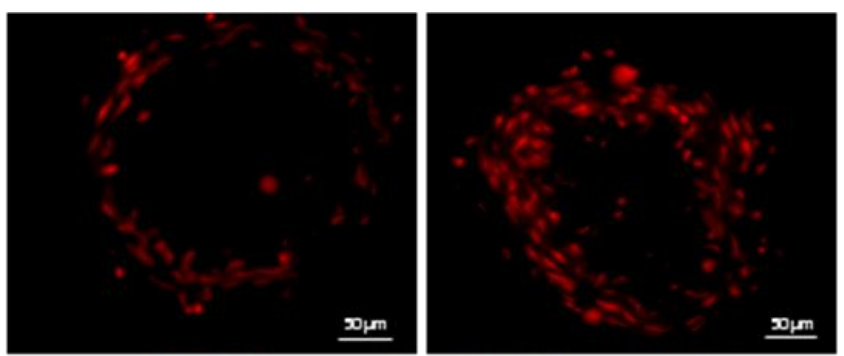

DOCA-

SAL
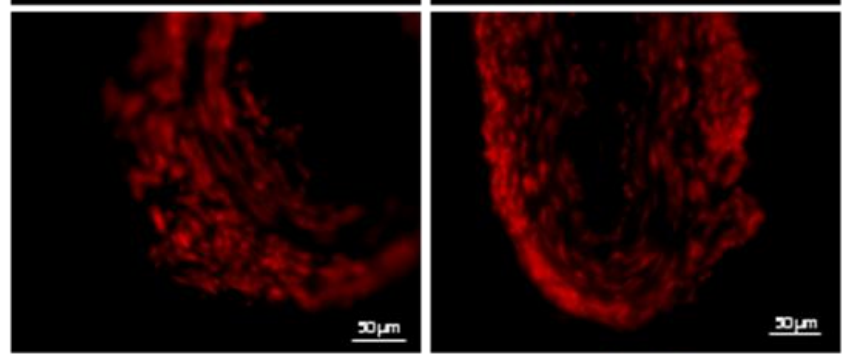

ROSTA
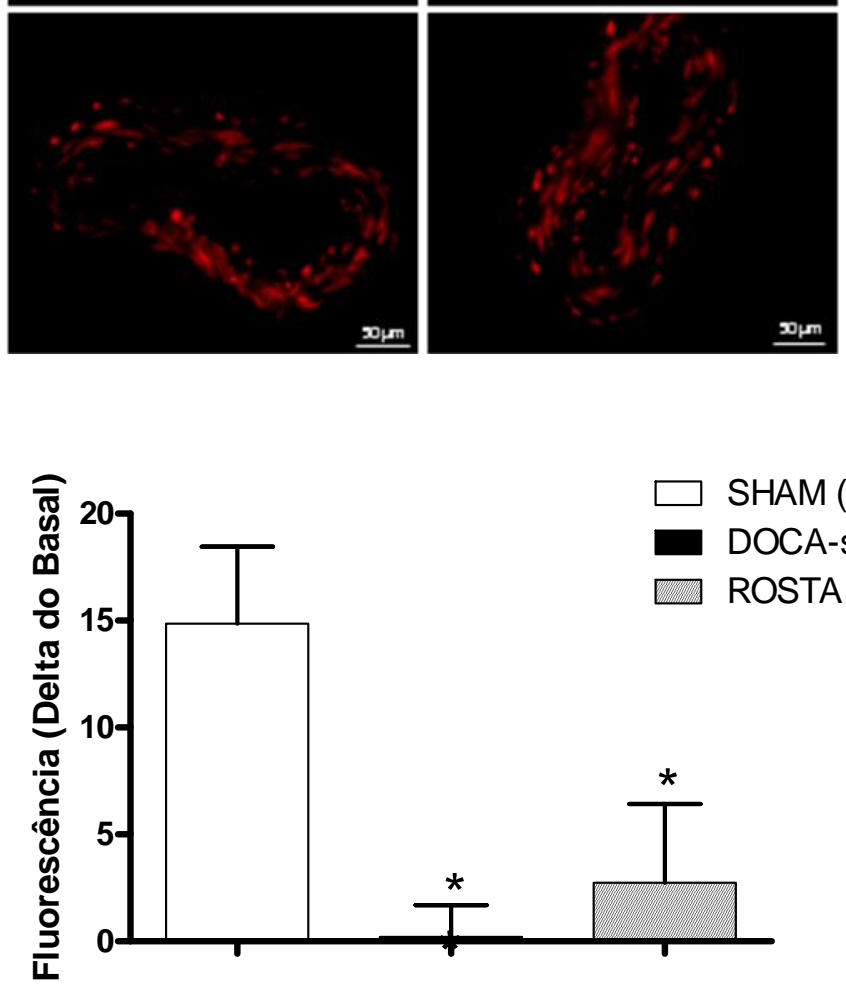

Painel superior demonstra imagem da fluorescência emitida pela oxidação da DHE em cortes transversais de artérias mesentéricas de resistência de animais SHAM, DOCA-sal e DOCA-sal tratados com rostafuroxina (ROSTA) na ausência ou na presença de L-NAME $(100 \mu \mathrm{M})$. O gráfico representa a análise densitométrica da intensidade da fluorescência emitida pela oxidação da DHE. Os resultados estão expressos como média \pm EPM. O número de animais analisados em cada grupo experimental está entre parênteses. ANOVA 1 via: $\mathrm{p}<0,05^{*}$ vs. SHAM.

Fonte: Wenceslau (2012) 
Figura 22 - Fluorescência emitida pela oxidação da DHE

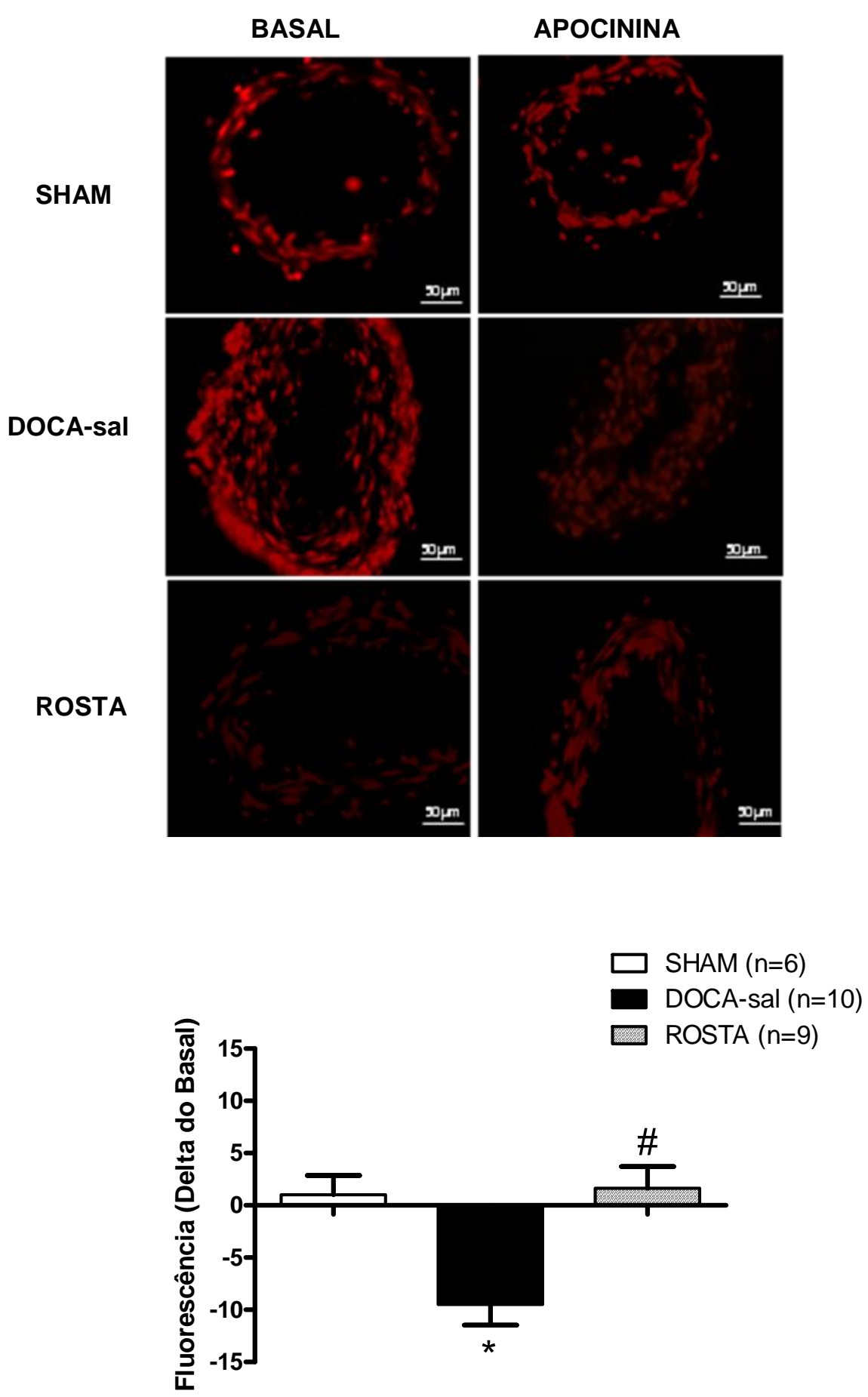

Painel superior demonstra imagem da fluorescência emitida pela oxidação da DHE em cortes transversais de artérias mesentéricas de resistência de animais SHAM, DOCA-sal e DOCA-sal tratados com rostafuroxina (ROSTA) na ausência ou na presença de apocinina $(10 \mu \mathrm{M})$. O gráfico representa a análise densitométrica da intensidade da fluorescência emitida pela oxidação da DHE Os resultados estão expressos como média \pm EPM. O número de animais analisados em cada grupo experimental está entre parênteses. ANOVA 1 via: $\mathrm{p}<0,05$ * vs. SHAM; * vs. DOCA-sal.

Fonte: Wenceslau (2012) 
Figura 23 - Fluorescência emitida pela oxidação da DHE

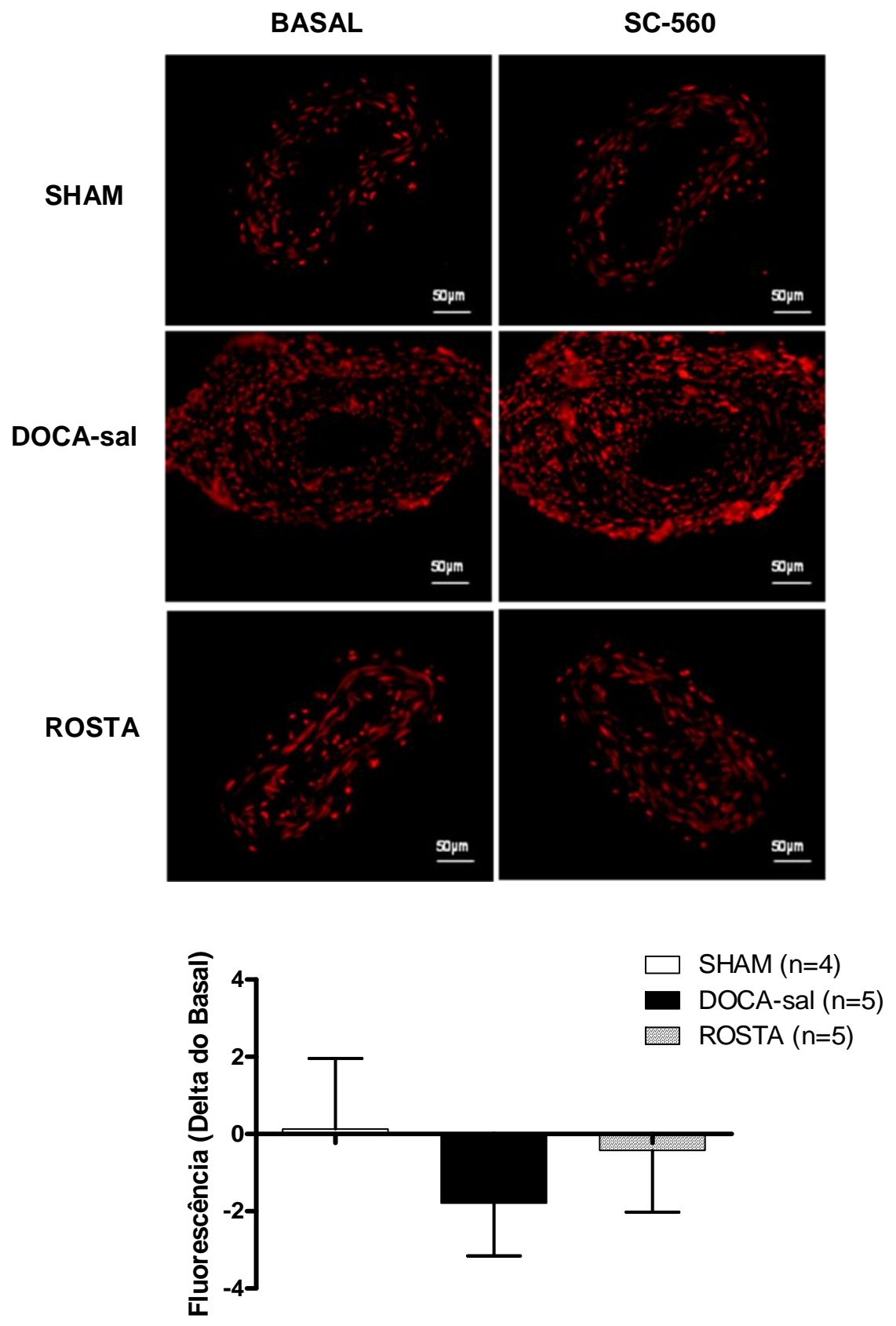

Painel superior demonstra imagem da fluorescência emitida pela oxidação da DHE em cortes transversais de artérias mesentéricas de resistência de animais SHAM, DOCA-sal e ROSTA na ausência ou na presença de SC-560 (9 nM). O gráfico representa a análise densitométrica da intensidade da fluorescência emitida pela oxidação da DHE. Os resultados estão expressos como média \pm EPM. O número de animais analisados em cada grupo experimental está entre parênteses. ANOVA 1 via.

Fonte: Wenceslau (2012) 
Figura 24 - Fluorescência emitida pela oxidação da DHE

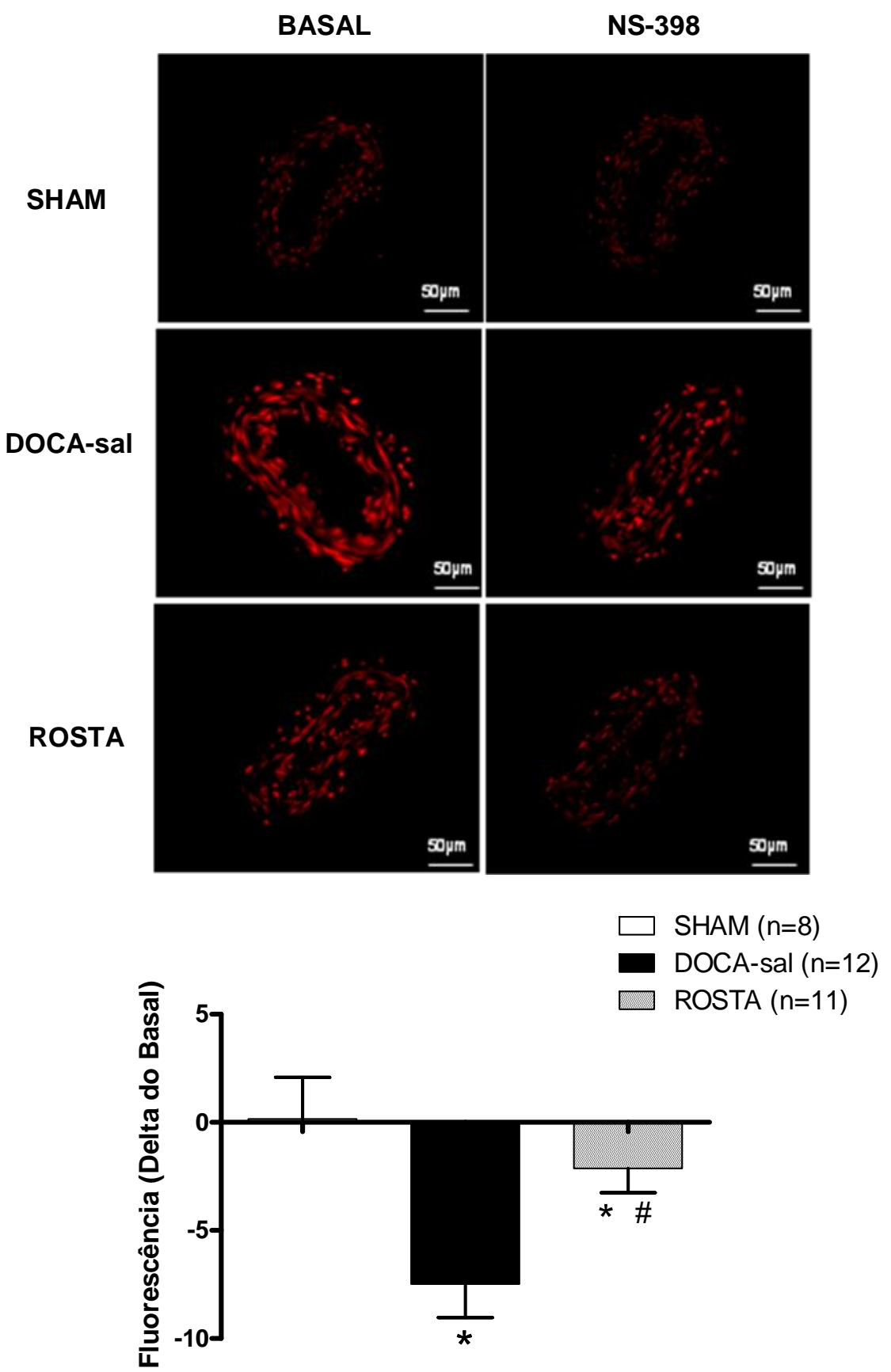

Painel superior demonstra imagem da fluorescência emitida pela oxidação da DHE em cortes transversais de artérias mesentéricas de resistência de animais SHAM, DOCA-sal e DOCA-sal tratados com rostafuroxina (ROSTA) na ausência ou na presença de NS-398 $(10 \mu \mathrm{M})$. O gráfico representa a análise densitométrica da intensidade da fluorescência emitida pela oxidação da DHE. Os resultados estão expressos como média \pm EPM. O número de animais analisados em cada grupo experimental está entre parênteses. ANOVA 1 via: $\mathrm{p}<0,05$ * vs. SHAM; ${ }^{*}$ vs. DOCA-sal.

Fonte: Wenceslau (2012) 


\subsection{Avaliação da expressão proteica}

Como representado na figura 25 ( $\mathrm{A}$ e B), a hipertensão DOCA-sal promoveu redução significativa na expressão proteica tanto da isoforma da sintase de óxido nítrico neuronal (nNOS) quando da isoforma de óxido nítrico endotelial (eNOS) em artérias mesentéricas de resistência quando comparado ao grupo SHAM. O grupo ROSTA também apresentou redução significativa da expressão proteica de ambas isoformas quando comparado ao grupo SHAM (Figura 25 A e B). Porém, o tratamento com rostafuroxina aumentou significativamente a expressão proteica da eNOS em relação ao grupo DOCA-sal (Figura 25 A) e não modificou a expressão protéica da nNOS (Figura $25 \mathrm{~B}$ ).

A expressão proteica da isoforma $\mathrm{Cu} / \mathrm{Zn}-\mathrm{SOD}$ foi reduzida em artérias mesentéricas de resistência do grupo DOCA-sal em relação ao grupo SHAM (Figura 26 A). Por sua vez, o tratamento com rostafuroxina aumentou a expressão proteica dessa isoforma (Figura 26 A) apesar da mesma ainda diferir em relação ao grupo SHAM. A expressão proteica da isoforma EC-SOD foi significativamente maior em artérias mesentéricas de resistência do grupo DOCA-sal e ROSTA em relação ao grupo SHAM (Figura 26 B). Não houve alteração da expressão proteica da isoforma Mn-SOD e da catalase entre os três grupos estudados (Figura $26 \mathrm{C}$ e D).

A expressão proteica das isoformas NOX-1/2 e p47-phox foram aumentadas em artérias mesentéricas de resistência do grupo DOCA-sal em relação ao grupo SHAM (Figura 27 A e C). Por sua vez, o tratamento com rostafuroxina reduziu a expressão dessas proteínas fazendo com que as mesmas não diferissem dos animais SHAM (Figura 27 A e C). Não houve diferença significativa na expressão proteica das isoformas $p$-67phox e p-22phox nas artérias dos três grupos avaliados (Figura 27 B e D). 
Figura 25 - Expressão proteica

A)
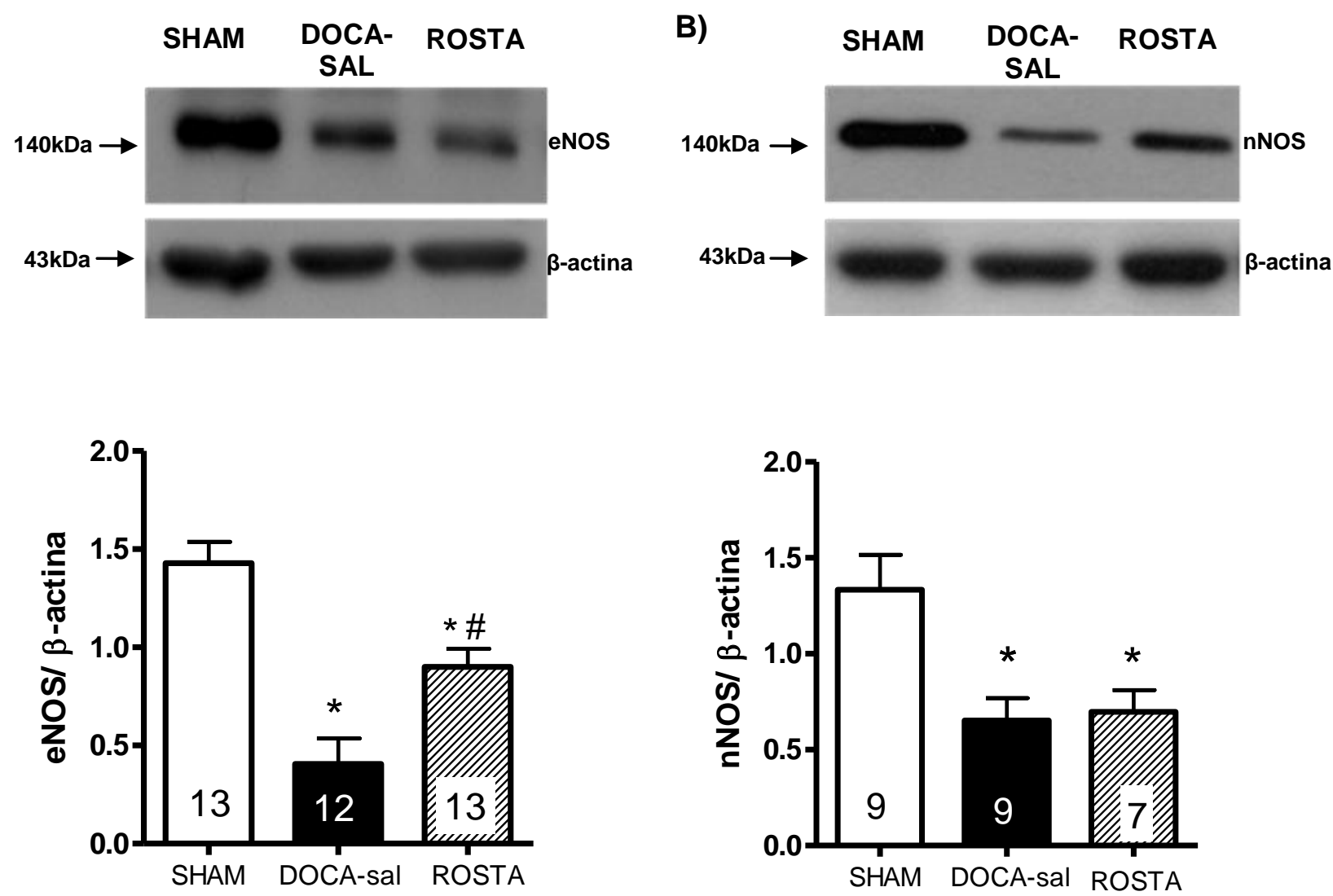

Painel superior demonstra imagens (blots) representativas da expressão proteica da eNOS (A), nNOS (B) e $\beta$-actina (A e B) em artérias mesentéricas de resistência de ratos SHAM, DOCA-sal e DOCA-sal tratados com rostafuroxina (ROSTA). Os gráficos representam a análise densitométrica da expressão proteica da eNOS (A) e nNOS (B) normalizadas pela $\beta$-actina. Os resultados estão expressos como média \pm EPM. O número de animais analisados em cada grupo experimental está indicado dentro das barras. ANOVA 1 via: $p<0,05{ }^{*} v s$. SHAM; " vs. DOCA-sal.

Fonte: Wenceslau (2012) 
Figura 26 - Expressão proteica

A)
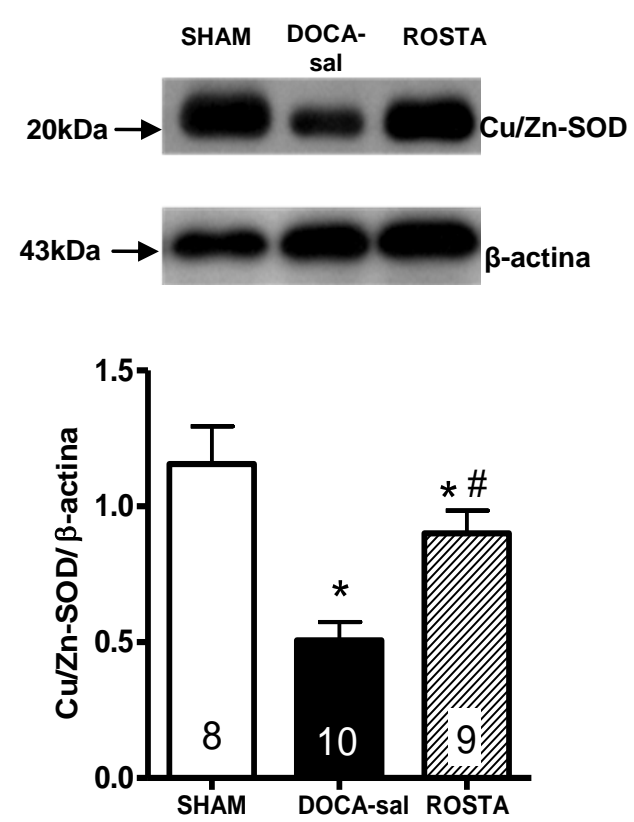

B)
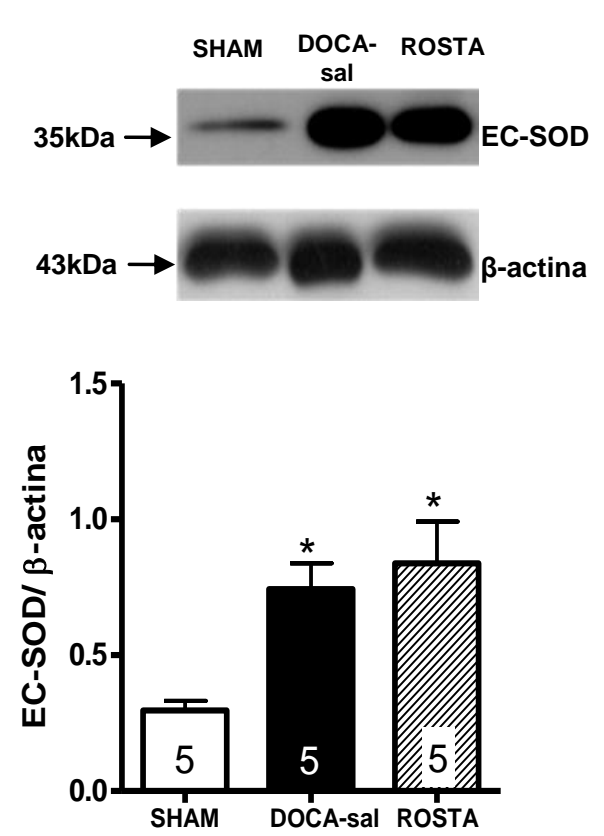

C)

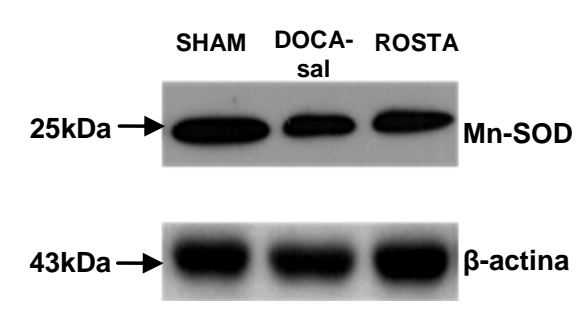

D)
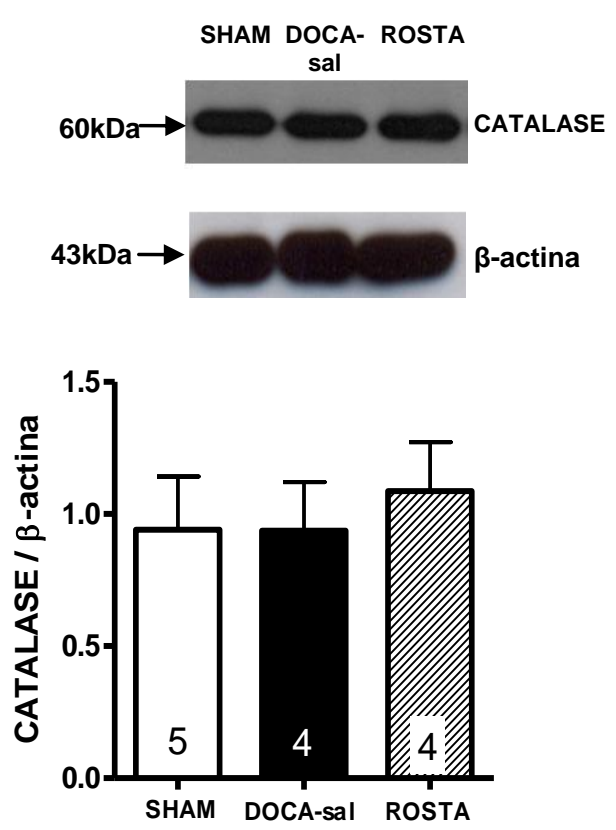

Painel superior demonstra imagens (blots) representativas da expressão proteica da Cu/Zn-SOD (A), EC-SOD (B), Mn-SOD (C), catalase (D) e $\beta$-actina (A, B, C e D) em artérias mesentéricas de resistência de ratos SHAM, DOCA-sal e DOCA-sal tratados com rostafuroxina (ROSTA). Os gráficos representam a análise densitométrica da expressão das proteica da Cu/Zn-SOD (A), EC-SOD (B), Mn-SOD (C) e catalase (D) normalizadas pela $\beta$-actina. Os resultados estão expressos como média \pm EPM. $O$ número de animais

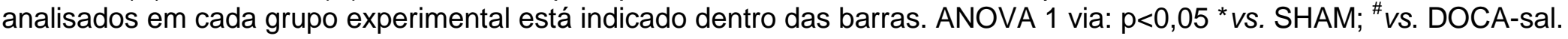
Fonte: Wenceslau (2012) 
Figura 27 - Expressão proteica

A)
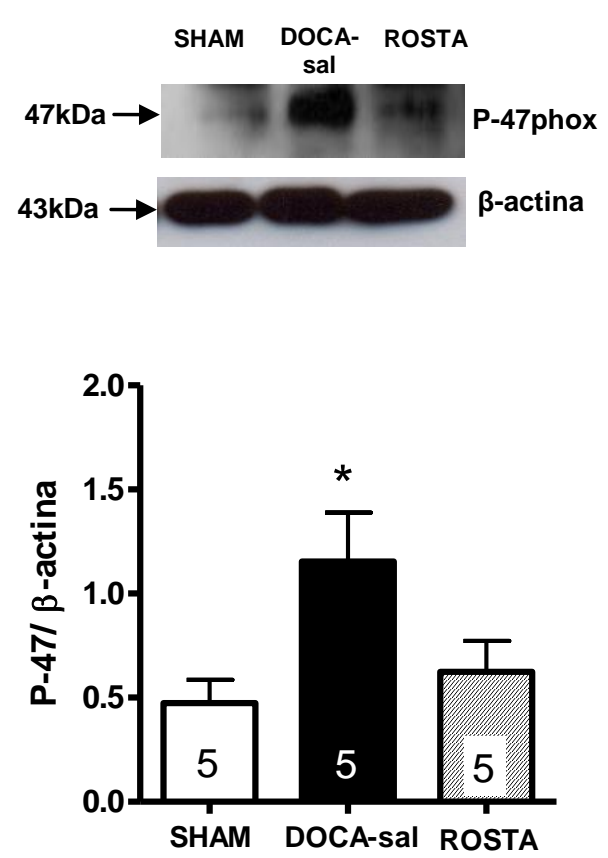

B)
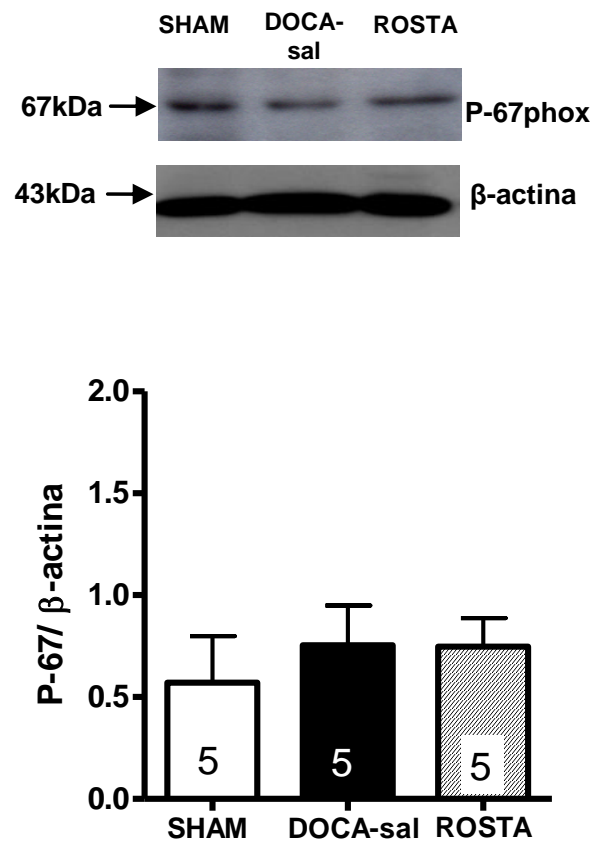

C)
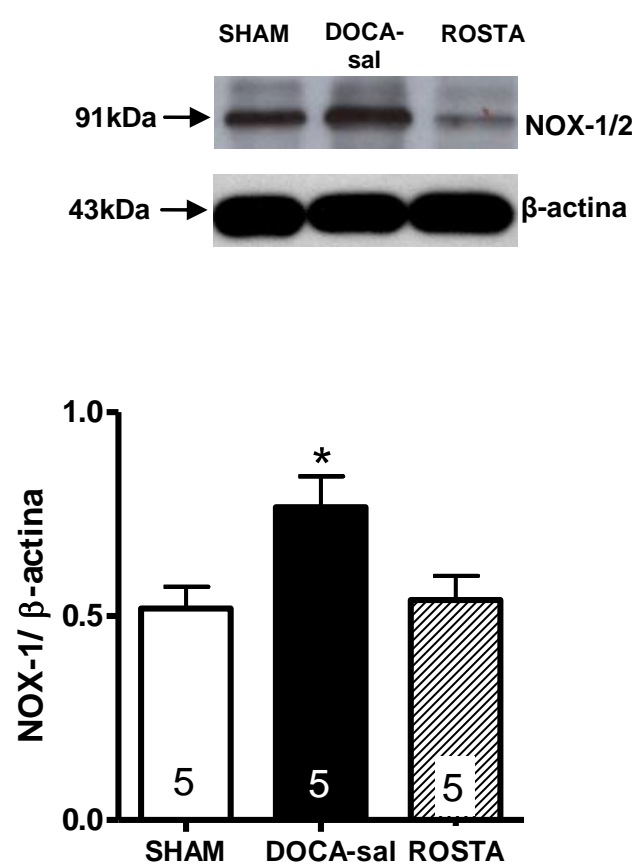

D)
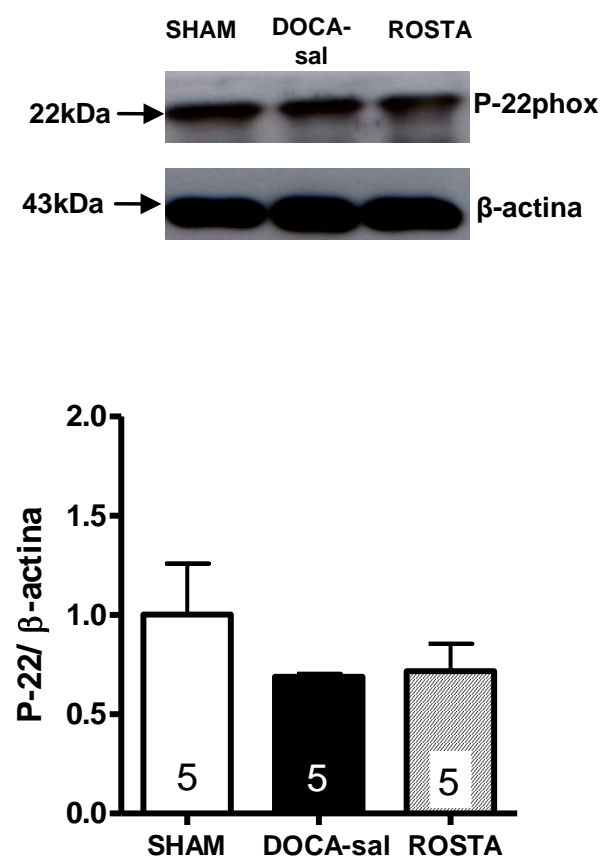

Painel superior demonstra imagens (blots) representativas da expressão proteica da P-47phox (A), P-67phox (B), NOX-1(C), P22phox (D) e $\beta$-actina (A, B, C e D) em artérias mesentéricas de resistência de ratos SHAM, DOCA-sal e ROSTA. Os gráficos representam a análise densitométrica da expressão proteica da P-47phox (A), P-67phox (B), NOX-1/2 (C) e P-22phox (D) normalizadas pela $\beta$-actina. Os resultados estão expressos como média \pm EPM. O número de animais analisados em cada grupo experimental está indicado dentro das barras. ANOVA 1 via: $p<0,05$ * $v s$. SHAM.

Fonte: Wenceslau (2012) 
Como representado na figura $28 \mathrm{~A}$, a hipertensão DOCA-sal promoveu aumento significativo na expressão proteica da COX-1 quando comparado ao grupo SHAM. O tratamento com rostafuroxina não alterou este parâmetro (Figura 28 A). A expressão proteica da COX-2 não diferiu entre os grupos avaliados (Figura $28 \mathrm{~B}$ ).

Por sua vez, a expressão proteica do $\mathrm{TxA}_{2}$ sintase foi reduzida nas artérias do grupo DOCA-sal e do grupo ROSTA quando comparados ao grupo SHAM (Figura 28 C).

$\mathrm{Na}$ figura 29 A é posssível observar que a expressão proteica da c-SRC não alterou entre os grupos avaliados. Entretanto, a sua fosforilação em tirosina 418 aumentou significativamente nas artérias do grupo DOCA-sal comparado ao grupo SHAM (Figura 29 B). O tratamento com rostafuroxina reduziu essa fosforilação para o nível observado nas artérias dos animais SHAM (Figura 29 B). 
Figura 28 - Expressão proteica

A)
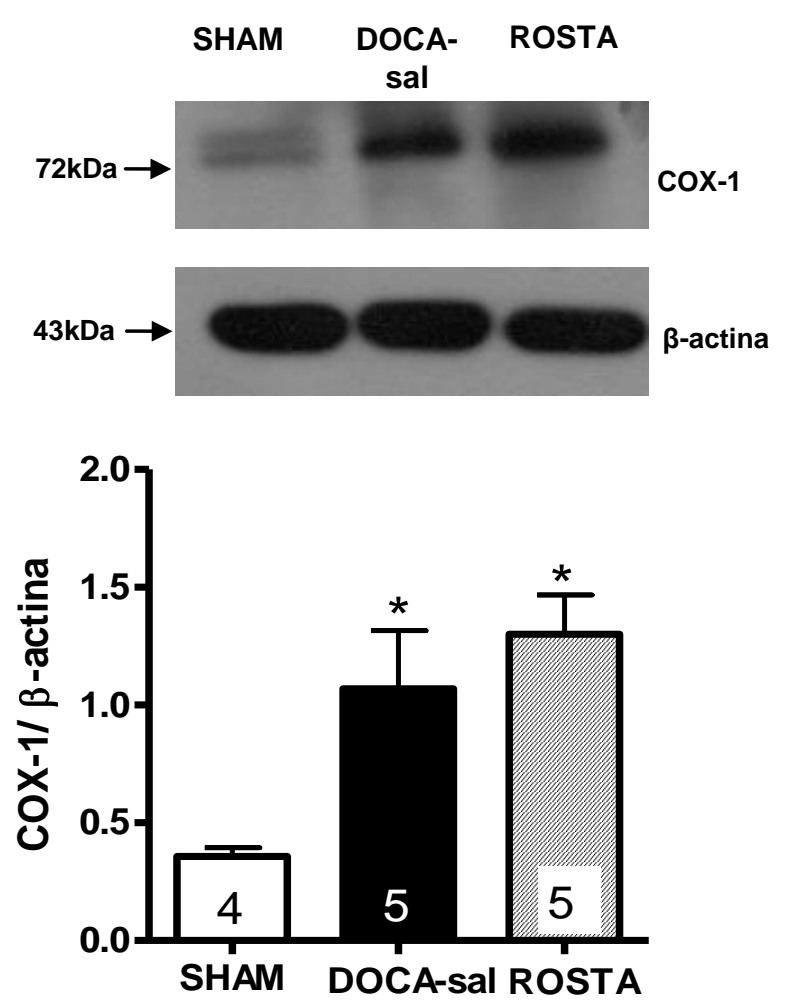

B)
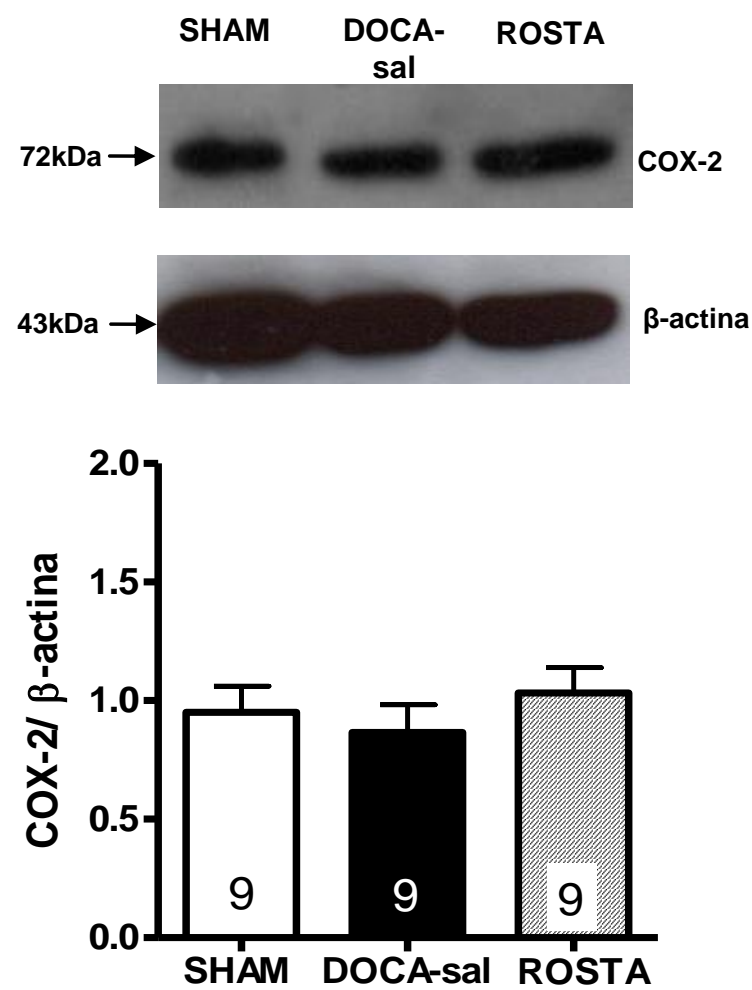

C)
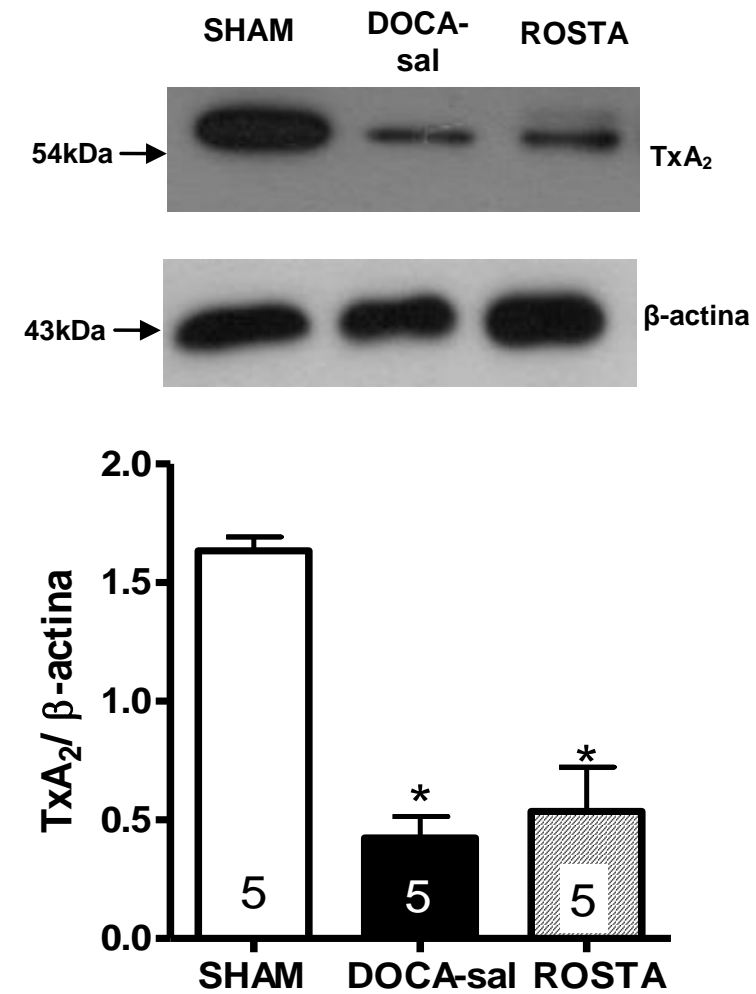

Painel superior demonstra imagens (blots) representativas da expressão proteica da COX-1 $(A), \operatorname{COX}-2(B)$, TxA $2(C)$ e $\beta$-actina ( $A, B$ e C) em artérias mesentéricas de resistência de ratos SHAM, DOCA-sal e DOCA-sal tratados com rostafuroxina (ROSTA). Os gráficos representam a análise densitométrica da expressão das proteica da COX-1 (A), COX-2 (B) e TxA $A_{2}(C)$ normalizadas pela $\beta$-actina. Os resultados estão expressos como média \pm EPM. O número de animais analisados em cada grupo experimental está indicado dentro das barras. ANOVA 1 via: $\mathrm{p}<0,05$ * $v s$. SHAM.

Fonte: Wenceslau (2012) 
Figura 29 - Expressão proteica
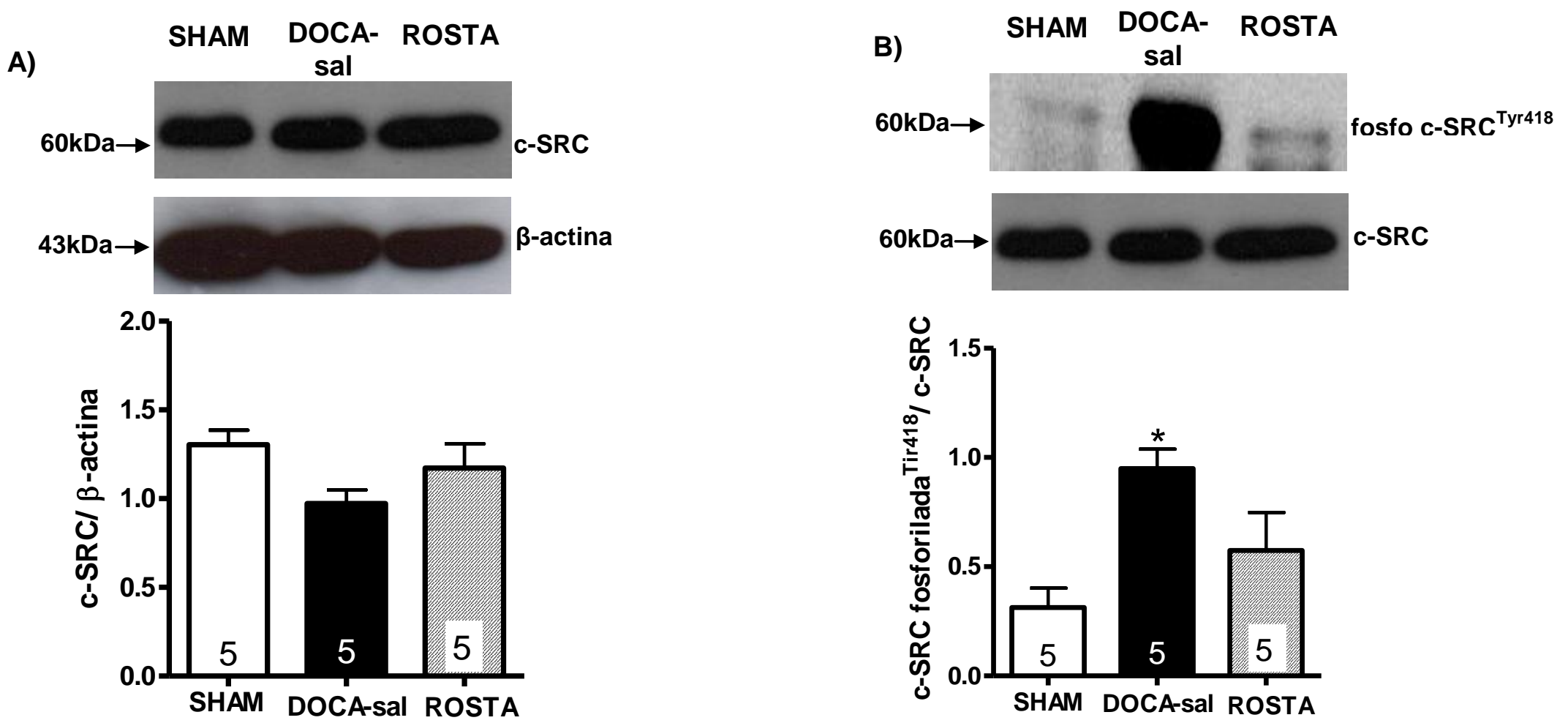

Painel superior demonstra imagens (blots) representativas da expressão proteica da c-SRC (A), cSRC fosforilada em tirosina 418 (B) e $\beta$-actina ( $A$ e B) em artérias mesentéricas de resistência de ratos SHAM, DOCA-sal e DOCA-sal tratados com rostafuroxina (ROSTA). Os gráficos representam a análise densitométrica da expressão das proteica da c-SRC (A) e cSRC fosforilada em tirosina 418 (B) normalizadas pela $\beta$-actina e c-SRC respectivamente. Os resultados estão expressos como média \pm EPM. $O$ número de animais analisados em cada grupo experimental está indicado dentro das barras. ANOVA 1 via: $p<0,05{ }^{*} v s$. SHAM.

Fonte: Wenceslau (2012) 


\section{DISCUSSÃO}

\subsection{Papel da ouabaína endógena sobre a mortalidade e a pressão arterial de ratos DOCA-sal}

Nos últimos anos o tratamento farmacológico da hipertensão arterial evoluiu de uma abordagem empírica, passando de tratamentos para de um grande número de pacientes, para uma abordagem mais individual, a qual aponta para mecanismos específicos que afetam subgrupos de paciente hipertensos (Calhoun et al., 2008; Ferrari et al., 2006). Desta forma, o sucesso do tratamento da hipertensão arterial no futuro dependerá sobre a compreensão dos mecanismos ambientais, fisiológicos e genéticos/ moleculares atuando em subgrupos de pacientes e a capacidade de novos fármacos para corrigir especificamente tais alterações.

A identificação de esteróides cardiotônicos como ouabaína, no plasma sanguíneo (Hamlyn et al., 1989), nas glândulas supra-renais (Laredo et al., 1997; Ludens et al., 1992; Nesher et al., 2009), no hipotálamo (De Wardener e Clarson, 1985; Murrell et al., 2005) e na região anteroventral do terceiro ventrículo (AV3V) (Pamnani et al., 1981; Songu-Mize et al., 1982) dos mamíferos levou à novas perspectivas sobre uma melhor compreensão da hipertensão arterial, desde que várias linhas de pesquisa experimental e clínica, apresentam evidências do papel patogênico da ouabaína na hipertensão arterial e complicações de órgãos alvo. Estes efeitos ocorrem por meio de uma interação complexa entre mecanismos genético/ moleculares (Ferrari et al., 2006); funcionais (Briones et al., 2006; Hernaz et al., 2008; Rossoni et al., 2002a,b, Padilha et al., 2008; Wenceslau et al., 2011; Xavier et al. 2004a,b,c), cardíaco (Jiang et al., 2007; Rossoni et al., 2006; Skoumal et al., 2007), neural (Huang et al., 1994; Leenen, 2002) e renal (Cao et al., 2009;

Kimura et al., 2000; Kurashina et al., 1996) e variáveis ambientais, como a ingestão de sal (Kojima et al., 1982; Pamnani et al., 1988; Park et al., 2004; Songu-Mize et al., 1982).

Com base nestas evidências e para melhor entendimento dos mecanismos da ouabaína é relevante estudar a interferência de fármacos que atenuem ou até mesmo revertam os efeitos desse glicosídeo sobre o processo hipertensivo e que atestem a sua real contribuição para instalação e/ou manutenção da hipertensão arterial. Neste sentido, o presente estudo avaliou o papel endógeno da ouabaína 
sobre a manutenção da pressão arterial no modelo de hipertensão DOCA-sal, o qual apresenta aumento das concentrações de ouabaína plasmática (Kojima et al., 1982; Pamnani et al., 1981; Park et al., 2004; Songu-Mize et al., 1982). Desta maneira, os resultados obtidos confirmam estudos anteriores (Ferrari et al., 2006; Kojima et al., 1982; Songu-Mize et al., 1982), no sentido de que a ouabaína tem importante papel na hipertensão DOCA-sal, visto que após 1 semana do início do tratamento com o inibidor de suas ações, a rostafuroxina, ocorreu queda significativa da pressão arterial dos animais DOCA-sal, a qual permaneceu estável até o fim do tratamento.

Ferrari et al. (2006; 2010), avaliaram a eficácia da rostafuroxina como antihipertensivo em diferentes modelos experimentais. Assim, nos modelos de animais hipertensos de Milão, DOCA-sal, com redução da massa renal, e hipertensos pelo tratamento por 8 semanas com ouabaína apresentaram redução da pressão arterial sem alteração da frequência cardíaca quando oralmente tratados de forma terapêutica com rostafuroxina. É digno de nota que animais normotensos e também os ratos espontaneamente hipertensos (SHR) quando tratados com rostafuroxina não apresentaram alteração nos valores de pressão arterial (Ferrari et al., 1993; 2006; 2010). Sobre estes achados, é possível sugerir que a rostafuroxina não afetou os valores pressóricos dos animais SHR devido ao fato de não apresentarem aumento de ouabaína plasmática, diferentemente dos modelos de hipertensão arterial dependente de volume (Doris, 1994), como o modelo DOCA-sal estudado na presente tese.

Cabe ressaltar que a hipertensão arterial em humanos é dividida, etiologicamente, em hipertensão essencial ou primária e hipertensão secundária (The Seventh Report of the Joint National Committee on Prevention, Detection, Evaluation, and Treatment of High Blood Pressure, 2004). A hipertensão essencial, a qual os animais SHR representam, afeta 95\% da população de hipertensos, ao passo que, a hipertensão secundária abrange apenas 5\%. Esse fato implica que a rostafuroxina pode ter efeito satisfatório apenas em uma pequena população de hipertensos, ou seja, em um subgrupo que apresenta, por exemplo, aumento das concentrações de ouabaína plasmática (Manunta et al., 2011; Staessen et al., 2011). Reforçando essa sugestão, um grande ensaio clínico conduzido pelo grupo do Dr. Bianchi na Itália e na Bélgica demonstrou que a rostafuroxina não teve efeito significativo na maior parte da população hipertensa avaliada, entretanto o estudo revelou diminuição significativa da pressão arterial em pacintes portadores de um 
perfil genético específico, os quais apresentam no fenótipo aumento da ouabaína plasmática, alteração de proteínas que participam da síntese de ouabaína e/ou alteração da aducina, uma proteína do citoesqueleto que modula a função da $\mathrm{Na}^{+} \mathrm{K}^{+}$ATPase (Staessen et al., 2011). Sendo assim, sugere-se que a rostafuroxina seja uma nova intervenção farmacológica para corrigir especificamente pacientes hipertensos com tais alterações.

Como descrito na introdução da presente tese, as doenças cardiovasculares, dentre elas a hipertensão arterial, apresentam expressiva e excessiva morbimortalidade em todo o mundo. Desta forma, foi plausível hipotetizar que um fármaco capaz de reduzir os valores pressóricos também seja capaz de reduzir a taxa de mortalidade. Entretanto, neste estudo não foi observada a participação da ouabaína endógena na mortalidade dos animais DOCA-sal, pois o tratamento com rostafuroxina não alterou a curva de mortalidade desses animais. Esse resultado vai de encontro aos dados da literatura, os quais demonstram a eficiência de alguns anti-hipertensivos, como o losartan (Dahlöf et al., 2002) e os diuréticos (Messerli et al., 1998) em reduzir a taxa de mortalidade.

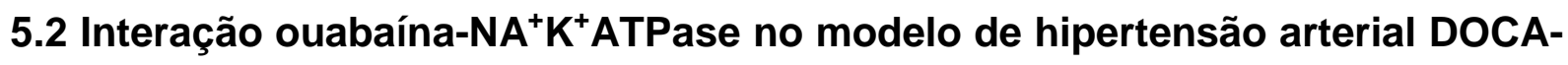 sal}

No modelo de hipertensão DOCA-sal a atividade da $\mathrm{NA}^{+} \mathrm{K}^{+}$ATPase está reduzida devido ao aumento da ouabaína endógena (Kim et al., 1997; Pamnani et al., 1981). Indo ao encontro de trabalhos prévios, no presente estudo também foi observado redução da atividade da $\mathrm{NA}^{+} \mathrm{K}^{+} \mathrm{ATPase}$. Entretanto, o tratamento com rostafuroxina não reverteu essa resposta. Baseado neste dado, na presente tese, descarta-se a possibilidade de que a ouabaína endógena neste modelo de

hipertensão arterial tenha seus efeitos sobre alteração na atividade da $\mathrm{NA}^{+} \mathrm{K}^{+} \mathrm{ATPase}$.

Como já descrito na presente tese, nossos dados demonstraram que a ouabaína não age apenas como um inibidor da atividade da $\mathrm{Na}^{+} \mathrm{K}^{+} \mathrm{ATPase}$, mas, em baixas concentrações, pode atuar como um indutor de sinal gerando uma cascata de sinalização, o signalosoma, tendo como ativação inicial a fosforilação da cSRC. Assim, no presente estudo foi observado aumento da fosforilação da cSrc ${ }^{\text {Tyr418 em }}$ artérias mesentérica de resistência de animais DOCA-sal quando comparado ao grupo SHAM e o tratamento com rostafuroxina reverteu esse resultado. Esses dados 
vão ao encontro da teoria de Xie e Cai (2003) que sugerem a interação ouabaína$\mathrm{Na}^{+} \mathrm{K}^{+}$ATPase-cSRC e ativação do signalosoma, sem alteração da atividade da $\mathrm{Na}^{+} \mathrm{K}^{+}$ATPase. Nossos dados corroboram os achados de Ferrandi et al. (2004), os quais demonstraram que células do epitélio renal de ratos quando tratadas agudamente com ouabaína apresentam aumento da associação da $\mathrm{Na}^{+} \mathrm{K}^{+}$ATPasecSRC quando co-imunoprecipitadas e a incubação com rostafuroxina reverte este resultado.

Em conjunto esses resultados confirmam a eficiência da rostafuroxina em atuar sobre a inibição das ações da ouabaína, sem alterar a atividade da $\mathrm{Na}^{+} \mathrm{K}^{+}$ATPase.

\subsection{Papel da ouabaína endógena sobre a atividade simpática do nervo esplâncnico de ratos DOCA-sal}

O efeito hipertensinogênico da ouabaína tem sido associado com aumento do tônus simpático (Huang et al., 1994) devido ativação de sistemas regulatórios centrais, como o sistema renina-angiotensina (Huang e Leenen, 1999) e da endotelina (Di Filippo et al., 2003).

Ratos sensíveis ao sal quando tratados agudamente com o anticorpo antidigoxina apresentam redução da pressão arterial e da atividade simpática (Huang et al., 1994). Além disso, o tratamento por duas semanas com ouabaína promove hiperatividade simpática associada a prejuízo da função barorreflexa e hipertensão arterial (Huang e Leenen, 1999).

Em modelos genéticos de hipertensão arterial sensíveis ao sal, como o Dahlsal sensível, o controle do sódio no líquido cefalorraquidiano está alterado associado à ativação da ouabaína central, levando assim, a hiperatividade simpática e hipertensão arterial, aparentemente independente do genótipo renal (Leenen, 2002). Também já foi descrito que Infusão central de aldosterona aumenta o conteúdo hipotalâmico de ouabaína com consequente simpatoexcitação (Leenen, 2010).

Indo ao encontro de dados na literatura, o presente estudo demonstrou que a ouabaína endógena participa da hiperatividade simpática observadas em ratos DOCA-sal, desde que ratos tratados com rostafuroxina apresentaram redução da atividade simpática para valores similares ao grupo SHAM. Por outro lado, de encontro ao trabalho de Huang e Leenen (1999) as quais sugerem a participação da 
ouabaína na disfunção barorreflexa na hipertensão arterial, no presente estudo não foi observado alteração da função barorreflexa no modelo de hipertensão DOCA-sal e o tratamento com rostafuroxina não modificou este padrão de resposta.

De acordo com desses dados, Veelken et al. (1994) demonstrarm que o barorreflexo arterial não está alterado e não participa na gênese da hipertensão arterial no modelo DOCA-sal. Por outro lado, sabe-se que na hipertensão arterial ocorre depressão do barorreflexo (Sleigth, 1991) e que em SHR o prejuízo no barorreflexo está associado a alteração no sistema renina angiotensina (HeringerWalther et al., 2001). Assim, não se descarta a possibilidade que no modelo DOCAsal o fato da sensibilidade do barorreflexo não ter sido afetado em nossos estudos, pode ser devido ao nível de anestesia, o qual poderia mascarar os efeitos discretos de alteração na sensibilidade barorreflexa dentre os grupos estudados.

$\mathrm{Na}$ hipertensão DOCA-sal a hiperatividade simpática está associada com aumento de ânion superóxido no terminal nervoso via ativação da $\mathrm{NAD}(\mathrm{P}) \mathrm{H}$ oxidase (Dai et al., 2006); com aumento de $\mathrm{NaCl}$ plasmático (Yemane et al., 2009); com aumento de endotelina, angiotensina-II e vasopressina (Yemane et al., 2009). Além disso, Jacob et al. (2005) demonstraram que desnervação renal atenua a hipertensão DOCA-sal.

$\mathrm{Na}$ presente tese, o(s) motivo(s) pelo(s) qual(is) a ouabaína endógena participa da gênese e/ ou manutenção da hiperatividade simpática não foi(ram) analisado(s). Entretanto, é possível presumir que a ouabaína possa ativar o simpático diretamente no terminal nervoso via interação ouabaína- $\mathrm{Na}^{+} \mathrm{K}^{+}$-ATPase no gânglio simpático via ativação da cSRC e indiretamente via ativação do sistema renina angiotensina e do sistema endotelina. Porém é necessário mais estudos para avaliar as vias de ativação do sistema nervoso simpático pela ouabaína endógena. 


\subsection{Papel da ouabaína endógena sobre a função vascular: Relaxamento vascular}

Independente da etiologia da hipertensão arterial, a disfunção endotelial é um dos marcadores dessa doença (Davel et al., 2011; Fortes et al., 1990; Konishi, Su, 1983; White et al., 1996). No entanto, os mecanismos fisiopatológicos podem diferir entre as formas de hipertensão arterial e entre diferentes tipos de leitos vasculares. Particularmente, dois tipos de alterações funcionais nas artérias têm sido amplamente observados na hipertensão arterial. Primeiro, aumento da sensibilidade à agentes vasoconstritores e, segundo, redução do relaxamento induzido por acetilcolina (Davel et al., 2011). Estas mudanças têm sido observadas em numerosos modelos experimentais, tais como DOCA-sal (Callera et al., 2003; Cordellini et al., 1990; Fortes et al., 1990; Ko et al., 2007; Nunes et al., 2000; Somers et al., 2000; White et al., 1996), SHR (Konishi e Su, 1983; Virdis et al., 2009), hipertensão renovascular (Chen et al., 1990; Higashi et al., 2002), hipertensão induzida pela ouabaína (Cao et al., 2009; Wenceslau et al., 2010), entre outros.

Ao encontro dos trabalhos na literatura (Cordellini et al., 1990; Ko et al., 2007; Lima et al., 2009; Somers et al., 2000; White et al., 1996), no presente estudo também foram observadas alterações na função vascular, em artérias mesentéricas de resistência dos animais DOCA-sal, tanto em relação ao aumento da sensibilidade a agentes vasoconstritores quando na redução significativa do relaxamento induzido pela acetilcolina. Sabe-se que nesse modelo de hipertensão arterial, vários fatores podem colaborar com estas alterações: (1) prejuízo da síntese e/ ou biodisponibilidade do óxido nítrico e/ou aumento de fatores vasoconstritores derivado da COX (Adeagbo et al., 2005; Cordellini et al., 1990; Glosh et al., 2004; Ko et al., 2007; Somers et al., 2000; White et al., 1996); (2) aumento do influxo de $\mathrm{Ca}^{2+}$, o qual é abolido na presença de bloqueador de canal para $\mathrm{Ca}^{2+}$, do inibidor da $\mathrm{NAD}(\mathrm{P}) \mathrm{H}$ oxidase e do inibidor da COX (Glosh et al., 2004); (3) aumento de espécies reativas derivadas do oxigênio, principalmente o ânion superóxido (Callera et al., 2006), tendo como principais fontes a NAD(P)H oxidase (Beswick et al., 2001), a xantina oxidase e/ ou a mitocôndria (Viel et al., 2008); (4) redução da atividade Cu/Zn SOD (Wu et al., 2001); e (5) aumento de citocinas proinflamatórias, do fator de transcrição nuclear (NF-KB) (Beswick et al., 2001; Ko et al., 2007; Schiffrin, 2005). 
$\mathrm{Na}$ presente tese evidenciamos que o tratamento com rostafuroxina melhorou o relaxamento induzido pela acetilcolina, independente do agonista pré-contrátil utilizado em artérias mesentéricas de resistência dos animais DOCA-sal, sugerindo a participação da ouabaína endógena na disfunção endotelial nesse modelo experimental. Por outro lado, os relaxamentos induzidos pelo nitroprussiato de sódio e pela papaverina não foram diferentes entre os grupos, o que sugere que as alterações vasculares no relaxamento promovidos pela ouabaína endógena são dependentes do endotélio. Esse dado vai ao encontro do trabalho de Fortes et al. (1990), os quais demonstraram que em microvasos do leito mesentérico de animais DOCA-sal não ocorre alteração no relaxamento ao nitroprussiato de sódio e a papaverina quando comparado ao grupo controle (Fortes et al., 1990).

A disfunção endotelial em artérias mesentéricas de resistência promovida pela ouabaína endógena pode ser explicada, ao menos em parte, por redução da síntese de óxido nítrico, visto que a curva de relaxamento à acetilcolina na presença do L-NAME reduziu a resposta tanto nas artérias dos animais SHAM quando dos animais ROSTA e não alterou esta resposta nas artérias dos animais DOCA-sal. Além disso, corroborando este resultado a quantidade de óxido nítrico medida pela técnica de fluorescência utilizando o DAF-2 após o estímulo com acetilcolina é reduzida nas artérias dos animais DOCA-sal quando comparada ao SHAM e o tratamento com ROSTA aumenta a quantidade de óxido nítrico de maneira significativa. Estes dados indicam que a ouabaína endógena participa da redução de óxido nítrico nesse modelo de hipertensão arterial.

No presente estudo foi observado que a diminuição da participação do óxido nítrico é tanto via redução da síntese quanto da sua biodisponibilidade, pois o tratamento com rostafuroxina melhorou a expressão proteica da eNOS e de um importante fator antioxidante, a Cu/Zn-SOD, sugerindo aumento na quantidade e na disponibilidade do óxido nítrico. Ao encontro desses dados, em um trabalho recente, do nosso grupo, demonstrou que o tratamento crônico por 20 semanas com ouabaína promove prejuízo na função vascular, o qual está associado a aumento da degradação do óxido nítrico (Wenceslau et al., 2011). Além disso, Xavier et al. (2009) também observaram que ratos SHR tratados com ouabaína apresentam redução na biodisponibilidade do óxido nítrico em pequenas artérias.

É digno de nota que a redução no relaxamento à acetilcolina observada nas artérias dos animais DOCA-sal e a melhora desta resposta após o tratamento com 
rostafuroxina foram independentes do agonista pré-contrátil utilizado. Entretanto, há diferenças tanto na potência quanto na resposta máxima na resposta de relaxamento à acetilcolina entre os agonistas pré-contráteis utilizados. Assim, quando o agonista pré-contrátil era o mimético do tromboxano $A_{2}$ (U-46619) a resposta prejudicada à acetilcolina observada nos segmentos arteriais dos animais DOCA-sal foi revertida após o tratamento com ROSTA e, parcialmente revertida quando o agonista pré-contrátil utilizado era a noradrenalina ou a serotonina. A resposta para essa diferença ainda precisa ser elucidada, e merece maior atenção.

\subsection{Papel da ouabaína endógena sobre o estresse oxidativo}

$\mathrm{Na}$ presente tese embora a(s) pergunta(s) de como e qual(is) a(s) via(s)/mecanismo(s) a ouabaína está envolvida para promover redução do conteúdo proteico da eNOS e consequentemente diminuição na síntese do $\mathrm{NO}$ em artérias mesentéricas de resistência de animais DOCA-sal ainda está(ão) sem resposta(s), a pergunta de como a ouabaína promove redução da biodisponibilidade do NO culminando assim, em redução do relaxamento à acetilcolina, foi, em parte e, inicialmente, esclarecida.

Sob certas circunstâncias, como na hipertensão arterial, a degradação do NO é aumentada na presença de níveis excessivos de ânion superóxido $\left(\mathrm{O}_{2}{ }^{-\cdots}\right)$ (Rubanyi e Vanhoutte, 1986; Touyz, 2004), a qual pode aumentar a resposta vasoconstritora e/ou reduzir à vasodilatadora. No modelo de hipertensão DOCA-sal já foi demonstrado aumento de espécies reativas derivadas do oxigênio, principalmente o $\mathrm{O}_{2}{ }^{-1}$ (Callera et al., 2003;2006; Viel et al., 2008; Wu et al., 2001), tendo como principais fontes a $\mathrm{NAD}(\mathrm{P}) \mathrm{H}$ oxidase (Beswick et al., 2001), a xantina oxidase e a mitocôndria (Viel et al., 2008). Além disso, o aumento de $\mathrm{O}_{2}{ }^{-1}$ também foi associado à redução do sistema antioxidante, como a Cu/Zn-SOD (Wu et al., 2001). Inibição da geração de espécies reativas derivadas do oxigênio (ROS) com apocinina (inibidor da $N A D(P) H)$ ou alopurinol (inibidor da xantina oxidase) e o uso de "sequestradores" de ROS previnem o desenvolvimento de hipertensão arterial em vários modelos experimentais, incluindo o DOCA-sal (Elhaïmeur et al., 1973; Jiménez et al., 2007; Touyz, 2004).

Assim, como na literatura, na presente tese foi observado estresse oxidativo sistêmico e tecidual nos animais DOCA-sal. De maneira interessante, o tratamento 
com rostafuroxina reduziu tanto a peroxidação lipídica, a qual ocorre na presença de espécies reativas derivada do oxigênio, observada pela técnica do TBARS quanto à quantidade de ânion superóxido presente nas artérias mesentéricas de resistência. No presente estudo, também foi observado que o relaxamento à acetilcolina em artérias mesentéricas de resistência na presença do varredor do ânion superóxido, o TIRON, melhora de maneira significativa nas artérias dos animais DOCA-sal, enquanto que não altera esta resposta nas artérias do grupo SHAM e ROSTA, o que sugere a participação da ouabaína na geração de ânion superóxido. Reforçando este dado, observamos que a fluorescência emitida pela oxidação da DHE em cortes transversais de artérias mesentéricas de resistência foi significativamente maior no grupo DOCA-sal quando comparado ao grupo SHAM e o tratamento com rostafuroxina reverte este resultado. Cabe ressaltar que não houve diferença no relaxamento induzido pela acetilcolina entre as artérias dos grupos DOCA e ROSTA quando incubadas com catalase, descartando a participação do peróxido de hidrogênio na disfunção endotelial induzida pela ouabaína.

De acordo com a teoria de Xie e Cai (2003) no signalosoma há ativação da cSrc pela ouabaína e sabe-se que a cSRC induz a geração de ROS, principalmente via ativação da $p 47^{\text {phox }}$ e da proteína $G$ pequena (Rac), subunidades da $N A D(P) H$ oxidase (Clempus e Griendling, 2006; Seshiah et al., 2002). Também, as espécies reativas derivadas do oxigênio ativam a cSrc, sendo, assim uma retroalimentação positiva (Clempus e Griendling; 2006).

Aizman et al. (2001) demonstraram que baixa concentração de ouabaína promove oscilação de $\mathrm{Ca}^{2+}$ o que leva à formação de ROS. De acordo com estes resultados, Valente et al. (2003) identificaram $\mathrm{O}_{2}{ }^{-\cdots}$ como uma das ROS formado pelo tratamento com ouabaína em células epiteliais de rim de cães.

Desta forma, baseado no dado da presente tese é plausível concluir que a interação ouabaína- $\mathrm{Na}^{+} \mathrm{K}^{+} \mathrm{ATPase}$ via fosforilação da cSRC em tirosina 418 induz a síntese de ânion superóxido.

Assim, a disfunção endotelial promovida pela ouabaína endógena observada nos animais DOCA-sal é, em parte, por uma menor modulação nitrérgica, tanto pela síntese quanto pela disponibilidade de NO, via: (1) redução da expressão proteica na eNOS; (2) redução da expressão proteica da Cu/Zn-SOD e (3) aumento de ânion superóxido. 
As ROS vasculares são produzidas em células endoteliais, adventícia, e no músculo liso, as quais são derivadas principalmente da $\mathrm{NAD}(\mathrm{P}) \mathrm{H}$ oxidase, enzima que catalisa a produção de $\mathrm{O}_{2}^{-*}$ pela redução do oxigênio usando $\mathrm{NAD}(\mathrm{P}) \mathrm{H}$ como doador de elétron (Touyz, 2004). Os homólogos (família da NOX) da NAD(P)H oxidase de fagócitos encontrados no músculo liso vascular e no endotélio são NOX-

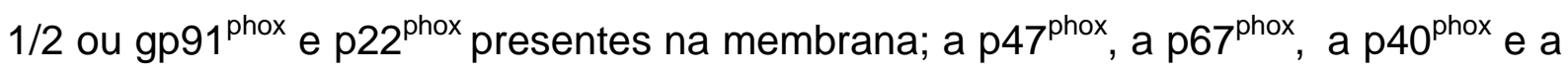
pequena proteína G (RAC) presentes no citoplasma (Bedard e Krause; 2007). A fosforilação da $\mathrm{p} 47^{\text {phox }}$ leva a interação com a p40 ${ }^{\text {phox }}$ e com a p67 $7^{\text {phox }}$ os quais são translocados até a membrana interagindo com a NOX-1/2 e p22 ${ }^{\text {phox }}$ para a geração de ânion superóxido (Bedard e Krause; 2007).

O que torna a $\mathrm{NAD}(\mathrm{P}) \mathrm{H}$ oxidase tão importante na função vascular é a sua capacidade de resposta a uma variedade de agonistas, como sua ativação pela angiotensina-Il (Griendling et al., 2000; Touyz, 2004).

No modelo DOCA-sal o aumento de $\mathrm{O}_{2}{ }^{-*}$ vascular está associado com aumento da expressão da p22 ${ }^{\text {phox }}$ (Beswick et al., 2001; Griendling et al., 2000). Beswick et al. (2001) demonstraram que em aorta de animais DOCA-sal ocorre aumento da síntese de $\mathrm{O}_{2}{ }^{-\cdots}$ proveniente da $\mathrm{NAD}(\mathrm{P}) \mathrm{H}$ oxidase e que o tratamento com apocinina (inibidor da $\mathrm{NAD}(\mathrm{P}) \mathrm{H}$ oxidase, o qual atua no bloqueio da migração da subunidade $\mathrm{p} 47^{\text {phox }}$ do citoplasma para a membrana (Touyz, 2008)) atenuou a pressão arterial sistólica dos animais DOCA-sal.

$\mathrm{Na}$ presente tese, o relaxamento induzido pela acetilcolina, na presença de apocinina melhorou significativamente em artérias dos animais DOCA-sal, enquanto que não alterou a resposta em artérias do grupo SHAM e do grupo ROSTA. Além disso, confirmando esses dados, o tratamento agudo com apocinina dos cortes das artérias mesentéricas de resistência de animais DOCA-sal reduziu a fluorescência emitida pela oxidação do DHE. Também, a aumentada expressão proteica da NOX$1 / 2$ e da $p 47^{\text {phox }}$ observada em artérias do grupo DOCA-sal foi revertida após 0 tratamento com rostafuroxina. Esses dados, em conjunto, sugerem que a $N A D(P) H$ é, ao menos em parte, a fonte geradora das ROS nesse modelo de hipertensão arterial e que a ouabaína endógena está envolvida na sua ativação.

Até o presente momento, não há dados na literatura demonstrando ativação da $\mathrm{NAD}(\mathrm{P}) \mathrm{H}$ oxidase pela ouabaína, entretanto se sabe que a cSRC ativa $\mathrm{p} 47^{\text {phox }} \mathrm{e}$ a proteína $\mathrm{G}$ pequena (Rac), subunidades da $\mathrm{NAD}(\mathrm{P}) \mathrm{H}$ oxidase (Clempus e Griendling, 2006; Seshiah et al., 2002), assim é aceitável conjecturar que a interação 
ouabaína- $\mathrm{Na}^{+} \mathrm{K}^{+} \mathrm{ATPase}$ ativa a $\mathrm{NAD}(\mathrm{P}) \mathrm{H}$ oxidase via cSRC. Além disso, fatores intermediários, os quais são ativados pela ouabaína como a endotelina-1 (Di Filippo et al., 2003) e a angiotensina-Il (Padilha et al., 2004) local, possam também estar envolvidos na ativação da $\mathrm{NAD}(\mathrm{P}) \mathrm{H}$ oxidase. Visto que, já foi demonstrado que esses dois componentes estão presentes no modelo de hipertensão DOCA-sal (Schiffrin, 2005; Xu et al., 2010), ambos promovem a ativação da NAD(P)H oxidase (Schiffrin, 2005) e, finalmente, ambos participam da gênese e manutenção da hipertensão arterial promovida pela ouabaína (Di Filippo et al., 2003; Huang e Leenen., 1999; Xavier et al., 2004 b,c).

Sabe-se que na hipertensão arterial ocorre aumento de prostanóides vasoconstritores derivados tanto da COX-1 quanto da COX-2 (Cordellini et al., 1988; Vanhoutte et al., 2005). Em ratos Wistar e SHR tratados cronicamente com ouabaína a disfunção endotelial está associada ao aumento de tromboxano $\mathrm{A}_{2}$ e/ ou prostaglandina $\mathrm{H}_{2}$ e da expressão proteica da COX-2 e não alteração da expressão proteica COX-1 (Xavier et al. 2009; Wenceslau et al., 2011). No modelo de hipertensão DOCA-sal a incubação do antagonista do receptor TP em anéis de aorta com o endotélio intacto abole o tônus miogênico ao passo que o inibidor da trombaxano $A_{2}$ sintase não tem efeito sobre esse mecanismo (Glosh et al., 2004).

$\mathrm{Na}$ presente tese foi observado aumento do tromboxano $A_{2}$ no sobrenadante de artérias mesentéricas de resistência após o estímulo com acetilcolina nos três grupos estudados. Entretanto, o aumento foi maior no grupo DOCA-sal e não foi revertido pelo tratamento com ROSTA. Porém, de maneira interessante, o conteúdo proteico da trombaxano $A_{2}$ sintase é reduzido em artérias dos animais DOCA-sal e ROSTA quando comparado ao SHAM. Nós ainda não temos uma explicação plausível para este dado, no entanto, como hipótese, é possível que o aumento da trombaxano $A_{2}$ possa, como retroalimentação negativa, reduzir a expressão proteica da trombaxano $A_{2}$ sintase.

Também, de maneira interessante, foi observado no presente estudo aumento da expressão proteica da COX-1 e não alteração da COX-2 em artérias do grupo DOCA-sal comparado ao grupo SHAM. Esse dado vai ao encontro do trabalho de Welch et al. (2007) os quais demonstraram que na hipertensão arterial dependente de volume a COX-1, mas não a COX-2, promove aumento da síntese de tromboxano $\mathrm{A}_{2}$ e participa das complicações do processo hipertensivo. Já, Callera et al. (2006) demonstraram aumento da expressão proteica da COX-2 em aorta de 
ratos DOCA-sal. No presente estudo o tratamento com rostafuroxina não modificou essas respostas. Esses dados sugerem que a via de síntese de tromboxano $A_{2}$, provavelmente é dependente da COX-1 no modelo de hipertensão DOCA-sal. Entretanto, a estimulação dessa via é independente do aumento da ouabaína endógena, visto que o tratamento com rostafuroxina não alterou nenhum desses parâmetros.

Por outro lado, como observado na presente tese, o relaxamento a acetilcolina em artérias do grupo DOCA-sal melhora significativamente após a incubação com o inibidor específico da COX-2, o que não acontece nas artérias do grupo SHAM e do grupo ROSTA. Esses dados demonstram a participação da ouabaína endógena na disfunção endotelial via ativação da COX-2 nas artérias do grupo DOCA-sal. Além disso, também sugere-se que a disfunção endotelial dependente de ouabaína via COX-2 é independente do aumento da síntese de tromboxano $\mathrm{A}_{2}$.

Já foi demonstrada que a COX-2 também pode ser uma fonte geradora de ânion superóxido (Hernanz et al., 2004). Trabalho anterior de nosso grupo evidenciou que 0 tratamento crônico com ouabaína por 20 semanas promove aumento de ânion superóxido via COX-2 em artérias mesentérica de resistência (Wenceslau et al., 2011). Neste sentido, na presente tese observamos que a fluorescência ao DHE em cortes transversais de artérias de resistência do grupo DOCA-sal foi reduzida após a incubação com o inibidor específico da COX-2 e não alterada em cortes arteriais do grupo SHAM e ROSTA. Estes dados sugerem que, em associação com a NAD(P)H oxidase, a COX-2 como fonte geradora de ROS na dependência da ouabaína endógena. Também, a partir desse dado, conclui-se que a disfunção endotelial dependente de COX-2 é via a síntese de ROS e não de prostanóides vasoconstritores. É possível sugerir que o aumento da geração de ROS via COX-2 é devido ao aumento de sua atividade, visto que, não foi observado alteração na expressão proteica desta enzima nos três grupos avaliados. Porém, são necessários mais estudos sobre tal hipótese. Cabe ressaltar que a administração do inibidor específico da COX-1 não alterou a fluorescência ao DHE em cortes de artérias dos do grupo DOCA-sal e ROSTA o que sugere que não há participação desta enzima na geração de ROS neste modelo de hipertensão arterial.

Tem sido demonstrado que em determinadas condições patológicas, como hipertensão arterial, a óxido nítrico sintase (NOS) passa a contribuir para a geração 
de ROS, essa situação é devido a um desacoplamento da NOS (Förstermann e Münzel, 2006). Landmesser et al. (2003) demonstraram que na hipertensão arterial DOCA-sal ocorre significante aumento da geração de ROS via NOS desacoplada devido a oxidação do cofator tetrahydrobiopterina. No presente estudo, a incubação com L-NAME em cortes de artérias mesentéricas de resistência de ratos DOCA-sal e DOCA-sal tratados com rostafuroxina não modificou a fluorescência. Esse dado sugere que a NOS, assim como a COX-1, não participa da geração de ROS nesse modelo de hipertensão arterial.

\subsection{Papel da ouabaína endógena sobre a função vascular: contração vascular}

A contração independente de receptor promovida por altas concentrações de $\mathrm{KCl}$, a qual estava prejudicada em artérias dos animais DOCA-sal, foi revertida nos animais tratados com rostafuroxina. Esse dado ainda é intrigante, visto que em animais hipertensos pelo tratamento crônico com ouabaína não ocorre alteração na contração ao KCl independente do leito estudado (Hernanz et al., 2008; Rossoni et al., 2002a,b; Padilha et al., 2008; Wenceslau et al., 2011; Xavier et al., 2004a,b,c). Giulumian et al., (1998) demonstraram que tanto em coronária quanto em artérias mesentéricas de resistência de animais DOCA-sal ocorre prejuízo na contração ao $\mathrm{KCl}$ e que o tratamento crônico com o antagonista do receptor $\mathrm{ET}_{\mathrm{A}}$ melhora essa resposta (Giulumian et a., 1998). De encontro com esses dados, Soltis e Field (1986) demonstraram que em artéria femoral de animais DOCA-sal ocorre aumento da contratilidade ao $\mathrm{KCl}$. Esses autores sugerem que essa alteração é devido ao aumento da sensibilidade das proteínas contráteis ao $\mathrm{Ca}^{2+}$, pois quando foi retirado $\mathrm{Ca}^{2+}$ do meio extracelular e as artérias foram expostas novamente a altas concentrações de $\mathrm{KCl}$, houve uma redução da resposta contrátil tanto para o SHAM quanto para o DOCA-sal, porém a redução foi maior no grupo DOCA-sal (Soltis e Field; 1986). Já, Johnson et al. (2002) demonstraram que a curva concentração resposta ao $\mathrm{KCl}$ foi similar em vasos de animais DOCA-sal e SHAM. Desta forma, ainda é necessário experimentos mais específicos para melhores explicações do por que e/ou como a ouabaína altera essa resposta.

Ao encontro dos dados disponíveis na literatura, no presente estudo, a hipertensão DOCA-sal promoveu aumento da contração à noradrenalina. Cordellini 
et al., (1988) demonstraram que em DOCA-sal ambos macro e micro vasos apresentam aumento na resposta contrátil à noradrenalina. De acordo, Adeagbo et al. (2005) observaram que a resposta contrátil aumentada induzida por noradrenalina em aorta é dependente do endotélio, visto que a remoção da camada endotelial eliminou a diferença de resposta entre o grupo SHAM e DOCA-sal. Ambos os trabalhos de Cordellini et al., (1999) e de Adeagbo et al. (2005) observaram o envolvimento de fatores vasoconstritores derivados da COX.

Além dos fatores vasoconstritores derivados da COX, outros agentes vasoconstritores também estão alterados na hipertensão arterial. Assim, no modelo DOCA-sal a endotelina-1 (Giulumian et al., 1998), a angiotensina-II local (Rodrigues e Granger, 2012), as ROS (Somers ate al., 2000) e os fatores inflamatórios (Ko et al., 2007) participam do dano na função e estrutura vascular. Esses fatores não induzem somente vasoconstrição, mas possuem propriedades pro-inflamatória, hipertrófica e profibrótica (Ko et al., 2007; Schiffrin, 2005).

De maneira interessante, observamos que o tratamento com rostafuroxina não alterou a hiperreatividade à noradrenalina em artérias mesentéricas de resistência dos animais DOCA-sal. Esse resultado vai de encontro a alguns trabalhos, os quais demonstram o papel da ouabaína na alteração à resposta contrátil em diferentes leitos vasculares. Nesse sentido, Rossoni e colaboradores (2002a,b) explorando o modelo experimental de hipertensão arterial induzida pela ouabaína observaram que o tratamento por 5 semanas com este glicosídeo reduz a resposta vasoconstritora à agonistas $\alpha_{1}$-adrenérgicos em vasos de condutância. Estudos subsequentes do grupo da Dra. Rossoni indicaram que a função vascular alterada na hipertensão arterial induzida pela ouabaína é dependente do tempo e do leito vascular estudado (Wenceslau et al., 2011; Xavier et al., 2004b). Assim, enquanto 5 e 10 semanas de tratamento com ouabaína não ocorre alteração na contração induzida por noradrenalina em artérias mesentéricas de resistência (Wenceslau et al., 2011; Xavier et al., 2004b), após 20 semanas de tratamento a contração a noradrenalina é significativamente aumentada. Esta resposta foi correlacionada com declínio do $\mathrm{NO}$ e aumento de fatores vasoconstritores derivados da COX-2 (Wenceslau et al., 2011). Adicionalmente, Xavier et al. (2004c) demonstraram que a hipertensão arterial induzida pela ouabaína por 5 semanas promove aumento na expressão do RNA mensageiro da pre-pro-endotelina e do receptor $\mathrm{ET}_{\mathrm{A}}$ em aorta. 
Com as evidências descritas acima, não se descarta a possibilidade de que a ouabaína participe na liberação de fatores vasoconstritores nesse modelo de hipertensão arterial. Essa inferência é baseada em trabalhos ao quais demonstraram que a ouabaína promove alterações vasculares na dependência do tempo e do leito estudado (Briones, et al., 2006; Cao et al.,2009; Hernanz et al.,2008; Padilha et al., 2004,2008; Rossoni et al., 2002a,b; Wenceslau et al., 2011; Xavier et al., 2004a,b,c). Assim, é possível que tratamento preventivo ou terapêutico mais prolongado (acima de três semanas) seja capaz de melhorar a vasoconstrição aumentada nesse modelo.

A concentração de íons $\mathrm{Ca}^{+2}$ nas células do músculo liso vascular é um fator crucial para iniciar e manter a contração vascular. Há duas fontes fisiológicas para suprir o $\mathrm{Ca}^{+2}$ na célula do músculo liso vascular: o $\mathrm{Ca}^{+2}$ do meio extracelular e o $\mathrm{Ca}^{2+}$ proveniente de estoques intracelulares (Clapham, 2007).

Já está estabelecido na literatura que a concentração intracelular do $\mathrm{Ca}^{+2}$ está alterada na hipertensão arterial (Blaustein et al., 1998; Kim et al., 1997). Neste sentido, Kim et al. (1997) demonstraram que em aorta de animais DOCA-sal ocorre aumento de $\mathrm{Ca}^{+2}$ no retículo sarcoplasmático devido a redução da atividade da $\mathrm{Na}^{+} \mathrm{K}^{+}$-ATPase. Esses autores sugerem que a redução da atividade desta enzima é devido ao aumento das concentrações de ouabaína plasmática neste modelo de hipertensão arterial.

O mecanismo pelo qual a ouabaína pode aumentar $\mathrm{Ca}^{+2}$ no retículo sarcoplasmático e sensibilizar o músculo liso vascular a agentes vasoconstritores pode ser explicado, em parte, de acordo com a teoria, baseada em fatos, proposta por Blaustein et al. (1998) via ação da ouabaína inibindo preferencialmente as isoformas $\alpha_{2}$ e $\alpha_{3}$ da $\mathrm{Na}^{+} \mathrm{K}^{+}$-ATPase na microrregião da membrana plasmática denominada de plasmerosome.

Blaustein et al. (1998) identificaram uma microrregião celular entre a membrana plasmática e a membrana do retículo sarcoplasmático, denominada, por esses autores, plasmerosome, onde estão localizados o trocador $\mathrm{Na}^{+} / \mathrm{Ca}^{+2}$, o retículo sarcoplasmático e as isoformas $\alpha_{2}$ e $\alpha_{3}$ da $\mathrm{Na}^{+} \mathrm{K}^{+}$-ATPase. Nesta microrregião, os compostos digitálicos, como a ouabaína, possuem uma importante função sobre a mobilização de $\mathrm{Ca}^{2+}$ intracelular. A ouabaína ao inibir as subunidades $\alpha_{2}$ e $\alpha_{3}$ da $\mathrm{Na}^{+} \mathrm{K}^{+}$-ATPase aumenta a concentração de $\mathrm{Na}^{+}$intracelular nesse microdomínio 
específico, o que resulta na redução da atividade do trocador $\mathrm{Na}^{+} / \mathrm{Ca}^{+2}$ e consequente aumento da concentração dos íons $\mathrm{Ca}^{+2}$ livre no interior da célula. Esse $\mathrm{Ca}^{+2}$ é captado pela $\mathrm{Ca}^{+2}$-ATPase do retículo sarcoplasmático e estocado no interior dessa organela citoplasmática. Desta forma, após o estímulo de um agonista vasoconstritor como a noradrenalina, a resposta contrátil resultante seria amplificada em consequência de maior liberação de $\mathrm{Ca}^{+2}$ pelo retículo sarcoplasmático. Esse mecanismo ajuda a explicar, em parte, como concentrações nanomolares de ouabaína podem amplificar a resposta a um agente vasoconstritor e representa um mecanismo adicional por meio do qual a ouabaína endógena pode contribuir para o processo hipertensivo.

A partir dos indícios acima descritos, avaliou-se o papel do $\mathrm{Ca}^{+2}$ intracelular $\mathrm{e}$ extracelular na resposta vasoconstritora à noradrenalina e ambos foram alterados na hipertensão DOCA-sal. Esses resultados corroboram o trabalho de Kim et al., (1997) os quais demonstraram que nesse modelo de hipertensão arterial ocorre aumento dos estoques de $\mathrm{Ca}^{+2}$ no retículo sarcoplasmático. Entretanto, o tratamento com rostafuroxina não alterou este parâmetro, o que confirma o dado observado da atividade da $\mathrm{Na}^{+} \mathrm{K}^{+}$-ATPase.

Esses resultados vão de encontro com a teoria de Blaustein et al. (1998), desde que a ouabaína em concentrações nanomolares atua principalmente em aumentar $\mathrm{Ca}^{+2}$ do retículo sarcoplasmático via inibição da $\mathrm{Na}^{+} \mathrm{K}^{+}$-ATPase. Porém, são necessários experimentos mais específicos que avaliem a sensibilidade de liberação de $\mathrm{Ca}^{+2}$ do retículo, como uma curva concentração a cafeína (Kim et al., 1997) e experimentos que quantifiquem, por imagem, a real concentração de $\mathrm{Ca}^{+2}$ no retículo sarcoplasmático. Assim, é possível confirmar ou não a real atuação da ouabaína endógena sobre os estoques do retículo sarcoplasmático em artérias mesentérica de resistência no modelo DOCA-sal.

Com relação à melhora do influxo de $\mathrm{Ca}^{+2}$ pelo tratamento com rostafuroxina observada no presente estudo, muitas questões ainda estão em aberto. Mas é digno de nota que na hipertensão arterial ocorre alteração tanto da sensibilidade das proteínas contráteis ao $\mathrm{Ca}^{+2}$ quanto do número de canais para $\mathrm{Ca}^{+2}$ promovendo aumento das concentrações intracelulares desse íon e culminando em aumento da contração (Morel e Godfraind, 1994; Shibuya et al., 1998). Watts et al. (2003) demonstraram aumento do influxo de $\mathrm{Ca}^{2+}$ via aumento da atividade do canal para $\mathrm{Ca}^{2+}$ do tipo $\mathrm{L}$ em artérias mesentéricas de ratos DOCA-sal. Além disso, já foi 
demonstrado em aorta de animais SHR a endotelina-1 está envolvida na hiperatividade de canais para $\mathrm{Ca}^{+2}$, desde que $\mathrm{BQ}-123$ (antagonista do receptor $\mathrm{ET}_{\mathrm{A}}$ ) diminui a sensibilidade ao Bay K 8644 (ativador de canal para $\mathrm{Ca}^{+2}$ do tipo L) para valores menores que o controle (Morel e Godfraind, 1994). Entretanto, os experimentos para elucidar o papel da ouabaína endógena sobre a cinética do $\mathrm{Ca}^{+2}$, tanto via sensibilidade das proteínas contráteis quanto o influxo de $\mathrm{Ca}^{+2}$, merecem maiores considerações. 


\section{CONCLUSÃO}

Baseado nos resultados da presente tese é possível concluir que a ouabaína, via ação sobre o sistema cardiovascular, participa na manutenção da hipertensão arterial no modelo DOCA-sal.

A ouabaína endógena interage com a $\mathrm{Na}^{+} \mathrm{K}^{+} \mathrm{ATPase}$ e ativa uma cascata de sinalização via cSRC o que promove hiperatividade simpática, estresse oxidativo via $\mathrm{NAD}(\mathrm{P}) \mathrm{H}$ oxidase e COX-2, redução da síntese e biodisponibilidade de $\mathrm{NO}$ o que gera disfunção endotelial no modelo de hipertensão arterial DOCA-sal. Estas alterações em conjunto contribuem para a manutenção da elevada pressão arterial neste modelo de hipertensão arterial. Assim, sugere-se que a ouabaína possa ser um possível alvo para o tratamento da hipertensão arterial dependente de volume. 


\section{REFERÊNCIAS*}

Aarhus LL, Shepherd JT, Tyce GM, Verbeuren TJ, Vanhoutte PM. Contractions of canine vascular smooth muscle cells caused by ouabain are due to release of norepinephrine from adrenergic nerve endings. Circulation Research, 1983;52(5):501-507.

Adeagbo AS, Zhang X, Patel D, Joshua IG, Wang Y, Sun X, Igbo IN, Oriowo MA. Cyclo-oxygenase-2, endothelium and aortic reactivity during deoxycorticosterone acetate salt-induced hypertension. Journal of Hypertension, 2005;23(5):1025-1036.

Aizman $\mathrm{O}$, Uhlén $\mathrm{P}$, Lal $\mathrm{M}$, Brismar $\mathrm{H}$, Aperia A. Ouabain, a steroid hormone that signals with slow calcium oscillations. Proceedings of the National Academy of Sciences, 2001;98:13420-13424.

Ambard L, Beaujard E. Causes de I' hypertension artérielle. Archives of General Medicine, 1904;1:520-533.

Antunes VR, Yao ST, Pickering AE, Murphy D, Paton JF. A spinal vasopressinergic mechanism mediates hyperosmolality-induced sympathoexcitation. The Journal of Physiology, 2006;576(Pt 2) :529-583.

Bauer N, Müller-Ehmsen J, Krämer U, Hambarchian N, Zobel C, Schwinger RHG, Neu H, Kirch U, Grünbaum, Schoner W. Ouabain-like compound changes rapidly on physical exercise in humans and dogs: effects of b-blockade and angiotensinconverting enzyme inhibition. Hypertension, 2005;45:1024-1028.

Bedard K, Krause KH. The NOX family of ROS-generating NADPH oxidases: physiology and pathophysiology. Physiology Reviews, 2007;87:245-313.

Beswick RA, Dorrance AM, Leite R, Webb R.C. (2001). NADH/NADPH oxidase and enhanced superoxide production in the mineralocorticoid hypertensive rat. Hypertension, 2001;38:1107-1111.

Blaustein MP. Physiological effects of endogenous ouabain: control of intra-celular $\mathrm{Ca}^{2+}$ stores and cell responsiveness. American Journal of Physiology, 1993;264:C1367-C1387.

Blaustein MP, Juhaszova M, Golovina VA. The cellular mechanism of action of cardiotonic steroids: A new hypothesis. Clinical and Experimental Hypertension, 1998;20:691-703.

Briones AM, Xavier FE, Arribas SM, Gonzalez MC, Rossoni LV, Alonso MJ, Salaices $M$. Alterations in structure and mechanics of resistance arteries from ouabain induced hypertensive rats. American Journal Physiology, 2006;291:H193-H201.

\footnotetext{
${ }^{\star}$ De acordo com:

International Committee of Medical Journal Editors. Uniform requeriments for manuscripts submitted to Biomedical Journal: sample references. Available from:http://www.icmje.org [2007 May 22].
} 
Briones AM, Padilha AS, Cogolludo AL, Alonso MJ, Vassallo DV, Pérez-Vizcaino F, Salaices M. Activation of BKCa channels by nitric oxide prevents coronary artery endothelial dysfunction in ouabain-induced hypertensive rats. Journal of Hypertension, 2009;27(1):83-91.

Bova S, Blaustein MP, Ludens JH, Harris DW, DuCharme DW, Hamlyn JM. Effects of an endogenous ouabainlike compound on heart and aorta. Hypertension, 1991;17:944-950.

Budzikowski AS, Leenen FH. Brain 'ouabain' in the median preoptic nucleus mediates sodium-sensitive hypertension in spontaneously hypertensive rats. Hypertension, 1997;29:599-605.

Budzikowski AS, Leenen FH. ANG II in median preoptic nucleus and pressor responses to CSF sodium and high sodium intake in SHR. Americam Journal of Physiology. Heart and Circulatory Physiology, 2001;281:H1210-H1216.

Callera GE, Touyz RM, Teixeira AS, Muscara MN, Carvalho MHC, Fortes ZB, Nigro $D$, Schiffrin LE, Tostes RC. ETA receptor blockade decreases vascular superoxide generation in DOCA-SAL-salt hypertension. Hypertension, 2003;42(Pt2):1-7.

Callera GE, Tostes RC, Yogi A, Montezano AC, Touyz RM. Endothelin-1-induced oxidative stress in DOCA-salt hypertension involves NADPH-oxidase-independent mechanisms. Clinical Science, 2006;110(2):243-253.

Calhoun DA, Jones D, Textor S, Goff DC, Murphy TP, Toto RD, White A, Cushman WC, White W, Sica D, Ferdinand K, Giles TD, Falkner B, Carey RM. Resistant hypertension: diagnosis, evaluation, and treatment: a scientific statement from the american heart association professional education committee of the council for high blood pressure research. Hypertension, 2008;51:1403-1419.

Cao C, Payne K, Lee-Kwon W, Zhang Z, Lim SW, Hamlyn J, Blaustein MP, Kwon HM, Pallone TL. Chronic ouabain treatment induces vasa recta endothelial dysfunction in the rat. American Journal of Physiology, 2009;296(1):F98-F106.

Carneiro FS. Efeito da vitamina E sobre a reatividade vascular e o comportamento leucocitário em ratos hipertensos DOCA-sal [dissertação (Mestrado em Farmacologia)]. Instituto de Ciências Biomédicas, Universidade de São Paulo, São Paulo; 2006.

Chen M, Webb RC, Malvin RL. Naloxone prevents increased vascular sensitivity in Goldblatt hypertensive rats. Clinical and Exeperimental Hypertension. Theory and Practice, 1990;12(8):1361-1376.

Clinical trial database. Efficacy of rostafuroxin in the treatment of essential hypertension. Available from: <http://clinicaltrials.gov/ct2/show/NCT00415038>. Cited from 2010 July 2010. 
Clapham DE. Calcium signaling. Cell, 2007;131(6):1047-1058.

Cordellini S, Nigro D, Carvalho MH, Fortes ZB, Scivoletto R. Reactivity of macro- and microvessels of DOCA-salt hypertensive rats: role of the endothelial cell. Brazilian Journal of Medical and Biological research, 1988;21(4):845-849.

Cordellini S, Carvalho MHC, Scivolleto R, Fortes ZB, Nigro D. Indirect evidence for an endothelium-derived contracting factor release in aorta of deoxicorticosterone acetate-salt hypertensive rats. Journal of Hypertension, 1990;8:53-60.

Cordellini S. Endothelial dysfunction in DOCA-salt hypertension: possible involvement of prostaglandin endoperoxides. General Pharmacology, 1999;32(3):315-320.

Dahl LK, Knudsen KD, and Iwai J. Humoral transmission of hypertension: evidence from parabiosis. Circulation Research, 1969;24 Suppl 5:21-33.

Dahlöf B , Devereux RB, Kjeldsen SE, Julius S, Beevers G, Faire U, Fyhrquist F, Ibsen H, Kristiansson K, Lederballe-Pedersen O, Lindholm LH, Nieminen MS, Omvik $\mathrm{P}$, Oparil S, Wedel H. Cardiovascular morbidity and mortality in the Losartan Intervention For Endpoint reduction in hypertension study (LIFE): a randomised trial against atenolol. The Lancet, 2002;359:995-1003.

Dai X, Cao X, Kreulen DL. Superoxide anion is elevated in sympathetic neurons in DOCA-salt hypertension via activation of NADPH oxidase. American Journal of Physiology. Heart and Circulatory Physiology, 2006;290:H1019-H1026.

D’Amico M, Di Filippo C, Piegari E, Rinaldi B, Rossi F, Filippelli A. ETA endothelin receptors are involved in the ouabain-induced haemodynamic effects in the periaqueductal gray area of rats. Life Sciences, 2003;72:2211-2218.

Davel AP, Wenceslau CF, Akamine E, Xavier FE, Couto GK, Rossoni. Endothelial dysfunction in cardiovascular and endocrine-metabolic diseases: an update. Brazilian Journal of Medical and Biological Research, 2011;44(9):920-932.

De Wardener HE, Mills IH, Clapham WF. Studies on the efferent mechanism of the sodium diuresis with follows administration of intravenous saline in dog. Clinical Science, 1961;21:249-258.

De Wardener HE e Clarkson EM. Concept of natriuretic hormone. Physiological Reviews, 1985;65:658-759.

Di Filippo C, Filippelli A, Rinaldi B, Piegari E, Esposito F, Rossi F, D'Amico M. Chronic peripheral ouabain treatment affects the brain endothelin system of rats. Journal of Hypertension, 2003;21:747-753.

Doris PA. Ouabain in plasma from spontaneously hypertensive rats. The American Journal of Physiology, 1994;266:(Pt 2)H360-H364. 
Dos Santos L, Xavier FE, Vassallo DV, Rossoni LV. Cyclooxygenase pathway is involved in the vascular reactivity and inhibition of the $\mathrm{Na}^{+}, \mathrm{K}^{+}$-ATPase activity in the tail artery from L-NAME-treated rats. Life Sciences, 2003;74:613-627.

Dostanic-Larson I, Van Huysse JW, Lorenz JN, Lingrel JB. The highly conserved cardiac glycoside binding site of Na,K-ATPase plays a role in blood pressure regulation Proceedings of the National Academy of Science of the United States of America, 2005;44:15845-15850.

Elhaïmeur F, Courderot-Masuyer C, Nicod L, Guyon C, Richert L, Berthelot A. Dietary vitamin C supplementation decreases blood pressure in DOCA-salt hypertensive male Sprague Dawley rats and this is associated with increased liver oxidative stress. Molecular and Cellular Biochemistry, 1973;237:77-83.

Esler M. The sympathetic system and hypertension. American Journal of Hypertension, 2000;13:99S-105S.

Ferrandi M, Molinari I, Barassi P, Minotti E, Bianchi G, Ferrari P. Organ hypertrophic signaling within caveolae membrane subdomains triggered by ouabain and antagonized by PST 2238. The Journal of Biological Chemestry, 2004;279(32):33306-33314.

Ferrari P, Ferrandi M, Minotti E, Duzzi L, Bianchi G. Effect of canrenone and hydrochlorothiazide on the development of hypetension in rat models of genetic hypertension. Journal of Hypertension, 1993;11 Suppl 5:S330-S331.

Ferrari P, Torielli L, Ferrandi M, Padoani G, Duzzi L, Florio M, Conti F, Melloni P, Vesci L, Corsico N, Bianchi G. PST2238: A New antihypertensive compound that antagonizes the long-term pressor effect of ouabain. The Journal of Pharmacology and Experimental Therapeutics, 1998;285:83-94.

Ferrari P, Ferrandi M, Torielli L, Tripodi G, Bianchi G. PST 2238: A New Antihypertensive Compound that modulates the Na-K Pump 'in Vivo' and 'in Vitro'. Hypertension Research, 2000;23 Suppl 2000:S15-S19.

Ferrari P, Ferrandi M, Valentini G, Bianchi G. Rostafuroxin: a ouabain antagonist that corrects renal and vascular $\mathrm{Na}^{+}-\mathrm{K}^{+}-$ATPase alterations in ouabain and adducindependent hypertension. American Journal of Physiology: Regulatory, Integrative and Comparative Physiology, 2006;290:R529-R535.

Ferrari P. Rostafuroxin: an ouabain-inhibitor counteracting specific forms of hypertension. Biochimica and Biophysica Acta, 2010;1802(12):1254-1258.

Folkow B, Grimby G, Thulesius O. Adaptive structural changes of the vascular walls in hypertension and their relation to the control of the peripheral resistance. Acta Acta Physiologica Scandinavica, 1958;44:255-272. 
Förstermann U, Münzel T. Endothelial Nitric Oxide Synthase in Vascular Disease : From Marvel to Menace. Circulation, 2006;113:1708-1714.

Fortes ZB, Nigro D, Scivoletto R, de Carvalho MH. Indirect evidence for an endothelium-derived contracting factor released in arterioles of deoxycorticosterone acetate salt hypertensive rats. Journal of Hypertension, 1990; 8(11):1043-8.

Giulumian AD, Pollock DM, Clarke N e Fuchs LC. Coronary vascular reactivity is improved by endothelin A receptor blockade in DOCA-salt hypertensive rats. American Journal of Physiology: Regulatory, Integrative and Comparative Physiology, 1998;274:R1613-R1618.

Ghosh M, Wang HD, McNeill JR. Role of oxidative stress and nitric oxide in regulation of spontaneous tone in aorta of DOCA-salt hypertensive rats. British Journal of Pharmacology, 2004;141:562-573.

Gottlieb SS, Rogowski AC, Weinberg M, Krichten CM, Hamilton BP, Hamlyn JM. Elevated concentration of endogenous ouabain in patientes with congestive heart failure. Circulation, 1992;86(2):420-425.

Griendling KK, Sorescu D, Ushio-Fukai M. NAD(P)H oxidase: role in cardiovascular biology and disease. Circulation Research, 2000;86:494-501.

Gruber KA, Whitaker JM, Buckalew VM. Endogenous digitalis-like substance in plasma of volume-expanded dogs. Nature, 1980;287:743-745.

Guyton AC, Coleman TG, Cowley AW, Scheel KW, Manning RD, Normn RA. Arterial pressure regulation overriding dominance of the kidneys in long-term regulation and in hypertension. American Journal of Medicine, 1972;52:584-594.

Hamilton BP, Manuta P, Laredo J, Hamilton JH, Hamlym JM. The new adrenal steroid hormone ouabain. Current Opinion in Endocrinology \& Diabetes, 1994;1:123131.

Hamlyn JM, Ringel R, Schaeffer J, Levinson PD, Hamilton BP, Kowarski AA, Blaustein MP. A circulating inhibitor of $(\mathrm{Na}+, \mathrm{K}+)$-ATPase associated with essential hypertension. Nature, 1982;300:650-652

Hamlyn JM, Harris DW, Ludens JH. Digitalis-like activity in human plasma: purification, affinity and mechanisms. Journal Biological and Chemistry, 1989;264:7395-7404.

Hamlyn JM, Hamilton BP, Manuta P. Endogenous ouabain, sodium balance and blood pressure: a review and a hypothesis. Journal of Hypertension, 1996;14:151171. 
Hamlyn JM, Laredo J, Shah JR, Lu ZR, Hamilton BP. 11-hydroxylation in the biosynthesis of endogenous ouabain: multiple implications. Annals of the New York Academy of Sciences, 2003;986:685-693.

Heringer-Walther S, Batista EN, Walther T, Khosla MC, Santos RAS, CampagnoleSantos MJ. Baroreflex improvement in SHR after ACE inhibition involves angiotensin(1-7). Hypertension, 2001;37:1309-1314.

Hernanz R, Briones AM, Martín A, Beltrán AE, Tejerina T, Salaices M, Alonso MJ. Ouabain treatment increases nitric oxide bioavailability and decreases superoxide anion production in cerebral vessels. Journal of Hypertension, 2008;26(10):19441954.

Hernanz R, Briones AM, Alonso MJ, Vila E, Sa laices M. Hy per t ension a It ers role of iNOS, COX-2, and oxidative stress in bradykinin relaxation impairment after LPS in rat cerebral arteries. American Journal of Physiology-Heart and Circulatory Physiology, 2004;258:H225-H234.

Higashi K, Sasaki S, Nakagawa K, Matsuura H, Oshima T, Chayama K. Endothelial Function and oxidative stress in renovascular hypertension. The New England Journal of Medicine, 2002;346:1954-1962.

Huang BS, Huang X, Harmsen E, Leenen FHH. Chronic central versus peripheral ouabain, blood pressure, and sympathetic activity in rats. Hypertension, 1994;23:1087-1090.

Huang BS, Leenen, FHH. Brain renin-angiotensin system and ouabain induced sympathetic hyperactivity and hypertension in wistar rats. Hypertension, 1999;34:107-112.

Huang BS, Ganten D, Leenen FHH. Responses to central Na+ and ouabain are attenuated in transgenic rats deficient in brain angiotensinogen. Hypertension, 2001;37:683-686.

Jacob F, Clark LA, Guzman PA, Osborn JW. Role of renal nerves in development of hypertension in DOCA-salt model in rats: a telemetric approach. American Journal of Hypertension, 2005;289:H1519-1529.

Jiang X, Ren YP, Lv ZR. Ouabain induces cardiac remodeling in rats independent of blood pressure. Acta Pharmacologica Sinica, 2007;28(3):344-352.

Jiménez R, López-Sepúlveda R, Kadmiri M, Romero M, Vera R, Sánchez M, Vargas F, O'Valle F, Zarzuelo A, Dueñas M, Santos-Buelga C, Duarte J. Polyphenols restore endothelial function in DOCA-salt hypertension: role of endothelin-1 and NADPH oxidase. Free Radical Biology \& Medicine, 2007;43:462-73 
Johnson RJ, Fink GD, Watts SW, Galligan JJ. Endothelin receptor function in mesenteric veins from deoxycorticosterone acetate salt-hypertensive rats. Journal of Hypertension, 2002;20(4):665-676.

Kaplan $\mathrm{JH}$. The sodium pump and hypertension: a physiological role for the cardiac glycoside binding site of the Na,K-ATPase. Proceedings of the National Academy of Science of the United States of America, 2005;44:15723-15724.

Kaplan NM. Clinical hypertension. 9 nd ed. Philadelphia: Williams \& Wilkins; 2006. p. 1.

Katholi R, Naftilan AJ, Oparil S. Importance of Renal Sympathetic Tone in the Development of DOCA-Salt Hypertension in the Rat. Hypertension, 1980;2:266-273.

Kempner W. Treatment of hypertensive vascular disease with rice diet. The American Journal of Medicine, 1948;4(4):545-577.

Kim WJ, Lee J, Park YH, Nam SC. Altered vascular calcium regulation in hypertension. Korean Journal of Physiology and Pharmacology, 1997;1:529-535.

Kimura K, Manunta P, Hamilton BP, Hamlyn JM. Different effects of in vivo ouabain and digoxin on renal artery function and blood pressure in the rat. Hypertension Research, 2000;23 Suppl 2000:67-76.

Ko EA, Amiri F, Pandey NR, Javeshghani D. Resistance artery remodeling in deoxycorticosterone acetate-salt hypertension is dependent o vascular inflammation: evidence from m-CSF-deficient mice. American Journal of Physiology Heart and Circulatory Physiology, 2007;292:H1789-H1795.

Kojima I, Yoshihara S, Ogata E. Involvement of endogenous digitalis-like substance in genesis of deoxycorticosterone-salt hypertension. Life Science, 1982;30(21):17751781.

Kojima I. Circulating digitalis-like substance is increased in DOCA-salt hypertension. Biochemical and Biophysical Research Communications, 1984;122:129-136.

Konishi M, Su C. Role of endothelium in dilator responses of spontaneously hypertensive rat arteries. Hypertension, 1983;5:881-886.

Kramer H, Gonick H, Paul W. Third factor: inhibitor of Na-K-ATPase? In: Proceedings of the Fourth International Congress on Nephrology. New York: Karger, 1969;373.

Kurashina T, Kirchner KA, Granger JP, Patel AR. Chronic sodium-potassium-ATPase inhibition with ouabain impairs renal haemodynamics and pressure natriuresis in the rat. Clinical Science, 1996;91:497-502.

Landmesser ULF, Dikalov S,1 Price SR, McCann L, Fukai T, Holland SM, Mitch WE, Harrison DG. Oxidation of tetrahydrobiopterin leads to uncoupling of endothelial cell 
nitric oxide synthase in hypertension. The Journal of Clinical Investigation, 2003; 111:1201-1209.

Laredo J, Shah JR, Lu ZR, Hamilton BP, Hamlyn JM. Angiotensin II stimulates secretion of endogenous ouabain from bovine adrenocortical cells via angiotensin type 2 receptor. Hypertension, 1997;29(Pt2):401-407.

Leenen $\mathrm{FHH}$. The brain and salt sensitive hypertension. Current Hypertension Reports, 2002;4:129-135.

Lima VV, Giachini FRC, Choi H, Carneiro FS, Carneiro ZN, Fortes ZB, Carvalho MHC, Webb RC, Tostes RC. Impaired vasodilator activity in DOCA-salt hypertension is associated with increased protein O-GlcNAcylation. Hypertension, 2009;53(2):16674.

Liu J, Tian J, Haas M, Shapiro JI, Askari A, Xie Z. Ouabain interaction with cardiac $\mathrm{Na} / \mathrm{K}$-ATPase initiates signal cascades independent of changes in intracellular $\mathrm{Na}$ and Ca2 concentrations. The Journal of Biological Chemistry, 2000;275:2783827844.

Liu L, Zhao X, Pierre SV, Askari A. Association of PI3K-Akt signaling pathway with digitalis-induced hypertrophy of cardiac myocytes. The American Journal of Physiology - Cell Physiology, 2007;293:C1489-C1497.

Ludens JH, Clark MA, Robinson FG, DuCharme DW. Rat adrenal cortex is a source of a circulanting ouabain-like compound. Hypertension, 1992;19:721-724.

Lüscher TF, Vanhoutte PM. Endothelium-dependent contractions to acetylcholine in the aorta of the spontaneously hypertensive rat. Hypertension, 1986;8:344-348.

Manunta P, Rogowski AC, Hamilton BP, Hamlyn JM. Ouabain-induced hypertension in the rat: relationships among plasma and tissue ouabain and blood pressure. Journal of Hypertension, 1994;12:549-560.

Manunta P, Hamlyn JM, Simonini M, Messaggio E, Lanzani C, Bracale M, Argiolas G, Casamassima N, Brioni E, Glorioso N, Bianchi G. Endogenous ouabain and the renin-angiotensin-aldosterone system: distinct effects on $\mathrm{Na}$ handling and blood pressure in human hypertension. Journal of Hypertension, 2011;29:349-356.

Moreira TS, Takakura AC, Colombari E. Important GABAergic mechanism within the NTS and the control of sympathetic baroreflex in SHR. Autonomic Neuroscience, 2011;20:159(1-2):62-70.

Marín J, Redondo J. Vascular Sodium Pump: Endothelial modulation and alterations in some pathological processes and aging. Pharmacology \& Therapeutics, 1999;84:249-271. 
Martin R, Hoeth M, Hofer-Warbinek R, Schmid JA. The transcription factor NF-kB and the regulation of vascular cell function. Arteriosclerosis, Thrombosis and Vascular Biology, 2000;20:e83-e88.

Messerli FH, Grossman E, Goldbourt U. Are beta-blockers efficacious as first-line therapy for hypertension in the elderly? A systematic review. Journal of the American Medical Association, 1998;279(23):1903-1907.

Morel N, Godfraind T. The endothelin ET A receptor antagonist, BQ-123, normalizes the response of $\mathrm{SHR}$ aorta to $\mathrm{Ca}^{2+}$ channel activator. European Journal of Pharmacology, 1994;252:R3-R4.

Mueller SM and Ertel PJ. Association between sympathetic nerve activity and cerebrovascular protection in young spontaneously hypertensive rats. Stroke, 1983;14:88-92.

Mulvany MJ, Halpern W. (1977). Contractile properties of small arterial resistance vessels in spontaneously hypertensive and normotensive rats. Circulation Research, 1977;41:19-26.

Mulvany MJ. Vascular remodelling of resistance vessels: can we define this? Cardiovascular Reserch, 1999;41:9-13.

Mulvany MJ. Small Artery remodeling and significance in the development of hypertension. News in Physiological Sciences, 2002;17:105-109.

Murrell JR, Randall JD, Rosoff J, Zhao J, Jensen RV, Gullans SR, Haupert GT. Endogenous ouabain: upregulation of steroidogenic genes in hypertensive hypothalamus but not adrenal. Circulation, 2005;112:1301-1308.

Nakamura T, Ichikawa S, Sato K, Tajima Y, Fujita H, Murata K. Time-related alterations in an endogenous digitalis-like factor in the development of DOCA-salt hypertension in rats. Clinical and Experimental Hypertension. Theory and Practice, 1987;9(11):1733-1744.

Nesher M, Dvela M, Igbokwe VU, Rosen H, Lichtstein D. Physiological roles of endogenous ouabain in normal rats. American Journal of Physiology. Heart and Circulatory Physiology, 2009;297:H2026-H2034.

Nunes VW, Fortes ZB, Nigro D, Carvalho MHC, Zorn TMT, Scivoletto R. Influence of enalapril on the endothelial function of DOCA-salt hypertensive rats. General Pharmacology, 2000;34:117-125.

O'Donaughy TL, Brooks VL. Deoxycorticosterone Acetate-Salt Rats : Hypertension and Sympathoexcitation Driven by Increased $\mathrm{NaCl}$ Levels. Hypertension, 2006;47:680-685. 
Padilha AS, Rossoni LV, Xavier FE, Vassallo DV. Ouabain at nanomolar concentration promotes synthesis and release of angiotensin II from the endothelium of the tail vascular bed of spontaneously hypertensive rats. Journal of Cardiovascular Pharmacology, 2004;44:372-380.

Padilha AS, Peçanha FM, Vassallo DV, Alonso MJ, Salaices M. Ouabain treatment changes the role of endothelial factors in rat resistance arteries. European Journal Pharmacology, 2008;600(1-3):110-116.

Padilha AS, Salaices M, Vassallo DV, Batista PR, Siman FDM. Hypertensive effects of the iv administration of picomoles of ouabain. Brazilian Journal of Medical and Biological Research, 2011;44(9):933-938.

Pamnani M, Huot S, Buggy J, Clough D, Haddy FJ. Demonstration of a humoral inhibitor of the $\mathrm{Na}^{+}-\mathrm{K}^{+}$pump in some models of experimental hypertension. Hypertension, 1981;3 Suppl II:II96-II101.

Pamnani MB, Haddy FJ. Humoral sodium-potassium inhibitor in reduced renal masssaline hypertension rats. Progress in Biochemical Pharmacology, 1988;23:35-45.

Park CG, Hong SJ, Suh SY, Lim HE, Kim, JW, Seo HS, Oh DJ, Ro YM. Time-related alterations of endogenous ouabain in DOCA-Salt hypertensive rats. The Korean Circulation Journal, 2004;34(12):1216-1222.

Pierdomenico SD, Bucci A, Manunta P, Rivera R, Ferrandi M, Hamlyn JM, Lapenna $D$, Cuccurullo F, Mezzetti A. Endogenous ouabain and hemodynamic and left ventricular geometric patterns in essential hypertension. American Journal of Hypertension, 2001;14:44-50.

Pitzalis MV, Hamlyn JM, Messaggio E, lacoviello M, Forleo C, Romito R, Tommasi E, Rizzon P, Bianchi G, Manunta P. Independent and incremental prognostic value of endogenous ouabain in idiopathic dilated cardiomyopathy. The European Journal of Heart, 2006;8:179-186.

Quadri L, Bianchi G, Cerri A, Fedrizzi G, Ferrari P, Gobbini M, Melloni P, Sputore S, Torri M. 17 beta-(3-furyl)-5 beta-androstane-3 beta, 14 beta, 17 alpha-triol (PST 2238). A very potent antihypertensive agent with a novel mechanism of action. Journal of Medical Chemestry, 1997;40:1561-1564.

Rodrigues SF, Granger DN. Cerebral microvascular inflammation in DOCA saltinduced hypertension: role of angiotensin II and mitochondrial superoxide. Journal of Cerebral Blood Flow and Metabolism, 2012;32(2):388-75.

Rodriguez-Iturbe B, Romero F, Johnson RJ. Pathophysiological Mechanisms of SaltDependent Hypertension. American Journal of Kidneys Diseases, 2007;50:655-672. 
Rodríguez-Mañas L, Sánchez-Ferrer CF, Pareja A, Casado MA, Arribas S, Salaices M, Marín J. Neurogenic component of ouabain-evoked contractions is modulated by the endothelium. Hypertension, 1994;23(1):10-17.

Rossoni LV, Cunha V, França A, Vassallo DV. The influence of nanomolar ouabain on vascular pressor responses is modulated by the endothelium. Journal of Cardiovascular Pharmacology, 1999;4:887-892.

Rossoni LV, Pinto VD, Vassallo DV. Effects of small doses of ouabain on the arterial blood pressure of anesthetized hypertensive and normotensive rats. Brazilian Journal of Medical and Biological Research, 2001;34:1065-1077.

Rossoni LV, Salaices M, Marín J, Vassallo DV, Alonso MJ. Alterations on vascular reactivity to phenylephrine and $\mathrm{Na}+, \mathrm{K}+-\mathrm{ATPase}$ activity and expression in hypertension induced by chronic administration of ouabain. British Journal of Pharmacology, 2002a;135:771-781.

Rossoni LV, Salaices M., Miguel M, Briones, AM, Barker LA, Vassallo DV, Alonso MJ. Ouabain-induced hypertension is accompanied by increases in endothelial vasodilator factors. American Journal of Physiology, 2002b;283:H2110-H2118.

Rossoni LV, dos Santos L, Barker LA, Vassallo DV. Ouabain changes arterial blood pressure and vascular reactivity to phenylephrine in L-NAME-induced hypertension. Journal of Cardiovascular Pharmacology, 2003;41:105-116.

Rossoni LV, Xavier FE, Moreira CM, Falcochio D, Amanso AM, Tanoue CU, Carvalho CR, Vassallo DV. Ouabain-induced hypertension enhances left ventricular contractility in rats. Life Sciences, 2006;79:1537-1545.

Rubanyi, GM. The role of endothelium in cardiovascular homeostasis and disease. Journal of Cardiovascular Pharmacology, 1993;22 Suppl 4:1-14.

Schiffrin, E. Vascular endothelin in hypertension. Vascular Pharmacology, 2005;43:19-29.

Schoner W, Scheiner-Bobis G. Endogenous and exogenous cardiac glycosides: Their roles in hypertension, salt metabolism, and cell growth. American Journal of Physiology, 2007;293:509-536.

Selye $\mathrm{H}$, Stone $\mathrm{H}$. Pathogeneses of the cardiovascular and renal changes which usually accompany malignant hypertension. Journal of Virology, 1946;56:399.

Seyle $\mathrm{H}$, Bois $\mathrm{P}$. The hormonal production of nephrosclerosis and periarteritis nodosa in the primate. British Medical Journal, 1957;1:183-6.

Shepherd JT. Increased systemic vascular resistance and primary hypertension: the expanding complexity. Journal of Hypertension, 1990;8 Suppl 7:S15-S17. 
Shibuya J, Ohyanagi M, Iwasaki T. Enhanced myogenic response in resistance small arteries from spontaneously hypertensive rats. American Journal of Hypertension, 1998;767-773.

Siman FD, Stefanon I, Vassallo DV, Padilha AS. A low concentration of ouabain $(0.18 \mathrm{microg} / \mathrm{kg})$ enhances hypertension in spontaneously hypertensive rats by inhibiting the $\mathrm{Na}+$ pump and activating the renin-angiotensin system. Brazilian Journal of Medical and Biological Research, 2010;43:767-776.

Skoumal R, Szokodi I, Aro J, Földes G, Göőz M, Seres L, Sármán B, Lakó-Futó Z, Papp L, Vuolteenaho O, Leppäluoto J, deChâtel R, Ruskoaho $H$, Tóth $M$. Involvement of endogenous ouabain-like compound in the cardiac hypertrophic process in vivo. Life Sciences, 2007;80:1303-1310.

Sleigth P. Role of the baroreceptor reflexes in circulatory control, with particular reference to hypertension. Hypertension, 1991;18(suppl III):III-31-III-34.

Soltis EE e Field FP. Extracellular calcium and altered vascular responsiveness in the deoxycorticosterone acetate-salt rat. Hypertension, 1986;8:526-532

Somers MJ, Mavromatis K, Galis ZS, Harrison DG. Vascular superoxide production and vasomotor function in hypertension induced by deoxycorticosterone acetate-salt. Circulation, 2000;101:1722-1728.

Songu-Mize E, Bealer SL, Caldwell W. Effect of AV3V lesions on development of DOCA-Salt hypertension and vascular Na+-Pump activity. Hypertension, 1982;4:575580.

Staessen JA, Thijs L, Stolarz-Skrzypek K, Bacchieri A, Barton J, Espositi ED, de Leeuw PW, Dłużniewski M, Glorioso N, Januszewicz A, Manunta P, Milyagin V, Nikitin Y, Souček M, Lanzani C, Citterio L, Timio M, Tykarski A, Ferrari P, Valentini G, Kawecka-Jaszcz K, Bianchi G. Main results of the ouabain and adducin for specific intervention on sodium in hypertension trial (OASIS-HT): a randomized placebocontrolled phase-2 dose-finding study of rostafuroxin. Trials, 2011;14;12:13.

Takahashi H, Okabayashi H, Matsuzawa M, Suga K, Ikegaki I, Yoshimura M, ljichi H. Centrally induced vasopressor responses to ouabain in DOCA-salt hypertensive rats. Cardiovascular Research, 1987;21(6):439-446.

Teruya H, Yamazato M, Muratani H, Sakima A, Takishita S, Terano Y, Fukiyama K. Role of ouabain-like compound in the rostral ventrolateral medulla in rats. The Journal of Clinical Investigation, 1997;99:2791-2798.

The seventh report of the joint national committee on prevention, detection evaluation, and treatment of high blood pressure. Journal of American of Association, 2004;289:2560-2572. 
Touyz RM. Reactive oxygen species, vascular oxidative stress, and redox signaling in hypertension: what is the clinical significance? Hypertension, 2004;44:248-252.

Touyz RM. Apocynin, NADPH oxidase, and vascular cells: a complex matter. Hypertension, 2008;51:172-174.

Valente RC, Capella LS, Monteiro RQ, Rumjanek VM, Lopes AG, Capella MAM. Mechanisms of ouabain toxicity. The Faseb Journal, 2003;17:1700-1702.

Van Huysse JW. Endogenous brain Na pumps, brain ouabain-like substance and the $\alpha 2$ isoform in salt-dependent hypertension. Pathophysiology, 2007;14:213-220.

Vanhoutte PM, Feletou M, Taddei S. Endothelium-dependent contractions in hypertension. British Journal of Pharmacology, 2005;144:449-458.

Veelken R, Hilgers KF, Ditting T, Leonard M, Mann JFE, Geiger H, Luft FC. Impaired cardiovascular reflexes precede deoxycorticosterone acetate-salt hypertension. Hypertension, 1994;24:564-570.

Viel EC, Benkirane K, Javeshghani D, Touyz RM, Schiffrin EL. Xanthine Oxidase and mitochondria contribute to vascular superoxide anion generation in DOCA-salt hypertensive rats. American Journal of Physiology Heart and Circulatory Physiology, 2008;H281-288.

Vinson GP. The mislabelling of deoxycorticosterone: making sense of corticosteroid structure and function. Journal of Endocrinology, 2011;211:3-16.

Virdis A, Colucci R, Versari D, Ghisu N, Fornai M, Antonioli L, Duranti E, Daghini E, Giannarelli C, Blandizzi C, Taddei S, Tacca MD. Atorvastatin prevents endothelial dysfunction in mesenteric arteries from spontaneously hypertensive rats. Role of cyclooxygenase 2-derived contracting prostanoids. Hypertension, 2009;53:10081016.

Xavier FE, Salaices M, Marquez-Rodas I, Alonso MJ, Rossoni LV, Vassallo DV, Balfagón G. Neurogenic nitric oxide release increases in mesenteric arteries from ouabain hypertensive rats. Journal of Hypertension, 2004a;22:949-957.

Xavier FE, Rossoni LV, Alonso MJ, Balfagón G, Vassallo DV, Salaices M. Ouabaininduced hypertension alters the participation of endothelial factors in a-adrenergic responses differently in rat resistance and conductance mesenteric arteries. British Journal of Pharmacology, 2004b;143:215-225.

Xavier FE, Yogi A, Callera GE, Tostes RC, Alvarez Y, Salaices M, Alonso MJ, Rossoni LV. Contribution of the endothelin and renin-angiotensin systems to the vascular changes in rats chronically treated with ouabain. British Journal of Pharmacology, 2004c;143:794-802. 
Xavier FE, Davel AP, Fukuda LE, Rossoni LV. Chronic ouabain treatment exacerbates blood pressure elevation in spontaneously hypertensive rats: the role of vascular mechanisms. Journal of Hypertension, 2009;27:1233-1242.

Xie Z, Cai T. $\mathrm{Na}^{+}-\mathrm{K}^{+}-$ATPase-mediated signal transduction: from protein interaction to cellular function. Molecular Interventions, 2003;3:157-168.

Xu J, Carretero OA, Liao TD, Peng H, Shesely EG, Xu J, Liu TS, Yang JJ, Reudelhuber TL, Yang XP. Local angiotensin II aggravates cardiac remodeling in hypertension. Amercan Journal of Physiology. Heart and Circulatory Physiology, 2010;299(5):H1328-H1338.

Wang $\mathrm{H}$, Huang BS, Leenen FH. Brain sodium channels and ouabainlike compounds mediate central aldosterone-induced hypertension. American Jorunal of Physiology. Heart and Circulation Physiology, 2003;285:H2516-H2523.

Webb RC, Bohr DF. Potassium-induced relaxation as an indicator of $\mathrm{Na}^{+} \mathrm{K}^{+} \mathrm{ATPase}$ activity in the vascular smooth muscle. Blood Vessels, 1978;15:198-207.

Welch WJ, Patel K, Modlinger P, Mendonca M, Kawada N, Dennehy K, Aslam S, Wilcox CS. Roles of vasoconstrictor prostaglandins, COX-1 and -2, and AT1 and TP receptors in a rat model of early $2 \mathrm{~K}, 1 \mathrm{C}$ hypertension. American Journal of Physiology - Heart and Circulatory Physiology, 2007; 293: H2644-H2649.

Wenceslau CF, Davel AP, Xavier FE, Rossoni LV. Long-term ouabain treatment impairs vascular function in resistance arteries. Journal of Vascular research, 2011;48(4):316-326.

Wenceslau CF. Papel da ouabaína endógena sobre a pressão arterial, atividade simpática e função vascular de artérias de resistência de ratos DOCA-Sal. [tese (Doutorado em Fisiologia Humana)] São Paulo: Instituto de Ciências Biomédicas, Universidade de São Paulo; 2012.

White MR, Rivera CO, Davison CB. Differential contribution of endothelial function to vascular reactivity in conduit and resistance arteries from deoxycorticosterone-Salt hypertensive rats. Hypertension, 1996;27:1245-1253.

Wu R, Millette E, Wu L, de Champlain J. Enhanced superoxide anion formation in vascular tissues from spontaneously hypertensive and desoxycorticosterone acetatesalt hypertensive rats. Journal of Hypertension, 2001;19(4):741-748.

Yamada K, Goto A, Nagoshi H, Terano Y, Omata M. Elevation of ouabainlike compound levels with hypertonic sodium chloride load in rat plasma and tissues. Hypertension, 1997;30:94-98.

Yemane, H, Busauskas M, Burris SK, Knuepfer MM. Neurohumoral mechanisms in deoxycorticosterone acetate (DOCA)-salt hypertension in rats. Experimental Physiology, 2009;95.1:51-55. 
Yuan CM, Manuta P, Hamlyn JM, Chen S, Bohen E, Yeun J, Haddy FJ, Pamnani MB. Long-term ouabain administration produces hypertension in rats. Hypertension, 1993;22:178-187.

Zhang J, Leenen FHH. AT1 receptor blockers prevent sympathetic hyperactivity and hypertension by chronic ouabain and hypertonic saline. American Journal of Physiology. Heart and Circulatory Physiology, 2001;280:H1318-H1323.

Zhang J, Lee MY, Cavalli M, Chen L, Berra-Romani R, Balke W, Bianchi G, Ferrari P, Hamlyn JM, Iwamoto T, Lingrel JB, Matteson DR, Wier WG, Blaustein MP. Sodium pump $\alpha_{2}$ subunits control myogenic tone and blood pressure in mice. The Journal of Physiology, 2005;569:243-256. 